Portland State University

PDXScholar

7-6-1994

\title{
Interactions of Ruthenium Red with Phospholipid Vesicles
}

Dirk Voelker

Portland State University

Follow this and additional works at: https://pdxscholar.library.pdx.edu/open_access_etds

Part of the Physics Commons

Let us know how access to this document benefits you.

\section{Recommended Citation}

Voelker, Dirk, "Interactions of Ruthenium Red with Phospholipid Vesicles" (1994). Dissertations and Theses. Paper 4881.

https://doi.org/10.15760/etd.6757

This Thesis is brought to you for free and open access. It has been accepted for inclusion in Dissertations and Theses by an authorized administrator of PDXScholar. Please contact us if we can make this document more accessible: pdxscholar@pdx.edu. 


\section{THESIS APPROVAL}

The abstract and thesis of Dirk Voelker for the Master of Science in Physics were presented July 6,1994 , and accepted by the thesis committee and the department.

COMMITTEE APPROVALS:

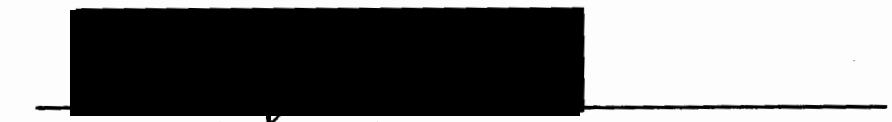

Pavel Smejtek, Chair

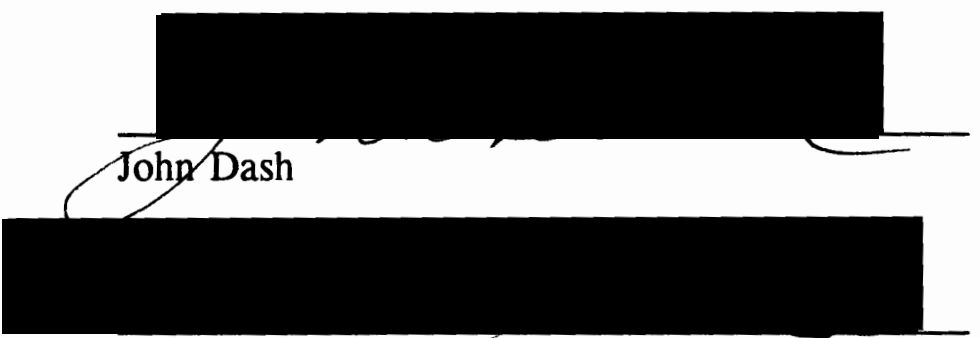

Arnold Pickar

DEPARTMENT APPROVAL:

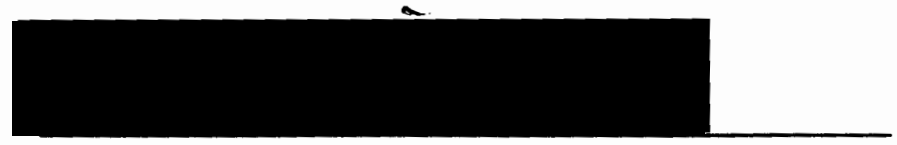

Robert Millette

Representative of the Office of Graduate Studies

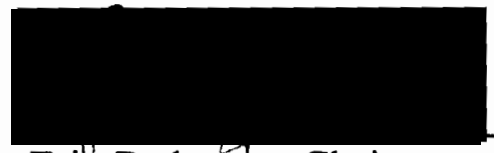

Erip Bodegom, Chair

Department of Physics

$* * * * * * * * * * * * * * * * * * * * * * * * * * * * * * * * * * * * * * * * * * * * * * * * * * * * * * * * * * * * * * * * * * * * * * * * *$

\section{ACCEPTED FOR PORTLAND STATE UNIVERSITY BY THE LIBRARY}

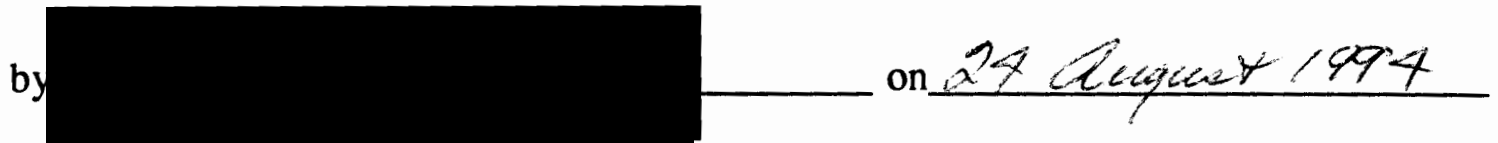




\begin{abstract}
An abstract of the thesis of Dirk Voelker for the Master of Science in Physics presented July 6, 1994.
\end{abstract}

Title: Interactions of Ruthenium Red with Phospholipid Vesicles

We have studied the electrostatic and other interactions of the inorganic, hexavalent dye Ruthenium Red (RR) with phospholipid vesicles composed of phosphatidylcholine (PC) and phosphatidylserine (PS) or phosphatidylinositol (PI) in various mixtures and concentrations. Experiments were based on spectrophotometric absorption measurements which compared RR concentrations in the presence and in the absence of liposomes at different dye concentrations. Multilamellar liposomes were obtained by handshaken preparations. Five freeze-and-thaw cycles of the lipid-RR suspension produced an ion equilibrium distribution at the membrane-water interface. Results are given in terms of the Gouy-Chapman-Stern adsorption theory with the linear partition coefficient and a newly introduced effective ion valency as parameters. Data on the time stability of RR solutions and their interaction with laboratory equipment are given. Furthermore, we characterize the freeze-and-thawing process and present an electron micrograph of liposomes. 
Two main results were found. First, the Gouy-Chapman-Stern theory correctly describes adsorption of a hexavalent ion to charged phospholipid vesicles if an effective valency is introduced. The effective valency accounts for the finite size of the ions and the repulsion between the ions. Values ranged between 2.9 and 4.1. Effective valencies decrease with increasing membrane surface charge density and are independent of the lipid concentration. Second, Ruthenium Red adsorbs to phospholipids and the adsorption is strongly related to the surface charge density of the membrane. Vesicles made from a mixture of PC and PI adsorb significantly less than vesicles made from a mixture of PC and PS. The second result is of special interest for molecular biology since biological membranes consist to a large extent of phospholipids. Sarcoplasmic reticulum (SR) membranes are discussed as an example. Liposomes (PC:PS 20:1) with surface charge densities comparable to SR membranes adsorb a maximum of about $9 \pm 3 \mathrm{nmol} R \mathrm{R}$ per mg lipid. 


\title{
INTERACTIONS OF RUTHENIUM RED WITH PHOSPHOLIPID VESICLES
}

\author{
by \\ DIRK VOELKER
}

A thesis submitted in partial fulfillment of the

requirements for the degree of

\section{MASTER OF SCIENCE \\ in \\ PHYSICS}

Portland State University

1994 


\section{ACKNOWLEDGEMENTS}

First and most of all I would like to thank Prof. Pavel Smejtek. It was a great pleasure to work with him and without his help I would never have been able to accomplish this work. He was always willing to discuss my research and our discussions were a valuable source of suggestions and ideas. His presence created a wonderful stimulating and exciting atmosphere.

Special thanks also to Prof. Shanru Wang who taught me liposome preparation and basic biochemical techniques and to Prof. John Dash who spent numerous hours explaining the electron microscope and discussing my results there. I am indebted to Prof. David Peyton for his help with the calibration of the spectrophotometer and to Christine Hoerber and Andreas Schilling for helpful discussions.

I want to thank the physics department here at Portland State University for the very friendly integration during my year as an exchange student; especially the chair Prof. Eric Bodegom who always found money to support my research and Margie Fyfield who helped me overcome my struggles with the English language.

I definitely have to mention my housemates which were very patient with me in the final stages of this thesis.

Finally, I want to thank my parents very much for their continuous support of my education and for making this year in the U.S. possible for me. 
TABLE OF CONTENTS

PAGE

ACKNOWLEDGEMENTS $\ldots \ldots \ldots \ldots \ldots \ldots \ldots$ ii

LIST OF TABLES $\ldots \ldots \ldots \ldots \ldots \ldots \ldots \ldots \ldots \ldots$

LIST OF FIGURES $\ldots \ldots \ldots \ldots \ldots \ldots \ldots \ldots$ vii

CHAPTER

I INTRODUCTION $\ldots \ldots \ldots \ldots \ldots \ldots \ldots \ldots \ldots$

II LIPID MEMBRANES AND RUTHENIUM RED $\ldots \ldots \ldots \ldots \ldots \ldots$

RUTHENIUM RED $\ldots \ldots \ldots \ldots \ldots \ldots \ldots$

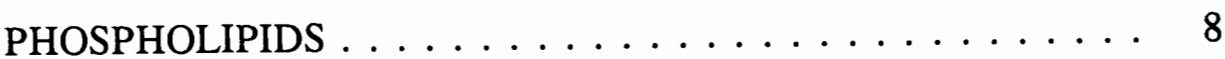

ADSORPTION THEORY $\ldots \ldots \ldots \ldots \ldots \ldots$

Gouy-Chapman Theory

Gouy-Chapman-Stern Theory

Limitations, Generalizations and Tests of the GCS Theory

LIGHT ABSORPTION AND SCATTERING $\ldots \ldots \ldots \ldots$

III MATERIALS AND METHODS $\ldots \ldots \ldots \ldots \ldots \ldots \ldots \ldots$

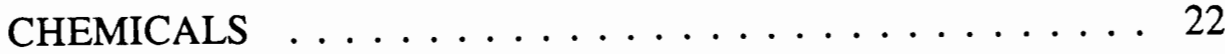

SAMPLE PREPARATION $\ldots \ldots \ldots \ldots \ldots \ldots$

Liposomes

Ruthenium Red

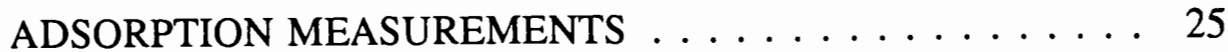

Experimental Procedure 
Spectrophotometer

ELECTRON MICROSCOPY .................. . . 29

IV $\operatorname{RESULTS}$ AND DISCUSSION $\ldots \ldots \ldots \ldots \ldots \ldots \ldots \ldots$

RUTHENIUM RED SPECTRUM . . . . . . . . . . . . 30

TEST OF EXPERIMENTAL PROCEDURES . . . . . . . . 32

Time Stability of RR Solutions

Interaction of RR with Glassware

FAT-Cycle Characterization

Measurement Errors

ELECTRON MICROGRAPH . . . . . . . . . . . . . . . 42

MAIN FEATURES OF THE ADSORPTION MODEL . . . . . 45

ADSORPTION TO LIPOSOMES . . . . . . . . . . . . 48

PC:PS Ratio Effects

PC:PS Lipid Concentration Effects

PC:PI Ratio Effects

PC:PI Lipid Concentration Effects

Discussion

Biological Importance

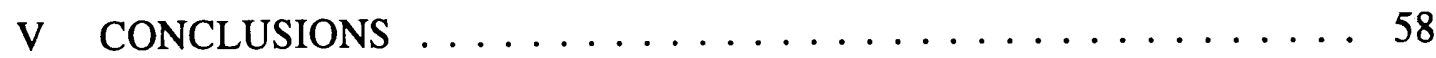

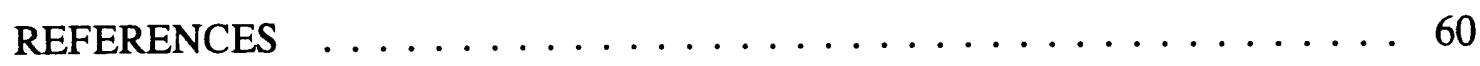

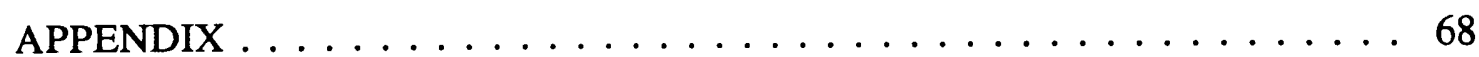

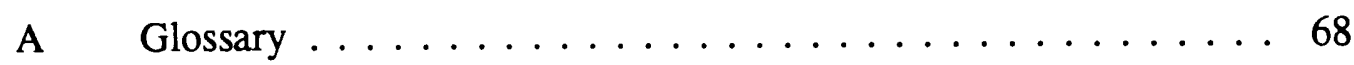

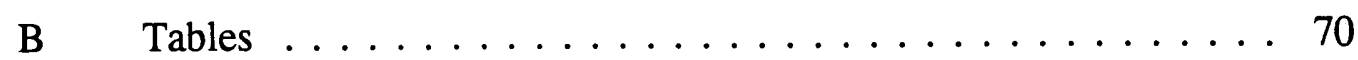




\section{LIST OF TABLES}

TABLE

PAGE

I Exponential fit of RR decay in buffer solution. . . . . . . 33

II Fits and interception points for the FAT cycle dependence

of scattering. $\ldots \ldots \ldots \ldots \ldots \ldots \ldots \ldots \ldots \ldots \ldots \ldots \ldots \ldots \ldots$

III Systematic and statistical measurement errors. . . . . . . . . 39

IV Fit parameter for the PC:PS ratio dependence (Fig.17). . . . 51

V Fit parameter for the lipid concentration dependence of

PC:PS (Fig. 18) ..................... 52

VI Fit parameter for the PC:PI ratio dependence (Fig.19) . . . . 53

VII Fit parameter for the lipid concentration dependence of

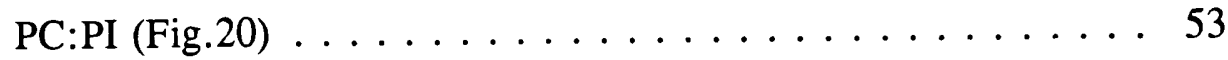

VIII Experimental and fitted data for PC:PS $20: 1 ; 1 \mathrm{mg} / \mathrm{ml} \ldots \ldots 70$

IX Experimental and fitted data for PC:PS $10: 1 ; 1 \mathrm{mg} / \mathrm{ml} \ldots \ldots 71$

X Experimental and fitted data for PC:PS $5: 1 ; 1 \mathrm{mg} / \mathrm{ml} \ldots \ldots 72$

XI Experimental and fitted data for PC:PS $10: 1 ; 0.3 \mathrm{mg} / \mathrm{ml} \ldots 73$

XII Experimental and fitted data for PC:PS 10:1;3mg/ml ..... 74

XIII Experimental and fitted data for PC:PS 10:1;10mg/ml $\ldots \ldots 75$

XIV Experimental and fitted data for PC:PI 10:1;1mg/ml $\ldots \ldots 76$ 
XV Experimental and fitted data for PC:PI 5:1;1 $1 \mathrm{mg} / \mathrm{ml} \ldots \ldots 77$

XVI Experimental and fitted data for PC:PI 10:1;0.3mg/ml $\ldots \ldots 78$

XVII Experimental and fitted data for PC:PI 10:1;3mg/ml $\ldots \ldots 79$

XVIII Experimental and fitted data for PC:PI 10:1;10mg/ml . . . . 80 


\section{LIST OF FIGURES}

FIGURE

PAGE

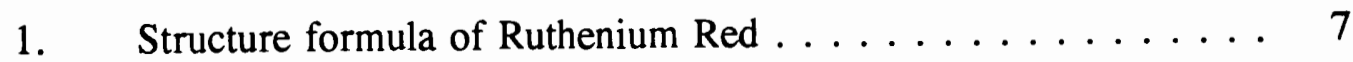

2. Structure formulas of the phospholipids used in this study $\ldots \ldots \ldots \ldots \ldots \ldots \ldots \ldots \ldots$

3. A lipid bilayer vesicle $\ldots \ldots \ldots \ldots \ldots \ldots \ldots$

4. Fluid mosaic model of biological membranes $\ldots \ldots \ldots \ldots 11$

5. The DU-7 spectrophotometer $\ldots \ldots \ldots \ldots \ldots \ldots$

6. Ruthenium Red spectrum in $\mathrm{B}^{-3} \ldots \ldots \ldots \ldots \ldots \ldots$

7. Time-dependent decay of the $533 \mathrm{~nm}$ RR peak in $\mathrm{B}^{-3}$ and HEPES buffer solution at $\mathrm{pH} 7.4 \ldots \ldots \ldots \ldots \ldots \ldots$

8. Interaction of $\mathrm{RR}$ with spectrophotometer cells $\ldots \ldots \ldots \ldots 34$

9. FAT cycle dependent adsorption of RR to liposomes . . . . . 36

10. Influence of FAT cycles on the wavelength dependence of absorption due to scattering of liposomes $\ldots \ldots \ldots \ldots \ldots 37$

11. Electron micrograph of liposome vesicles . . . . . . . . . 43

12. Interpretation of the electron micrograph $\ldots \ldots \ldots \ldots \ldots 44$

13. Size distribution of the liposomes showed in Fig.11 . . . . 45

14. Effect of simultaneous changes of $\mathrm{K}_{\mathrm{m}}$ and $\mathrm{P}_{\mathrm{s}}$ for $\mathrm{a}$ constant $\beta_{\mathrm{mRR}} \ldots \ldots \ldots \ldots \ldots \ldots \ldots \ldots \ldots$ 
15. Dependence of adsorption isotherms on the effective valency $\mathrm{q}_{\mathrm{eff}} \ldots \ldots \ldots \ldots \ldots \ldots \ldots \ldots$

16. Dependence of adsorption isotherms on the linear partition coefficient $\beta_{\mathrm{mRR}} \ldots \ldots \ldots \ldots \ldots \ldots \ldots$

17. Adsorption isotherms for different ratios of PC:PS . . . . 50

18. Adsorption isotherms for different lipid concentrations of

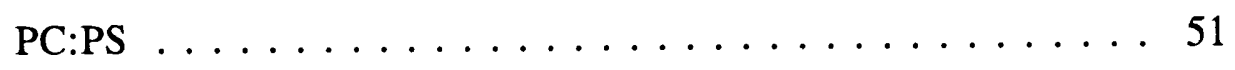

19. Adsorption isotherms for different ratios of PC:PI $\ldots \ldots \ldots 52$

20. Adsorption isotherms for different lipid concentrations of PC:PI $\ldots \ldots \ldots \ldots \ldots \ldots \ldots \ldots \ldots$ 


\section{CHAPTER I}

\section{INTRODUCTION}

Membranes are essential for all forms of life; they separate cells from their environment. Membranes also play an important role in biological communication since they are able to process or generate chemical or electrical signals. Photosynthesis and oxidative phosphorylation, the most important biological energy conversion processes, are carried out by membranes.

Biological membranes are mainly composed of lipids and proteins. The lipids form a sheetlike structure in which the proteins are embedded. The proteins work as pumps, gates, receptors, energy transducers, and enzymes (Stryer 1981). This way, membranes serve as a highly selective permeability barrier. Ions and molecules present in the environment of the membrane can disturb the proper function of the membrane in two ways: they can adsorb to the lipid bilayer and change the transmembrane potential or they can adsorb to the membrane proteins and alter their function. Drugs take advantage of these two effects. An understanding of adsorption is therefore essential for the understanding of membranes.

Biological membranes are complex and difficult to simulate. Since 20 to $80 \%$ of the membrane mass are phospholipids, artificial membranes made from well defined 
mixtures of various phospholipids (and occasionally some proteins) are the systems of choice for many adsorption studies (Smejtek and Wang 1993 and 1991, Langner et al. 1990, Chung et al. 1985 among others). All effects observed in artificial lipid bilayers have also been observed in biological membranes (Benz 1985).

Sarcoplasmic reticulum (SR) is a biological membrane that regulates the uptake and release of $\mathrm{Ca}^{2+}$ ions during contraction and relaxation in skeletal, cardiac, and smooth muscle (see Inesi et al. 1990 for a review). SR consists of approximately equal parts (mass) of proteins and phospholipids (mainly PC and PS). The native surface charge of SR is equivalent to approximately 20:1 PC:PS. $\mathrm{Ca}^{2+}$ uptake and release are done by two different proteins, the $\mathrm{Ca}^{2+}, \mathrm{Mg}^{2+}$-ATPase and the $\mathrm{Ca}^{2+}$ release protein, but the mechanisms are not completely understood yet. Several molecules stimulate or inhibit $\mathrm{Ca}^{2+}$ uptake or release in SR. Among them is the hexavalent ion Ruthenium Red (RR) which stimulates $\mathrm{Ca}^{2+}$ uptake and inhibits $\mathrm{Ca}^{2+}$ release. Numerous authors have examined the interaction of RR with SR and the membrane proteins (CorbalanGarcia et al. 1992, Charuk et al. 1990, Howell 1982 among others). RR also causes similar effects in other membrane systems. It inhibits $\mathrm{Ca}^{2+}$ uptake in mitochondria (Vasington et al. 1972, Moore 1971), in erythrocytes (Watson et al. 1971), and in chloroplasts (Kreimer et al. 1985). $\mathrm{RR}$ also stimulates $\mathrm{Ca}^{2+}$ release in mitochondria (Luthra and Olson 1977). Moutin et al. (1991) have studied the effect of RR on the $\mathrm{Ca}^{2+}-\mathrm{ATPase}$ of SR. They mention that the "interaction of the dye with lipids should not be excluded", but they didn't investigate this. Another work has shown that there is an association between the $\mathrm{Ca}^{2+}$-ATPase and particular lipids of the SR membrane 
(Bick et al. 1991). However, no study of interactions between RR and membrane phospholipids has been done so far.

This study intends to answer two questions:

(i) Does RR adsorb to phospholipid bilayers and what is the driving force for this effect?

(ii) Does the Gouy-Chapman-Stern (GCS) theory describe adsorption of the hexavalent ion RR to phospholipid bilayers correctly?

The GCS theory describes adsorption and electrostatic interaction of ions or molecules with charged or uncharged membrane surfaces. Despite the simplicity of the model behind this theory, it is still capable of describing adsorption of monovalent ions (Winiski et al. 1986, Eisenberg et al. 1979), divalent ions (Lau et al. 1981, McLaughlin 1977), and tetravalent ions (Chung et al. 1985). No test of the GCS theory for a hexavalent ion was found in literature.

We measured adsorption of RR to neutral phosphatidylcholine (PC) and to mixtures of PC with negatively charged phosphatidylserine (PS) or phosphatidylinositol (PI). Experimental results were fitted with the GCS theory. Influences of the various parameters of the GCS theory on the shape of the adsorption isotherm were discussed. Furthermore, experiments were done to characterize RR, its impurities, and its interactions with spectrophotometer cells and laboratory glassware. Electron micrographs of phospholipid bilayer vesicles (liposomes) were taken and the effects of freeze-and-thaw (FAT) cycles on the liposomes were measured. Results are given in 
chapter IV. Chapter II introduces the theoretical background for the different experiments and chapter III describes the main experimental procedures.

Our adsorption measurements are based on a spectrophotometric comparison of the light absorption* of two samples. The first one contains RR in buffer solution. The second one contains the same RR concentration but additional liposomes. Prior to the measurement this sample is processed by FAT to achieve an equilibrium distribution of $\mathrm{RR}$ at the membrane-water interface. The liposomes are then pelleted in a centrifugation step and the supernatant is compared to the first sample. The difference in absorption reflects a concentration difference of RR and together with the liposome concentration it characterizes adsorption. The strength of adsorption is given in terms of the linear partition coefficient $\beta_{\mathrm{mRR}}$, a parameter in the GCS theory, and an effective $\mathrm{RR}$ ion valency $\mathrm{q}_{\mathrm{eff}}$.

We have found that RR adsorbs to phospholipid bilayers and that this adsorption is strongly related to the membrane surface charge density. Membranes made from PC and PI adsorb significantly less than membranes made from PC and PS. Adsorption isotherms are surprisingly well described by the GCS theory if an effective valency is used. Effective valencies are independent of the lipid concentration and decrease with increasing membrane surface charge density.

* According to Random House Webster's College Dictionary (1992) 'absorption' is "the removal of energy or particles from a beam by the medium through which the beam propagates" and 'adsorption' is "the process by which an ultrathin layer of one substance forms on the surface of another substance". 


\section{CHAPTER II}

\section{LIPID MEMBRANES AND RUTHENIUM RED}

\section{RUTHENIUM RED}

Ruthenium Red (RR) was discovered in 1892 (Joly 1892). It is an inorganic, intensely colored compound prepared from $\mathrm{RuCl}_{3}$ in a $\mathrm{NH}_{3}$-solution (Gmelin 1938) and never occurs in nature. Mangin first described the staining properties of RR to visualize pectin in plant cells (Mangin 1893), and since then it has been widely used in biology. Light microscopy still uses RR as a generic stain for polyanions with a high charge density (Murano et al. 1990), or as a selective stain for mitochondria and muscle fibrils (Hirabayashi 1990). Reimann published the first electron micrographs employing RR as a stain (Reimann 1961) and several authors extensively discussed its usage for electron microscopy (Dierichs 1979, Luft 1971a and 1971b). Charuk et al. (1990) reported the usage of $\mathrm{RR}$ as a gel stain for $\mathrm{Ca}^{2+}$-binding proteins. $\mathrm{RR}$ is used in medicine as well. Amann and Maggi (1991) reviewed its use in sensory neuron research, especially as a capsaicin antagonist. Currently capsaicin is discussed as a potential new pain reliever. Anghileri et al. (1986) showed that RR inhibits tumor cell 
growth and Oberc-Greenwood et al. (1986) used RR to visualize tumors based on the affinity of RR to the mucopolysaccharide coat of these tumor cells.

Besides its staining properties, RR is widely used in molecular biology, often in connection with sarcoplasmic reticulum (SR) membranes. In low concentrations (80 to $200 \mathrm{nM}$ ), RR blocks the $\mathrm{Ca}^{2+}$ release channels of SR (Chiesi et al. 1988, Antoniu et al. 1985). A stimulatory effect of $\mathrm{RR}$ on the $\mathrm{Ca}^{2+}$ uptake by $\mathrm{SR}$ was also observed (Chu et al. 1987, M'esz'aros and Ikemoto 1985, Seiler et al. 1984 among others). However, Reed and Bygrave (1974) have shown that inhibition of mitochondrial $\mathrm{Ca}^{2+}$ transport is mostly due to an impurity of $R R$ present in even purified samples. A detailed description of this particular impurity can be found in Emerson (1993). Yet another impurity causes the stimulation of electron transport in mitochondria previously ascribed to RR (Hochmann et al. 1981).

The molecular formula of $\mathrm{RR}$ is $\left[\mathrm{Ru}_{3} \mathrm{O}_{2}\left(\mathrm{NH}_{3}\right)_{14}\right] \mathrm{Cl}_{6} \cdot 4 \mathrm{H}_{2} \mathrm{O}$ as proposed by Fletcher et al. (1961) with a molecular weight of 858.5. Fig.1 shows a structural formula of the hexavalent cation. X-ray crystal structure determinations are difficult for the chloride since it does not form a crystal. Smith et al. (1971) and Carrondo et al. (1980) have examined similar structures and found the Ru-O bonds to be about $1.85 \AA$, the Ru-N bonds to be about $2.1 \AA$, and the overall length of the backbone to be approximately $11.7 \AA$. Fletcher et al. (1961) also indicate that RR is easily oxidized to Ruthenium Brown (RB). The average oxidation number of the $\mathrm{Ru}$ atoms is $+10 / 3$ for $\mathrm{RR}$ and $+11 / 3$ for RB. Jørgensen and Orgel (1961) discuss $\pi$-bonds as reasons for the stability of these two compounds. Ruthenium Violet (RV) is also present in all RR 


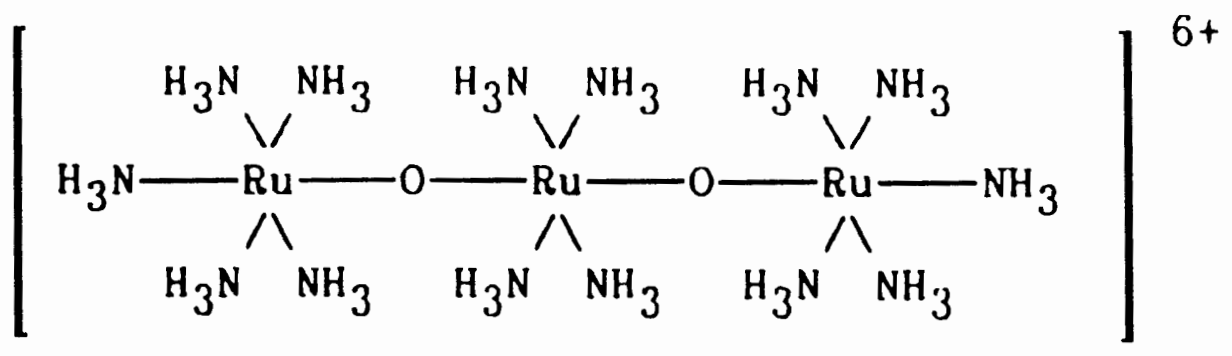

Fig.1: Structure formula of Ruthenium Red.

preparations. Luft (1971a) suggests that this might be a higher polymer of RR with four or five oxygen-bridged $\mathrm{Ru}$ atoms.

Commercially available RR is most often between 10 and $30 \%$ pure. Fletcher et al. (1961), Luft (1971a), and Hochmann et al. (1981) describe methods for purification. Solutions in water or buffer have a red magenta color and are the most stable near neutrality (Luft 1971a). For lower pH, RR is often oxidized to RB and for higher $\mathrm{pH}$ it decomposes. No effect of temperature on the stability was found in the literature or observed during the experiments $\left(20-90^{\circ} \mathrm{C}\right)$. According to Luft (1971a), absorption peaks can be found at $360 \mathrm{~nm}$ for $\mathrm{RB}$, at $533 \mathrm{~nm}$ for $\mathrm{RR}$, and at $734 \mathrm{~nm}$ for RV.

In addition to $R R$ there are several other ionic dyes that are active in $S R$ membranes: the anionic dye Rose Bengal (Stuart 1992, Xiong 1992) and the cationic dye Alcian Blue (Abramson 1988) both induce $\mathrm{Ca}^{2+}$ release from SR. It might be of interest to do similar research with these stains, especially Alcian Blue, since some similarities with RR were pointed out by Luft (1971a). Alcian Blue as well as RR are 
both metal-containing basic dyes which interact similarly with various substances and both bind primarily by electrostatic forces.

\section{PHOSPHOLIPIDS}

All biological membranes consist of mainly proteins and lipids. While proteins serve as pumps, gates, receptors, energy transducers, and enzymes, the lipid molecules form a bimolecular layer and serve as barrier to the flow of polar molecules (Stryer 1981).

Lipids are divided into three major classes: sterols, glycolipids, and phospholipids. Fig. 2 shows the molecular structure of the three different phospholipids used in this study. Phosphatidylcholine (PC) is neutral but has a polar headgroup, whereas phosphatidylserine (PS) and phosphatidylinositol (PI) are monovalent anions. These, are all composed of two fatty acid hydrocarbon chains that usually contain between 14 and 24 carbon atoms, glycerol, a phosphate group, and an alcohol. The polar headgroup is hydrophilic whereas the hydrocarbon tails are hydrophobic. Due to their amphipathic nature, these lipids form sheetlike structures in an aqueous environment, referred to as lipid bilayer vesicles or liposomes (Fig.3). The thickness of these bilayers ranges from 4 to $6 \mathrm{~nm}$, depending on the length of the hydrocarbon chains (Flewelling and Hubbell 1986). 
<smiles>[R]C(=O)OCC(COP(=O)([O-])OCC[N+](C)=O)OC([R])=O</smiles>

Phosphatidyl choline<smiles>[R]C(=O)OCC(COP(=O)([O-])OCC([NH3+])C([R])=O)OC([NH3+])=O</smiles>

Phosphatidyl serine

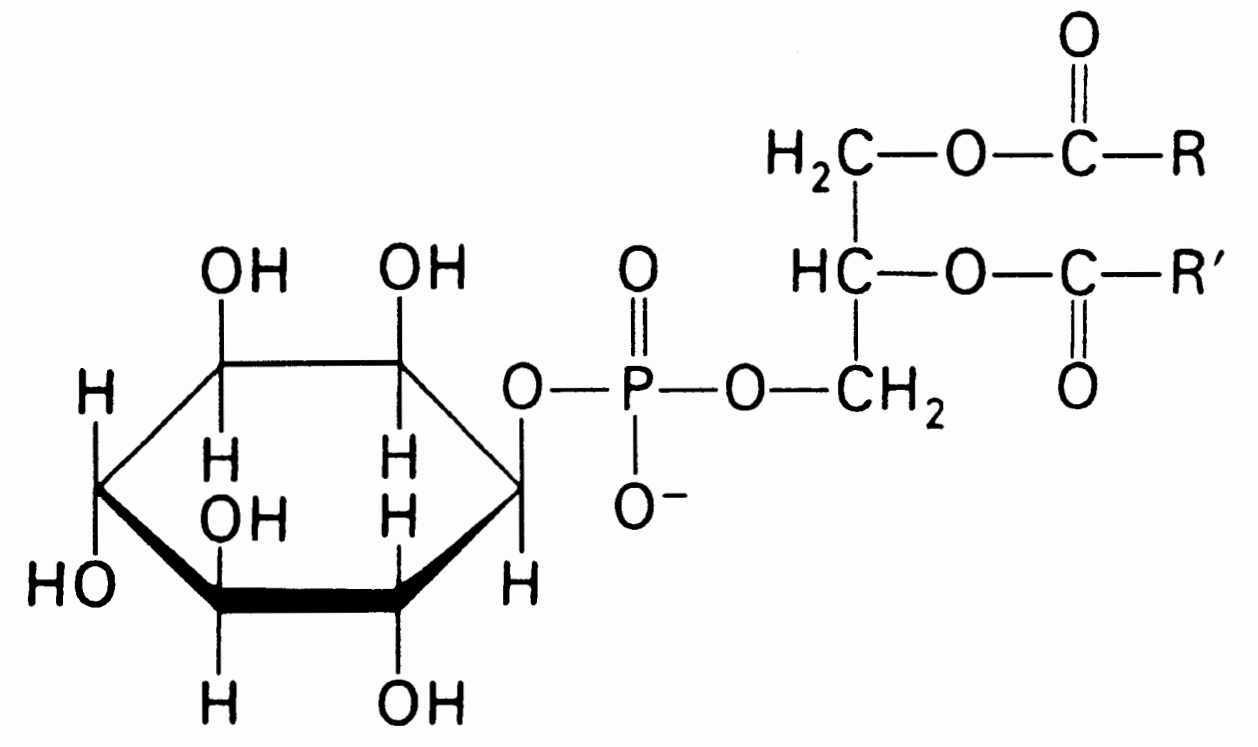

Phosphatidyl inositol

Fig.2: Structure formulas of the phospholipids used in this study. 


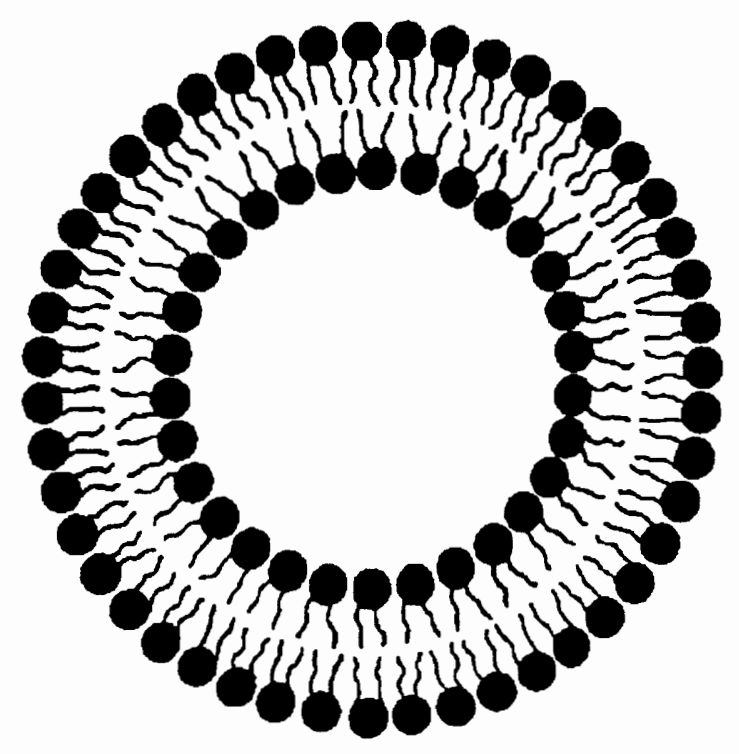

Fig.3: A lipid bilayer vesicle.

An early reference for liposomes can be found in a British patent in 1932 . Probably without knowing the cause of this effect, the patentholder found that "pharmaceutical preparations for injection ... can be prepared by combining medicaments with liquids, such as fats or fatty oils, ... with water" (cited from Bangham 1972). Bangham et al. (1965) first described the properties of liposomes. They are nowadays a common tool in biology, medicine and other areas. Their ability to trap and gradually release molecules makes them useful as drug delivery systems in cancer therapy (Sugarman and Perez-Soler 1992), ophthalmology (Niesman 1992), and vaccines (Gregoriadis and Florence 1993). Liposomes are used for gene transfer instead of viruses (Pickering et al. 1994) and by the cosmetics industry in skin care 
products (Sloan 1990). Furthermore, there is a potential to use liposomes as artificial blood substitutes (Mobed et al. 1992), as artificial odor receptors (Kashiwayanagi et al. 1990), or in food products, e.g. as enzyme carriers, to accelerate cheese ripening or to supplement food products with nutritious additives (Vuillemard 1991).

Since 20 to $80 \%$ of the mass in biological membranes are lipids (Stryer 1981), liposomes represent interesting model membranes widely used in adsorption studies (Smejtek and Wang 1993, Chung et al. 1985, Eisenberg et al. 1979 among others). Singer and Nicolsen (1972) proposed a fluid mosaic model for biological membranes (Fig.4) where the lipid bilayer serves as a solvent for membrane proteins and as a permeability barrier. Proteins are free to laterally diffuse in the lipid matrix but are not

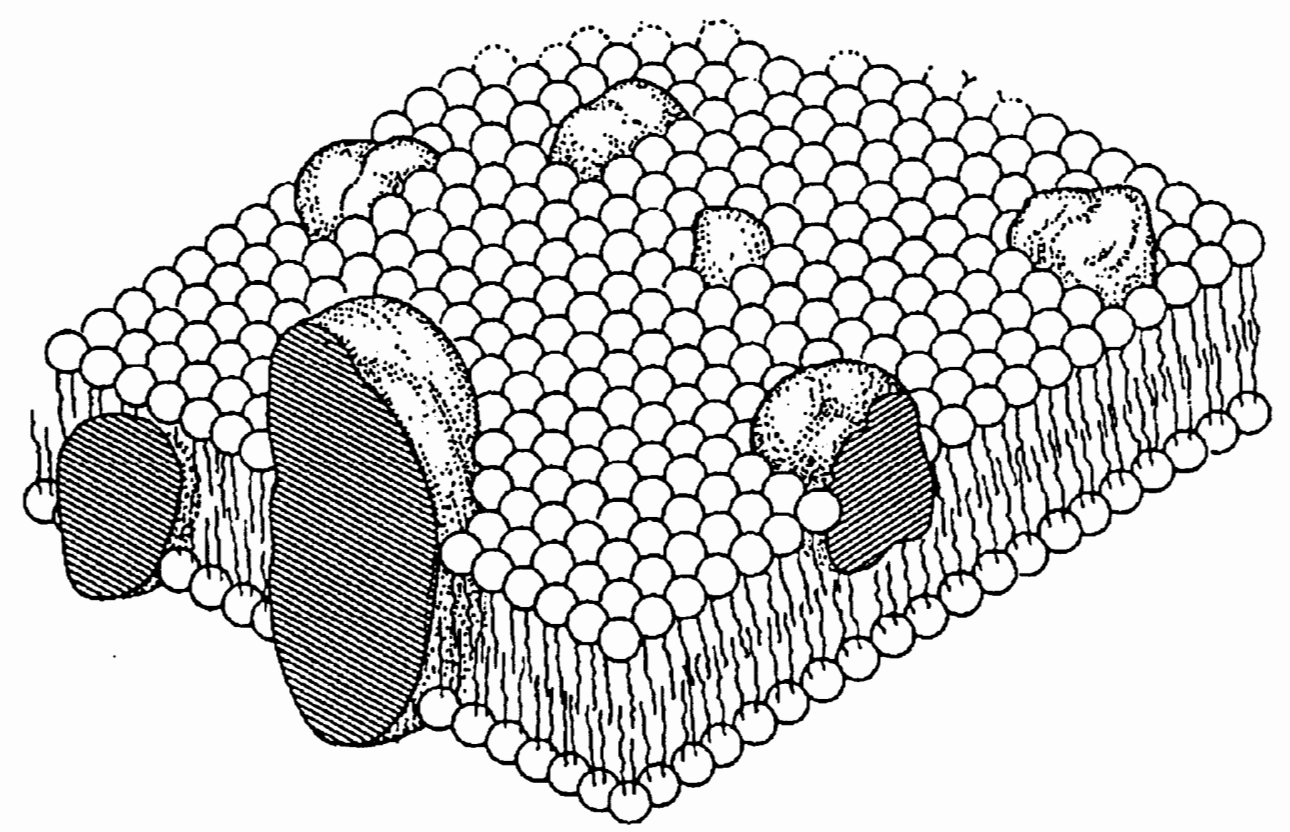

Fig.4: Fluid mosaic model of biological membranes (after Singer and Nicolson). 
free to rotate. Some lipids also may interact with particular membrane proteins and affect their function.

There are several different methods to produce liposomes, each resulting in vesicles with special characteristics. One has to distinguish between large multilamellar vesicles (MLV), and large or small unilamellar vesicles (LUV, SUV); however, all real samples will be mixtures with certain dominant forms. MLVs are usually obtained by handshaken preparations, as in our experiment, with typical diameters in the $\mu \mathrm{m}$ range (Gruner et al. 1985, Westman et al. 1982). LUVs can be prepared by detergent dialysis (Jiang et al. 1991) or by extrusion through filters (MacDonald 1991). SUVs are obtained by fragmentation of MLVs in an ultrasonic bath (Johnson 1971). Winterhalter and Lasic (1993) discuss influences of the various preparation methods on stability, formation, and size distribution of liposomes.

Some small lipophilic anions easily penetrate through lipid bilayers (Benz et al. 1976) if added to a liposome suspension. For most other atoms and molecules this is not the case. However, for measuring adsorption to lipid membranes it is necessary to reach an equilibrium distribution at the membrane-water interface. One way to reach this is to freeze and thaw (FAT) the liposome suspension repeatedly. Three to five FAT cycles seem to be sufficient (Mayer et al. 1985, compare also chapter IV). Expansion of water during the freezing process breaks the liposomes which then reseal upon warming. This process does not affect the properties of the bilayer membrane (Smejtek and Wang 1993). It is important for lipids to be in the fluid phase for fusion 
to occur (Papahadjopoulos 1973). FAT makes the particle size distribution more homogeneous and the average diameters smaller (Westman et al. 1982).

\section{ADSORPTION THEORY}

The theory used in this study to describe adsorption of ions to membranes is based on the Gouy-Chapman-Stern (GCS) theory. It combines Langmuir adsorption isotherms with the Gouy-Chapman theory of the diffuse double layer. We have adopted a version of a model proposed by McLaughlin and Harary (1976) which was previously used by Smejtek and Wang $(1993,1991)$.

\section{Gouy-Chapman Theory}

The diffuse double layer theory was independently proposed by Gouy (1910) and Chapman (1913). It considers an infinite plane surface carrying a smeared surface charge in contact with an electrolyte containing ions which are regarded as point charges. This theory relates the surface charge to the surface potential as a function of the ionic composition of the solution.

The statistical distribution of point charges with regard to a charged surface is expressed approximately by the Boltzmann relation

$$
n(x)=n(\infty) \exp \left(-\frac{q \Phi(x)}{k_{B} T}\right)
$$


where $n(x)$ is the volume density of the ion at a distance $x$ from the surface and $n(\infty)$ is the volume density in the bulk solution, $\mathrm{q}$ is the charge of the ion including the sign, $\Phi$ is the electrostatic potential, $\mathrm{k}_{\mathrm{B}}$ is the Boltzmann constant and $\mathrm{T}$ the temperature of the electrolyte.

The electrostatic interactions between the surface and the charges are given by the Poisson equation

$$
\frac{d^{2} \Phi(x)}{d x^{2}}=-\frac{1}{\epsilon_{w} \epsilon_{0}} \rho(x)
$$

$\epsilon_{\mathrm{w}}$ is the dielectric constant of the electrolyte, $\epsilon_{0}$ is the permittivity of free space, and $\rho$, the volume charge density, is given by

$$
\rho(x)=\sum z_{i} e n_{i}(x)
$$

where $e$ is the proton charge and $z_{i}$ is the valence of the ion including the sign.

Boundary conditions for this problem require that the potential at the surface is specified $\left(\Phi_{0}\right)$ and that the potential and its slope are zero at infinity. A combination of the boundary conditions with the above equations allows to solve for $\Phi$. For $\mathrm{q} \Phi_{0} \ll 2 \mathrm{k}_{\mathrm{B}} \mathrm{T}$ this may be linearized to

$$
\Phi(x)=\Phi_{0} \exp (-\kappa x)
$$

where

$$
\kappa=\sqrt{\frac{2}{\epsilon_{w} \epsilon_{0} k_{B} T} \sum\left(z_{i} e\right)^{2} C_{i}} .
$$


$\sum\left(\mathrm{z}_{\mathrm{i}} \mathrm{e}\right)^{2} \mathrm{C}_{\mathrm{i}}$ is the ionic strength, $1 / \kappa$ is the Debye length, and $\mathrm{C}_{\mathrm{i}}$ is the bulk concentration of ions (McLaughlin 1977).

Electroneutrality implies $\quad \sigma=-\int_{0}^{\infty} \rho(x) d x$

where $\sigma$ is the surface charge density. Finally we obtain Grahame's equation (Aveyard and Haydon 1973)

$$
\sigma=\sqrt{\left(2 \epsilon_{w} \epsilon_{0} k_{B} T\right) \sum C_{i}\left[\exp \left(\frac{-z_{i} e \Phi_{0}}{k_{B} T}\right)-1\right]}
$$

Grahame (1947) first solved the problem for an asymmetrical electrolyte.

\section{Gouy-Chapman-Stern Theory}

The adsorption model describes non-competitive adsorption of RR (or other ions) to a charged or uncharged membrane surface in the presence of buffer or salt ions. It can be characterized in five equations.

The Langmuir adsorption isotherm relates the RR volume concentration at the aqueous side of the membrane-solution interface, $[R R]_{i f}$, and the membrane surface density of adsorbed ions, $(\mathrm{RR})_{\mathrm{m}}$.

$$
(R R)_{m}=K_{m}[R R]_{i f}\left(\frac{1}{P_{S}}-(R R)_{m}\right)
$$


$\mathrm{K}_{\mathrm{m}}$ is the intrinsic association constant which describes the strength of the interaction between the adsorbing molecule and the membrane (Smejtek 1990) and $P_{s}$ is the membrane surface area per RR ion adsorption site.

Analogous to the derivation of Grahame's equation, the Boltzmann relation has to be used to relate $[R R]_{\text {if }}$ with $[R R]_{\text {eq }}$, the bulk aqueous concentration of $R R$ in the equilibrium after adsorption of the ions to the membrane.

$$
\frac{[R R]_{i f}}{[R R]_{e q}}=\exp \left(\frac{-q_{e f f} V_{m}}{k_{B} T}\right)
$$

$V_{m}$ is the effective potential at the membrane surface (analogous to $\Phi_{0}$ ). For the hexavalent cation RR it was necessary to introduce an effective charge of the ion, $\mathrm{q}_{\text {eff }}$, to take care of the effect that the RR ions are not idealized point charges.

The membrane surface charge density $\sigma_{\mathrm{m}}$ is given by

$$
\sigma_{m}=\sigma_{0}+q_{e f f}(R R)_{m}
$$

where $\sigma_{0}$ is the native surface charge density. Grahame's equation (Eq.7) relates $\sigma_{\mathrm{m}}$ to $\mathrm{V}_{\mathrm{m}}$.

In contrast to other adsorption studies it is necessary to introduce a balance equation because the adsorption significantly reduces the initial ion concentration $[R R]_{\text {init }}$.

$$
[R R]_{\text {inis }}=[R R]_{e q}+(R R)_{m}[L] P_{L}
$$

where [L] is the volume density of lipids and $P_{L}$ is the membrane surface area per lipid. A value for $P_{L}$ of about $70 \AA^{2}$ for PC and PS is most often found in recent literature 
(Small 1986, Chung 1984, Eisenberg 1979). We assume that $P_{L}$ for PI is about the same.

In the limit of low surface coverage with $R R\left(1 / P_{S} \gg(R R)_{m}\right)$ the linear partition coefficient $\beta_{\mathrm{mRR}}$ can be derived from eq.(8):

$$
\beta_{m R R}=\frac{K_{m}}{P_{S}} \quad\left(=\frac{(R R)_{m}}{[R R]_{i f}}\right)
$$

\section{Limitations, Generalizations and Tests of the GCS Theory}

The model allows computation of $[R R]_{e q}$ as a function of $[R R]_{\text {init }}$ with $P_{S}, K_{m}$, and $\mathrm{q}_{\mathrm{eff}}$ as parameters. Several assumptions had to be made in this simplest model:

(i) Adsorption of buffer or salt ions is negligible compared to RR adsorption. Competitive adsorption could be included for ions with known parameters by accounting for their contribution to the membrane surface charge density in Eq.(10). Eqs. (8), (9), and (11) would be analogous for all ions (Westman et al. 1981).

(ii) The surface density of adsorption sites $\left(1 / \mathrm{P}_{\mathrm{S}}\right)$ has to be much greater than the surface density of adsorbed ions (RR) $)_{m}$ if Langmuir adsorption isotherms are used. If both quantities become comparable, more general Vollmer adsorption isotherms could be used instead (McLaughlin 1977).

(iii) It is assumed that the whole membrane surface could be covered with adsorbed RR ions. However, due to repulsive electrostatic interactions, each RR ion excludes another ion from its vicinity (Smejtek 1993); thus, if the areas covered by one 
ion are considered circular disks which are not allowed to overlap with one another, the whole membrane could not be covered by RR. To include this in the model, $\left(1 / \mathrm{P}_{\mathrm{S}}\right)$ in Eq. (8) had to be replaced by $\left(\mathrm{SFF} / \mathrm{P}_{\mathrm{S}}\right)$, where $\mathrm{SFF}$ is the space filling factor. For hexagonal packing SFF would be 0.907 (Beiser 1969).

(iv) The derivation of Grahame's equation also requires some assumptions. It is assumed that neither the standard chemical potential nor the activity coefficient varies with distance from the membrane. Also, the dielectric constant of the aqueous solution is assumed to be constant up to the membrane surface, image charge effects are ignored and ions are considered point charges. Carnie and McLaughlin (1983) and Alvarez et al. (1983) discussed finite size effects. They found that large divalent cations have smaller effects on the potential of a negatively charged bilayer membrane than small divalent cations (i.e. large divalent cations adsorb less) and that the magnitude of this discrepancy is proportional to the ionic strength. McLaughlin (1989) suggests ignoring the finite size of ions if they are smaller than the Debeye length. Grahame's equation also requires the charges to be smeared uniformly over the membrane surface. Discretness of charge effects should be most important for low membrane charge densities and high ionic strengths (McLaughlin 1977). Winiski et al. (1986) tested for those hypotheses and found that their experimental results agreed much more closely with the GCS theory than with a modified theory that accounted for discrete charges. 


\section{LIGHT ABSORPTION AND SCATTERING}

For a long time, spectrophotometry was the most important tool for analytical chemists. This is based on the fact that every atomic or molecular structure has a fingerprint-like set of energy states which produce a distinct absorption spectrum. The Bohr-Einstein frequency equation

$$
\Delta E=E_{2}-E_{1}=h v
$$

relates the discrete atomic or molecular energy states $E_{1}, E_{2}$ to electromagnetic radiation with frequency $\nu$. Absorption of electromagnetic radiation induces a transition from a lower $\left(E_{1}\right)$ to a higher $\left(E_{2}\right)$ energy level if equation (13) is fulfilled. Relaxation from the $E_{2}$ level occurs shortly after excitation and involves either radiative or non-radiative transitions. For atoms and molecules in solution, non-radiative transitions are dominant. Although optical spectroscopy covers only a very narrow range of the electromagnetic spectrum (wavelengths typically between 200 and $900 \mathrm{~nm}$ ), this range is of extreme importance since it corresponds to the electronic transitions.

The basis of light-absorption measurements is the Bouguer-Lambert-Beer law (Perkampus 1992):

$$
A(\lambda) \equiv \log \left(\frac{I_{0}}{I}\right)=\varepsilon(\lambda) \cdot c \cdot d
$$

$A$ is the absorbance, $I_{0}$ is the intensity of the monochromatic light entering the sample and $I$ is the intensity of this light emerging from the sample. $\mathrm{c}$ is the concentration of 
the light-absorbing substance and $\mathrm{d}$ is the path length in the sample. $\varepsilon$, the molar decadic extinction coefficient, is characteristic for the substance. The linear form of this law is limited to dilute solutions, for concentrated solutions, $\varepsilon$ becomes dependent on the refractive index of the solution (Kortüm 1962).

If suspensions rather than solutions are used in spectrophotometric measurements, a second phenomenon occurs: scattering. A measure for the relative intensity scattered is the total scattering cross section $\sigma$. It links the incident intensity $\mathrm{I}_{0}$ to the emerging intensity $\mathrm{I}$ :

$$
I=I_{0} e^{-N o d}
$$

$\mathbf{N}$ is the number of particles per volume. A detailed discussion of scattering phenomena can be found in Hulst (1981) or Bohren and Huffman (1983). One has to distinguish three classes of scattering: First, Thomson scattering for particle sizes much bigger than the incident wavelength $\lambda$. Here, $\sigma_{\mathrm{T}}$ is independent of $\lambda$. Second, Rayleigh scattering for particle sizes much smaller than $\lambda$. Here, the particles are considered electric and magnetic multipoles (induced by the incident electromagnetic field) which radiate energy in directions other than the direction of incidence. $\sigma_{\mathrm{R}}$ is proportional to $\lambda^{4}$. Third, Mie scattering, the exact theory derived from Maxwell's equations is applicable to all particles. This general theory of scattering is used for regions between Thomson and Rayleigh scattering domains. $\sigma_{\mathrm{M}}$ is strongly dependent on size and material of the scatterer.

Comparing (14) and (15) one finds a proportionality between $\sigma$ and A. Absorbance measurements in conjunction with Mie scattering computations make it 
possible to determine size, concentration, and other parameters for particles comparable to the wavelength (Hulst 1981). In practice, this is not exactly applicable for complicated particles such as liposomes, but the dependence of absorbance on the wavelength and changes in absorbance values for one wavelength, could give a relative measure for the average diameter of the particles and changes in their concentration. Angström (1929) introduced the empirical formula

$$
A \sim \lambda^{-\alpha}
$$

for meteorological studies of haze and light mist. Johnson and Kaler (1986) used this concept to characterize aging of vesicular dispersions. The synthetic surfactant sodium 4-(1'-heptylnonyl)benzenesulfonate which they used forms, analogous to phospholipids, vesicles consisting of a single bilayer in an aqueous environment. The bigger $\alpha$, the smaller the average diameter of the particles. In the limit for small particles, $\alpha=4$ describes Rayleigh scattering and in the limit for large particles, $\alpha=0$ describes Thomson scattering. In our experiment Angström's formula was used to monitor changes in the size distribution of liposome suspensions due to FAT. 


\section{CHAPTER III}

\section{MATERIALS AND METHODS}

\section{CHEMICALS}

All experiments were carried out in either $B^{-3}$ or HEPES buffer solutions. $B^{-3}$ is a buffer containing potassium-phosphate, -citrate, and -borate in a molar ratio of 0.002:0.002:0.0005. Potassium-phosphate-dibasic-trihydrate $\left(\mathrm{K}_{2} \mathrm{HPO}_{4} \cdot 3 \mathrm{H}_{2} \mathrm{O}\right)$ and boric acid $\left(\mathrm{H}_{3} \mathrm{BO}_{3}\right.$, Mallinckrodt Chemicals, St.Louis, MO), potassium-citrate-monohydrate $\left(\mathrm{K}_{3} \mathrm{C}_{6} \mathrm{H}_{5} \mathrm{O}_{7} \cdot \mathrm{H}_{2} \mathrm{O}\right.$, Matheson Coleman \& Bell Manufacturing Chemists, Norwood, $\left.\mathrm{OH}\right)$, HEPES (N-2-ㅌydroxyEthyl-Piperazine-N'-2-Ethane-Sulfonic Acid, Research Organics Inc., Cleveland, $\mathrm{OH}$ ), and chloroform (American Burdick and Jackson, Muskegon, MI) were at least reagent grade. L- $\alpha$-phosphatidylcholine (egg yolk, PC, m.w. 760.09), L$\alpha$-phosphatidyl-serine (brain, PS, m.w. 810.03), and L- $\alpha$-phosphatidylinositol (bovine liver, PI, m.w. 909.12) were bought in various concentrations from Avanti Polar Lipids, Birmingham, AL. The phospholipids were dissolved in chloroform and were all $99 \%$ pure. Ruthenium Red (RR) was obtained from Sigma (Sigma Chemical Comp., St.Louis, MO; listed purity 35\%) and Fluka (Fluka Chemie AG, Buchs, Switzerland; listed purity $90-95 \%, 99.5 \%$ for this batch). 
All chemicals were used without further purification. Deionized water $\left(>10{\mathrm{M} \Omega \mathrm{cm}^{-1}}^{-1}\right)$ was used for all preparations.

\section{SAMPLE PREPARATION}

\section{Liposomes}

Chloroform solutions of PC, PS, and PI were mixed in different mass ratios in 50 or $100 \mathrm{ml}$ round bottom flasks and diluted with chloroform to a final volume of no more than half the flask volume. The chloroform was slowly evaporated in a rotary flash evaporator (Buchler Instruments, Fort Lee, NJ) leaving a thin lipid film on the inside wall of the flask. Remaining chloroform was removed from the flask with a rotary pump connected to the flask for one hour (more for higher lipid concentrations). In the next step a certain volume of the buffer solution was added to the flask which was then filled with nitrogen gas. Gentle shaking removed the lipid film and produced a suspension of multilamellar liposomes with a predetermined lipid concentration. For all experiments the buffer solution was $\mathrm{B}^{-3}$, titrated to $\mathrm{pH} 7.3$ with $\mathrm{KOH}$. All experiments were carried out at room temperature. None of the phospholipids had a phase transition temperature close to room temperature.

Solution $\mathrm{pH}$ was measured with a digital $\mathrm{pH}$-meter (model 6072, Jenco Electronics Ltd., Taipei, Taiwan). Prior to each measurement the meter was calibrated with pH 7 and pH 10 standard solutions (VWR Scientific, Portland, OR). 


\section{Ruthenium Red}

$R R$ was dissolved in buffer solution in a polycarbonate tube and heated to $60^{\circ} \mathrm{C}$ under continuous stirring. The solution was then centrifuged at $100,000 \times \mathrm{xg}\left(20^{\circ} \mathrm{C}\right)$ for two hours. The higher concentrations resulted in formation of a black pellet. Stock solutions were prepared at least one day in advance and not used for more than 5 days. They were kept in dark bottles in the refrigerator.

Actual concentrations were determined spectrophotometrically by the method described by Luft (1971a). He measured the absorbance of purified RR in water to be 1.583 for a concentration of $2.34 \times 10^{-5} \mathrm{M}$ in $10 \mathrm{~mm}$ quartz-cells at $533 \mathrm{~nm}$. Further, he published a formula to correct the absorbance at the RR-peak (533nm) for overlaps of Ruthenium Brown (RB, peak at 360nm) and Ruthenium Violet (RV, peak at $734 \mathrm{~nm}$ ).

$$
A_{R R, \text { corrected }}=A_{533 \mathrm{~nm}}-\left(0.20 A_{360 \mathrm{~nm}}+0.25 A_{734 \mathrm{~nm}}\right)
$$

Since we found similar absorbance values of $R R$ in water and in $B^{-3}$, this method was used. A calibration curve showed that, within the range of concentration used, there is a linear relationship between $R R$ concentration and absorbance. This formula was not usable for centrifuged liposome suspensions since remaining lipids caused additional absorption at $360 \mathrm{~nm}$. $\mathrm{A}_{360 \mathrm{~nm}}$ was replaced by $\mathrm{A}^{*}{ }_{360 \mathrm{~nm}}$ for these suspensions.

$$
A_{360 \mathrm{~nm}}^{*}=\text { ratio } * A_{333 \mathrm{~nm}}
$$

where 'ratio' is the ratio of $A_{360 \mathrm{~nm}}$ over $A_{533 \mathrm{~nm}}$ for $R R$ solutions without liposomes.

When the spectrophotometrically obtained concentration was compared with the concentration obtained from weighing, significant differences between listed and actual 
dye contents were found. Sigma-RR (listed dye content $35 \%$ ) contained about $30 \%$ of the dye. Fluka-RR (listed dye content $90-95 \%, 99.5 \%$ for this batch) actually contained only about $20-25 \%$. Fluka uses a chlorine-titration as purity test. This method fails because most impurities contain chlorine as the counterion (see chapter IV).

\section{ADSORPTION MEASUREMENTS}

All adsorption measurements were done by comparing two samples of the same initial RR concentration, one containing liposome-buffer solution, the other containing just buffer. Ultracentrifugation removes most of the liposomes as well as the adsorbed RR molecules. The resulting absorption difference between both solutions is determined spectrophotometrically and allows a calculation of the amount of $R R$ adsorbed.

\section{Experimental Procedure}

RR stock solutions were diluted to appropriate concentrations and mixed with the same volume of liposomes or buffer in $8 \mathrm{ml}$ round bottom polypropylene tubes. Final volumes were between 2 and $4 \mathrm{ml}$. For dilutions and repeated volumes, Finnpipettes with adjustable volume (50 to $200 \mu$ l and 200 to $1000 \mu$ l) were used (Labsystems, Helsinki, Finnland). The tubes were filled with nitrogen and vortexed briefly. Tubes containing the lipids were frozen in liquid nitrogen, thawed in water at 
$25^{\circ} \mathrm{C}$, and vortexed for a few seconds. It was found that five freeze-and-thaw cycles (FAT-cycles) are sufficient to reach an equal distribution of RR on the surface of the liposomes. Tubes made from glass or polystyrene tended to break during this process.

Next, the lipid containing solution was transferred to $13.5 \mathrm{ml}$ open-top, thickwalled ultracentrifuge tubes made from polycarbonate (Nalgene Company, Rochester, NY) and centrifuged at $100,000 \times x g\left(20^{\circ} \mathrm{C}\right)$ for two hours. A Beckman L2-65B Ultracentrifuge with a type $50 \mathrm{Ti}$ rotor (Beckman Instruments, Inc., Palo Alto, CA) was used at 40,000rpm. Pellet and supernatant were separated directly after centrifugation and the supernatant was kept in closed polypropylene tubes until measurements were taken.

It has been shown several times that neither FAT nor the centrifugation protocol had a measurable influence on the RR concentration.

For spectrophotometric measurements a Beckman DU-7 spectrophotometer was used (Beckman Instruments, Irvine, CA). Calibration of the meter was done with an absorbance standard (model 202, Gilford Instrument Laboratories, Inc., Oberlin, OH). The absorbance values were also compared to several other spectrophotometer.

Either semi-micro cells made from UV grade methacrylate (minimum wavelength $275 \mathrm{~nm}$ ) or selfmasking micro cells made from Spectrosil (minimum wavelength 190nm) were used. These were bought from VWR Scientific, Portland, OR. Each cell had $10 \mathrm{~mm}$ optical path length. Due to the variations in pathlength, the plastic cells were compared to saturated quartz cells. From this a correction factor was 
determined. Because they showed less interaction between solution and cell walls (see chapter IV), plastic cells were used whenever possible.

We preferred to use the spectrophotometer for absorbance units in the range of 0.1 and 1.5 only. Denser solutions were diluted 10 or 100 times and the actual dilution factor was figured spectrophotometrically. For less dense solutions it would have been better to use cells with larger path lengths, but this would have required much larger volumes of the expensive solutions.

It was found that absorbance values vary slightly with the position of the cell in the cell holder, therefore the cell was always inserted in the same direction and each measurement was repeated at least three times. If not stated otherwise, all absorbance values were measured with the same cell filled with buffer solution as background.

\section{Spectrophotometer}

Fig.5 shows an optical diagram of the DU-7 spectrophotometer. The instrument is designed for the visible and the near UV region of the optical spectrum. Scans between 190 and $800 \mathrm{~nm}$ are possible. The optical path starts with two source lamps: a deuterium gas discharge lamp for UV and a tungsten lamp for visible light. A mirror is used to switch between both lamps. A collimator focusses the beam onto the holographic grating that works as a single monochromator. The grating reflects a diffracted beam and out of this, the exit slit isolates a beam with a narrow wavelength range. The width of this slit determines the wavelength resolution of the spectrophotometer. The beam passes next through a series of filters which control the 


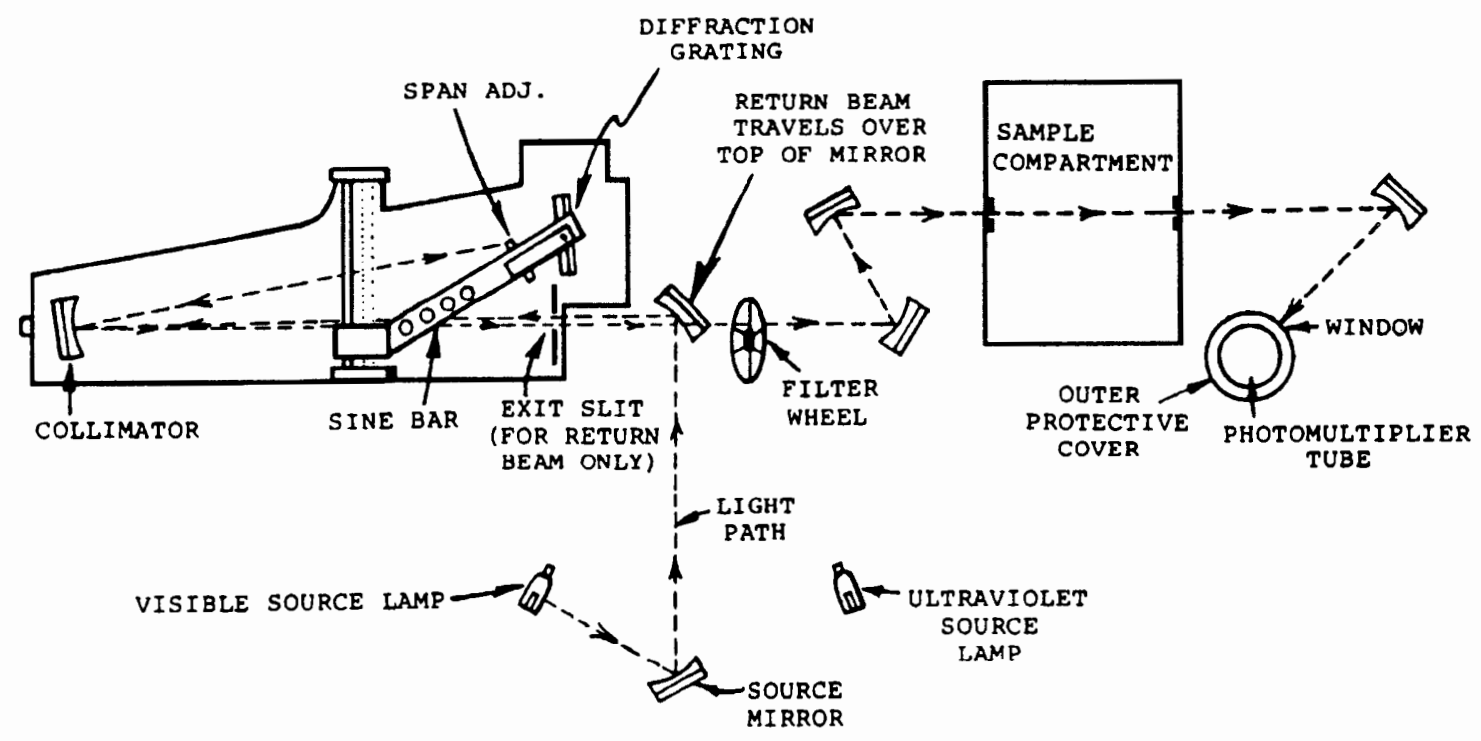

Fig.5: The DU-7 spectrophotometer.

amount of energy that proceeds through the system from that point on. Two transfer mirrors focus the beam into the sample compartment where the cell is fixed on the cell holder. The remaining part of the beam is focussed onto a photomultiplier tube that converts the optical beam into an electronic signal. This signal is amplified, and finally displayed as an absorbance value.

This spectrophotometer has a single beam system. That means that the background has to be determined separately, stored, and then automatically subtracted. An automatic calibration done before each use of the instrument ensures that measurements are independent of contamination or the position of the cell holder. We observed however, different absorbance values depending on the position of the cell holder. This is caused by a reduction in beam intensity when the focus of the beam is outside the 
cell and therefore parts of the beam are blocked by the cell holder. During all absorption measurements the beam focus was in the cell and the cell holder was not moved. Neither holder nor cell walls were struck by the beam. To check that, the grating was set in such a way as to reflect the zero order of the spectrum. This produced a beam that was bright enough to be seen with the unaided eye.

\section{ELECTRON MICROSCOPY}

Pictures of liposomes were taken on a Hitachi HS-7S transmission electron microscope (TEM, Hitachi Instruments, San Jose, CA) at 50KV acceleration voltage. The specimens were prepared on 300-mesh copper grids coated with a very thin carbon film, about $300 \AA$ thick. To produce such a thin carbon film, the grids were coated first with a parlodian film and then with a thin layer of carbon. Shortly before specimen preparation the parlodian film was dissolved in acetone and the grid washed in ethanol. This method produced easily and reproducibly stable thin carbon films with best quality for TEM imaging. Samples were stained by adding Ruthenium Red and processed as for the adsorption measurements. Drops containing 3 to $5 \mu 1$ of the suspension were brought onto a grid and dried. 


\section{CHAPTER IV}

\section{RESULTS AND DISCUSSION}

\section{RUTHENIUM RED SPECTRUM}

Fig.6 shows a typical spectrum of commercially available RR: a main peak at $535 \pm 1 \mathrm{~nm}(\mathrm{RR})$ with a slight shoulder at about 480 to $500 \mathrm{~nm}$, a very broad peak at $735 \pm 5 \mathrm{~nm}(\mathrm{RV})$, a small peak (sometimes without decrease to lower wavelengths) at $362 \pm 3 \mathrm{~nm}$, and a sharp peak at $256 \pm 1 \mathrm{~nm}$ with a broad shoulder around $300 \mathrm{~nm}$. Spectrophotometric concentration determination gives a purity of $21 \pm 3 \%$ for the batch used in our experiments.

The spectrum can be understood qualitatively when compared to the spectra of pure RR impurities given by Luft (1971a). He found RR at $533 \mathrm{~nm}, \mathrm{RV}$ at $734 \mathrm{~nm}$, and RB at 360 and $460 \mathrm{~nm}$. An overlay between the $533 \mathrm{~nm}$ RR peak and the $460 \mathrm{~nm}$ RB peak accounts for the slight shoulder and the average $2 \mathrm{~nm}$ offset of the $R R$ peak observed in our batch. RR shows another smaller peak at $376 \mathrm{~nm}$. Luft gives for the ratio of these peaks $533 \mathrm{~nm}: 376 \mathrm{~nm}=10.9$ (Fletcher et al. 1961: 9.8). Since we found a constant value of $5 \pm 0.6$ for the ratio of the $R R$ peak and the RB peak it is probable 
that half of the RB peak is caused by RR. The $376 \mathrm{~nm}$ RR peak also causes the average $2 \mathrm{~nm}$ offset of the RB peak.

Luft gives three other potential impurities: ruthenium (III) hexamine trichloride (273nm), ruthenium (III) chloropentamine dichloride $(327 \mathrm{~nm})$, and nitrosylruthenium (250nm). Hochmann et al. (1981) measured $275 \mathrm{~nm}$ for the peak of ruthenium (III) hexamine trichloride and $323 \mathrm{~nm}$ for ruthenium (III) chloropentamine dichloride. Our observed $256 \mathrm{~nm}$ peak might be caused by nitrosylruthenium. This is supported by an experimental observation: the black pellet, obtained during RR preparation, was only weakly soluble and the spectrum showed a single sharp peak at $258 \pm 2 \mathrm{~nm}$ in either

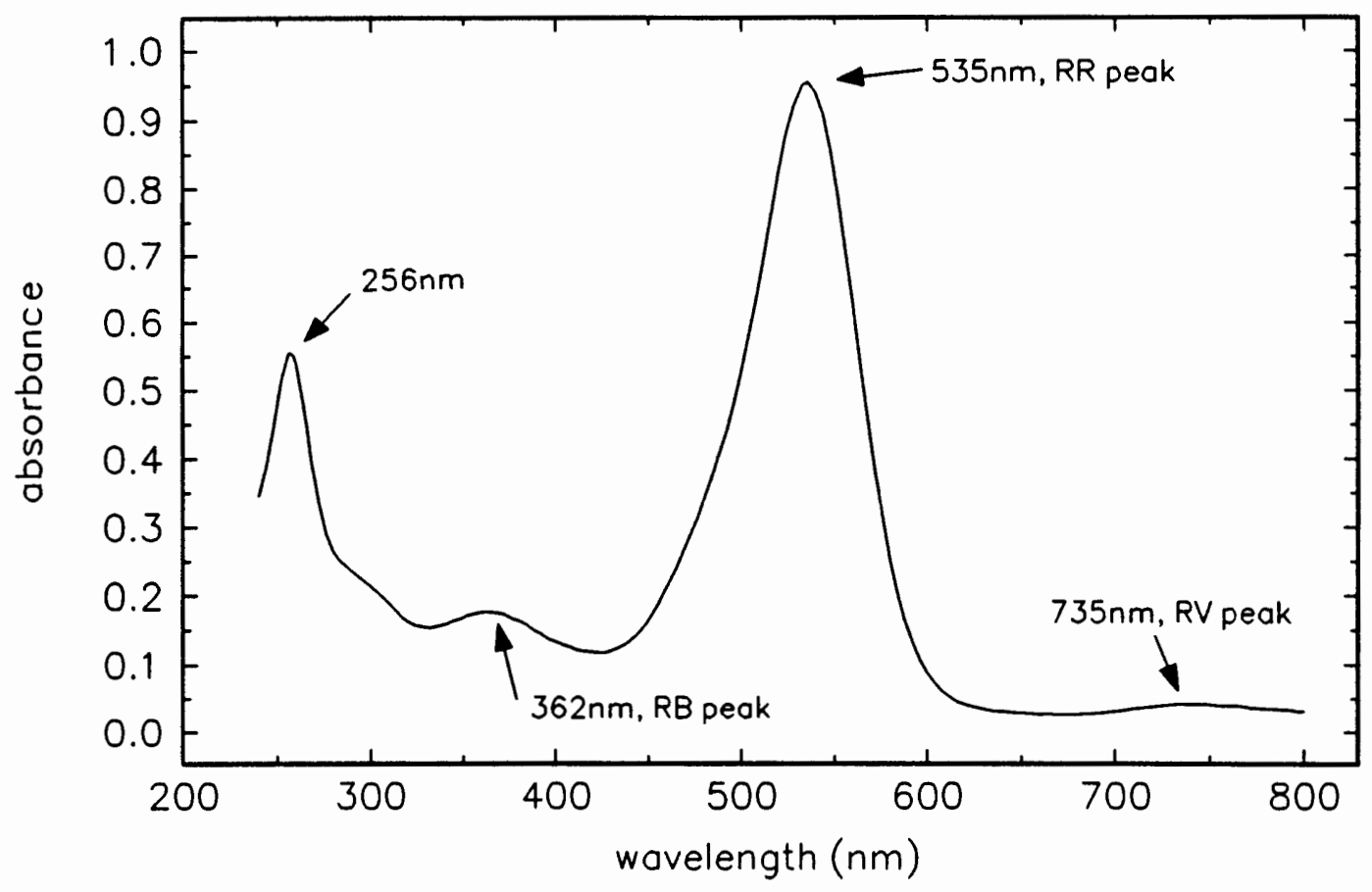

Fig.6: Ruthenium Red spectrum in $B^{-3}\left(1.34 \cdot 10^{-5} \mathrm{M} R R, 1 \mathrm{~cm}\right.$ quartz cell). 
distilled water or buffer solution. Fletcher et al. (1961) describe nitrosylruthenium as a weakly soluble substance obtained during centrifugation of a RR preparation. The 6 to $8 \mathrm{~nm}$ shift of this peak compared to the literature values is due to a solvatochromic effects since Luft measured the spectra in $0.1 \mathrm{M} \mathrm{NH}_{4} \mathrm{OAc}$. No other spectra of nitrosylruthenium were found in literature. The shoulder of the $256 \mathrm{~nm}$ peak in our batch is probably caused by ruthenium (III) hexamine trichloride. No shoulder was observed in the absorption spectra of the pellet. This agrees with ruthenium (III) hexamine trichloride being easily soluble in water (Gmelin 1938).

\section{TEST OF EXPERIMENTAL PROCEDURES}

\section{Time Stability of RR Solutions}

RR solutions were observed for 50 days. During this time they changed their color from magenta to reddish brown to clear. For $\mathrm{B}^{-3}$ as well as for HEPES buffer solutions an exponential decay of the 533nm RR peak was observed (Table I, Fig.7). RR in HEPES buffer seemed to decay a little bit faster than in $B^{-3}$ buffer. A previously observed anomalous behavior of $\mathrm{RR}$ in $\mathrm{B}^{-3}$ buffer (increase in absorbance during the first 100 hours) was found to be due to solvation of undissolved RR that was not centrifuged down. In preparations which were centrifuged for 2 hours at 100,000xg this effect was not observed. The peaks at $256 \mathrm{~nm}$ and $362 \mathrm{~nm}$ were stable during the 
Table I: Exponential fit of RR decay in buffer solution.

\begin{tabular}{|c|c|c|}
\hline model: & $\mathrm{a} \cdot \exp (-\mathrm{b} \cdot$ time $)$ \\
\hline \hline & $\mathrm{a}\left[\cdot 10^{-1}\right]$ & $\mathrm{b}\left[\cdot 10^{-3}\right]$ \\
\hline \hline $\mathrm{B}^{-3}$ & $1.73 \pm 0.01$ & $1.35 \pm 0.03$ \\
\hline HEPES & $1.94 \pm 0.03$ & $1.58 \pm 0.09$ \\
\hline
\end{tabular}

50 days of observation, although they fluctuated up to $17 \%$ of the mean. The peak at $734 \mathrm{~nm}$ showed a slight decay.

The unstable behavior of RR solutions after preparation demanded some compromise for their usage. We prepared stock solutions at least one day in advance and they were used for no more than 5 days.

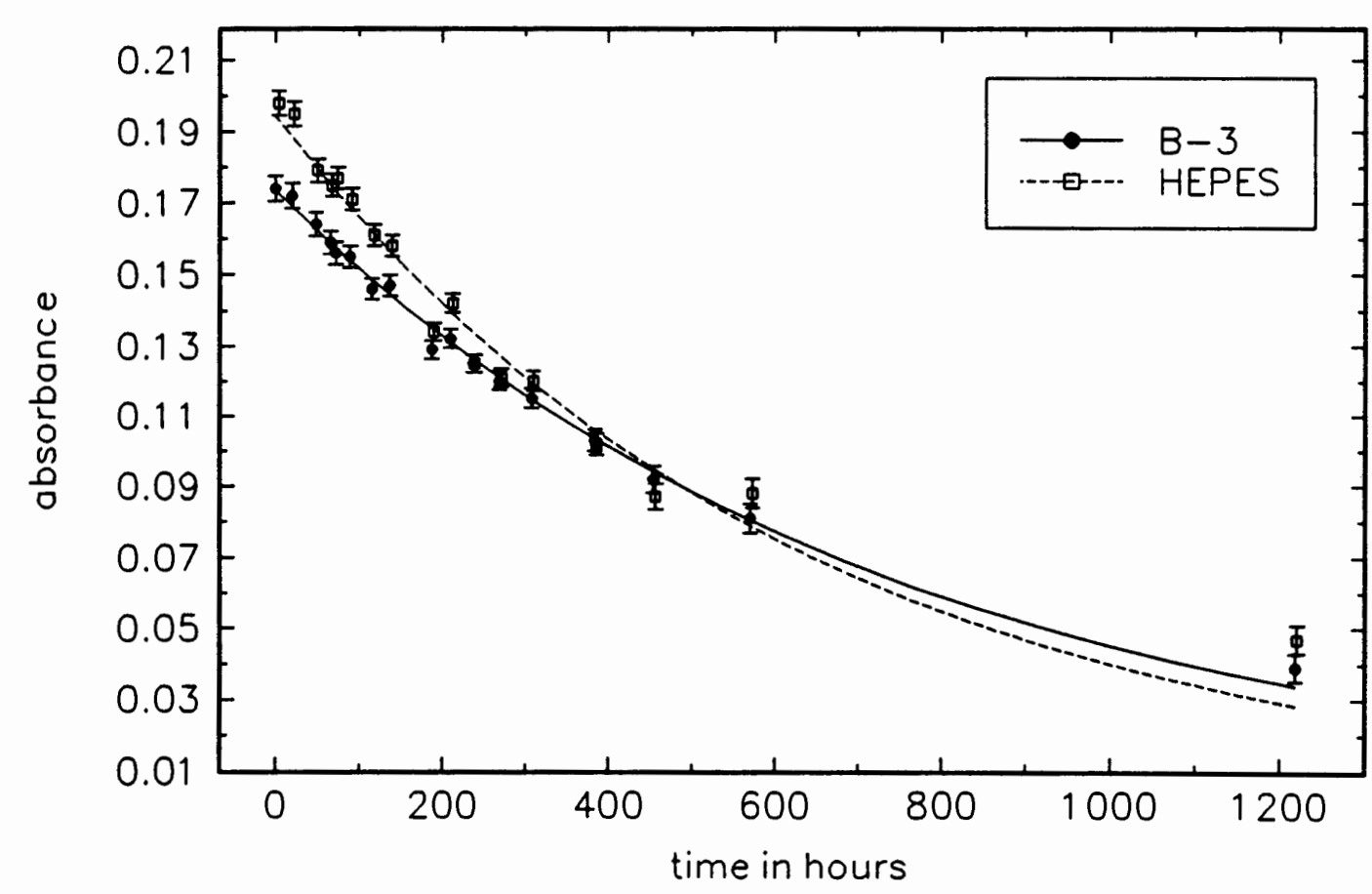

Fig.7: Time-dependent decay of the 533nm RR peak in $B^{-3}$ and HEPES buffer solution at $\mathrm{pH}$ 7.4. Exponential fits are given in Table I. 


\section{Interaction of RR with Glassware}

RR strongly interacted with all the glassware used in the experiment. Pyrex glass seemed to adsorb less than Kimax glass but either one introduced large measurement errors. All beakers and tubes used in connection with RR were therefore replaced by plastic ones. No measurable adsorption to polycarbonate, polypropylene, or polystyrene was found. Corbalan-Garcia et al. (1992) used a different approach to solve this problem. Instead of measuring free RR they measured directly the RR bound to the membrane by dissolving pelleted vesicles in SDS.

Fig. 8 shows the interaction of RR with the two different kinds of cells used in our spectrophotometer. Clean quartz cells strongly adsorbed RR and were saturated

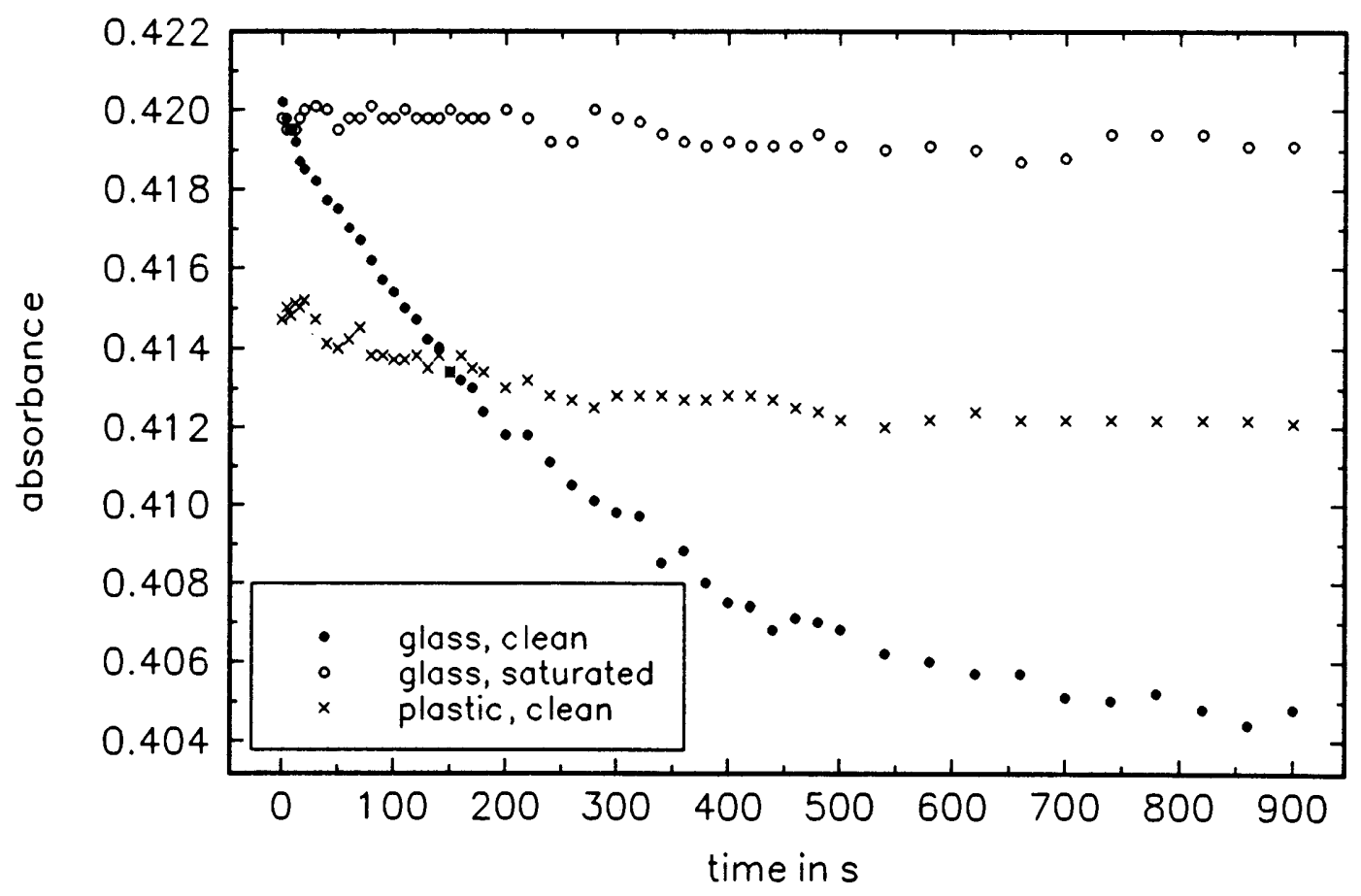

Fig.8: Interaction of RR with spectrophotometer cells. 
after about $15 \mathrm{~min}$. When the saturated cells were filled with the same RR solution without intermediate cleaning almost no adsorption was observed. Clean plastic cells showed far less interaction with RR than clean quartz cells. A difference in optical path length between both cells is causing the offset in Fig.8. All plastic cells were calibrated with two saturated quartz cells to get comparable results.

\section{FAT-Cycle Characterization}

We did two experiments to test and optimize our FAT procedure. In the first experiment we measured the RR concentration in the supernatant of centrifuged RRliposome suspension as a function of the number of FAT cycles (Fig.9). Adsorption is proportional to the difference between final equilibrium concentration of $R R$ and initial RR concentration when the adsorbing species are completely separated from the final solution. Only very small adsorption was observed without FAT. This indicates that the liposomes were mostly multilamellar and adsorption could only occur to the outermost layer. For up to 4 FAT cycles the adsorption increased with FAT cycle number. The solid line in Fig. 9 represents an exponential fit with the data for 0 to 4 FAT cycles. For 6 or more FAT cycles adsorption seems to decrease; this is an experimental artifact. FAT causes an increasing number of very small particles which are difficult to pellet by our centrifugation method. As a result the equilibrium concentration of RR increases. In agreement with Mayer et al. (1985) we considered 5 FAT cycles ideal. 


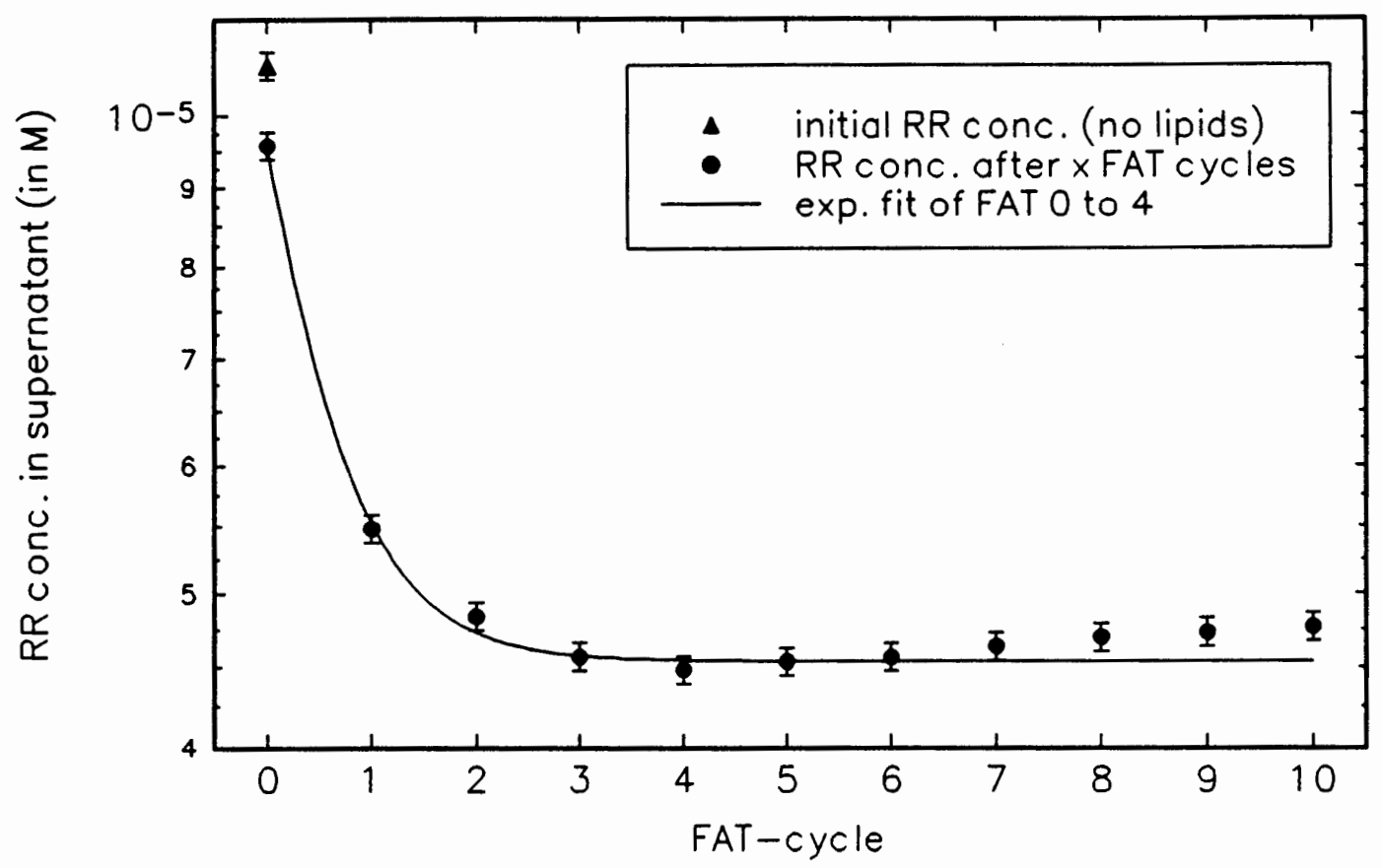

Fig.9: FAT cycle dependent adsorption of RR to liposomes ( $1 \mathrm{mg} / \mathrm{ml}$ lipids PC:PS 10:1, $1.03 \cdot 10^{-5} \mathrm{M} \mathrm{RR}, 2 \mathrm{~h}$ centr. at $\left.100,000 \mathrm{xg}\right)$.

The second experiment characterized liposome particle size as a function of FAT cycles. According to Angström's proportionality (Eq.(16)) scattering should produce a line in a log-log plot if the absorbance is plotted as a function of the wavelength. The slope of this line gives qualitative information about the particle size. For a given sample, increase of absorbance at a certain wavelength indicates increase in the density of particles with a diameter comparable to that wavelength. Fig. 10 shows a log-log plot of absorbance due to scattering as a function of the wavelength for liposome suspensions with different numbers of FAT cycles. Fits of the data are given in Table II. An increase in the wavelength-exponent $\alpha$ indicates decrease in the average liposome size. The values for 0 FAT cycles differ most from the predicted form of a 


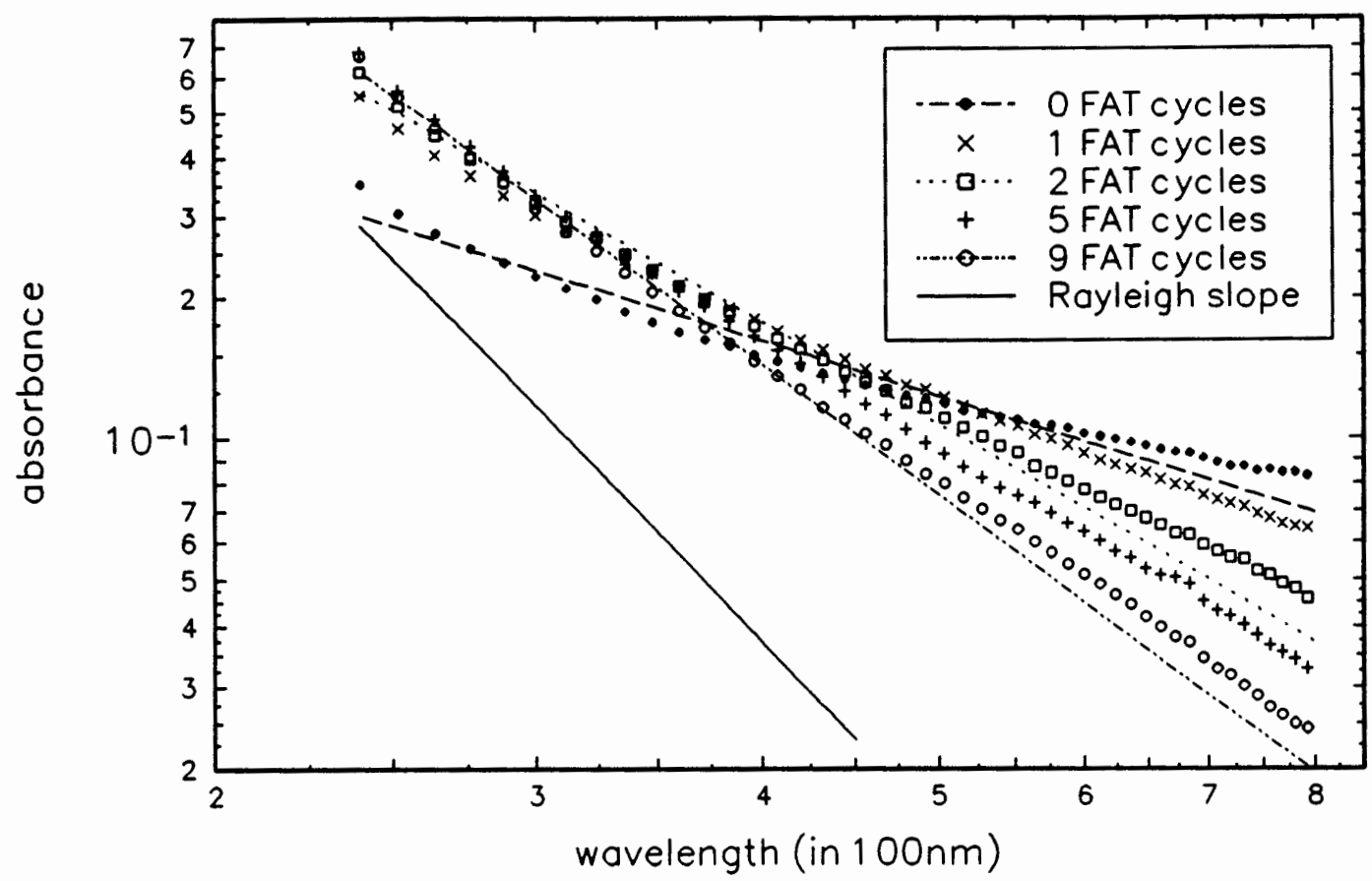

Fig. 10: Influence of FAT cycles on the wavelength dependence of absorption due to scattering of liposomes $\left(0.17 \mathrm{mg} / \mathrm{ml}\right.$ lipid, $\mathrm{PC}: \mathrm{PS} 10: 1$ in B $\left.^{-3}, \mathrm{pH} 7.3\right)$

line. FAT causes a decrease of absorbance values for large wavelengths and an increase for small wavelengths indicating a decrease respectively increase in particle density for particle sizes comparable to the wavelength.

Table II also gives the interception point of two fits each. Although measurement errors increase with increasing FAT cycle number this point might provide some valuable information about the liposome size. The interception point of two fits $\left(\mathrm{I}_{\mathrm{F}}\right)$ corresponds to the interception point of the two particle size distributions $\left(I_{D}\right)$ which produced the scattering. Fig.13 in 'Electron Micrographs' shows a typical theoretical size distribution. Only for $I_{D}$, particles smaller than this point (that is the left side of $I_{D}$ ) increase and particles larger than $I_{D}$ decrease if the transition from (n-1) 
Table II: Fits and interception points for the FAT cycle dependence of scattering.

\begin{tabular}{||c||c|c|c||}
\hline \hline model: & $\mathrm{A}=\mathrm{a} \cdot \lambda^{-\alpha}[\lambda$ in nm] & \\
\hline \hline FAT $\mathrm{n}$ & $\mathrm{a}$ & $\alpha$ & $\mathrm{I}_{\mathrm{F}}(\mathrm{n}, \mathrm{n}+1)$ [in nm] \\
\hline \hline FAT 0 & $(2.43 \pm 0.66) \cdot 10^{-9}$ & $1.22 \pm 0.02$ & 495 \\
\hline FAT 1 & $(1.70 \pm 0.49) \cdot 10^{-13}$ & $1.88 \pm 0.02$ & 352 \\
\hline FAT 2 & $(6.83 \pm 1.91) \cdot 10^{-16}$ & $2.25 \pm 0.02$ & 376 \\
\hline FAT 3 & $(3.47 \pm 1.06) \cdot 10^{-17}$ & $2.45 \pm 0.02$ & 283 \\
\hline FAT 4 & $(3.33 \pm 0.87) \cdot 10^{-18}$ & $2.61 \pm 0.02$ & 252 \\
\hline FAT 5 & $(2.11 \pm 0.57) \cdot 10^{-18}$ & $2.64 \pm 0.02$ & 224 \\
\hline FAT 7 & $(2.95 \pm 0.90) \cdot 10^{-19}$ & $2.77 \pm 0.02$ & 229 \\
\hline FAT 9 & $(6.60 \pm 1.84) \cdot 10^{-20}$ & $2.87 \pm 0.02$ & \\
\hline
\end{tabular}

* The model originates in eq.(16); a is a parameter without physical significance.

to $n$ FAT cycles is considered. For small changes in $I_{F}$ the maximum of a size distribution for $\mathrm{n}$ FAT cycles (that is the most probable size) is the average of the two fit interceptions $I_{F}(n-1, n)$ and $I_{F}(n, n+1)$. The result for 5 FAT cycles $(238 n m)$ comes close to the size distribution maximum found on the electron micrograph (about $290 \mathrm{~nm}$ diameter). It would be interesting to test this predicted relation more extensively since it would be an easy and cheap method to estimate liposome size.

\section{Measurement Errors}

Table III summarizes systematic and statistical errors which occur in our experiment. If not stated otherwise, errors are calculated or measured. Estimated values are values for the worst case. 
Table III: Systematic and statistical measurement errors.

\begin{tabular}{|c|c|c|}
\hline cause of error & description of error & effect ${ }^{*}$ \\
\hline \multicolumn{3}{|c|}{ systematic errors } \\
\hline spectrophotometer & $\begin{array}{l}\text { absorbance values are about } 5 \text { to } \\
10 \% \text { too large }\end{array}$ & $\begin{array}{l}\text { shift of adsorption isotherm } \\
\text { along the abscissa (about } 5 \text { to } \\
10 \% \text { ) }\end{array}$ \\
\hline remaining lipids & $\begin{array}{l}<1 \mu \mathrm{g} / \mathrm{ml} \text { lipid remain in the } \\
\text { supernatant after centrifugation }\end{array}$ & $<1 \%$ less adsorption \\
\hline$R R$ trapping & $\begin{array}{l}<0.7 \% \mathrm{RR} \text { per } \mathrm{mg} / \mathrm{ml} \text { might be } \\
\text { trapped by pelleted liposomes }\end{array}$ & $\begin{array}{l}<1 \% \text { more adsorption }(<7 \% \\
\text { for high lipid concentrations) }\end{array}$ \\
\hline laboratory equipment & $\begin{array}{l}\text { adsorption to beakers, tubes, or } \\
\text { cells }\end{array}$ & not measured \\
\hline competitive adsorption & $\begin{array}{l}\text { simultaneous adsorption of other } \\
\text { molecules than RR }\end{array}$ & smaller RR adsorption (see text) \\
\hline \multicolumn{3}{|c|}{ statistical errors } \\
\hline spectrophotometer & $\begin{array}{l}\text { noise, position of cell in cell } \\
\text { holder }\end{array}$ & $\begin{array}{lc}\text { absorbance } & \text { error } \\
0.00-0.02 & 20 \% \\
0.02-0.05 & 8 \% \\
0.05-0.10 & 5 \% \\
0.10-0.50 & 3 \% \\
0.50-2.00 & 2 \%\end{array}$ \\
\hline pipettes & reproducibility of dilutions & $\begin{array}{ll}1: 10 & 0.5 \% \\
1: 2 & 0.3 \% \\
\end{array}$ \\
\hline liposome preparation ${ }^{+}$ & lipid concentration & estimated 3\% \\
\hline & lipid composition & estimated $10-15 \%$ \\
\hline
\end{tabular}

- 'effect' compares the experimental result including the particular measurement error to the exact result. Standard deviations are obtained by multiplication with the respective value.

+ these errors affect the isotherm as a whole, not single measurement points. 
We calibrated the spectrophotometer with one absorption standard. Results indicate that our instrument might give about 5 to $10 \%$ too large absorbance values. However, no second standard was available and compared to other spectrophotometers the values were within their fluctuation. Larger absorbance values cause a shift of the adsorption isotherm in the direction of greater concentration.

Pelleting of liposomes in the centrifugation protocol was not completely successful for very small particles. This effect was larger for high ionic strengths (high RR concentrations) and larger for high surface charges but almost independent of the lipid concentration. Assuming a linear relation between lipid concentration and absorption we estimated the remaining lipid concentration to be smaller than $1 \mu \mathrm{g} / \mathrm{ml}$. If lipids remain in the sample the RR equilibrium concentration is higher and therefore adsorption values are smaller. Tortorella et al. (1993) describe a centrifugation method which is capable of pelleting even small particles by centrifugation. They aggregate particles by adding streptavidin. Smejtek and Wang (1993) separated liposomes by ultrafiltration. However, we considered ultracentrifugation the most convenient and exact.

Lipid membranes are permeable for small molecules (like water) but impermeable for large ones (like RR). Therefore there might be a possibility of RR being trapped in pelleted liposomes but the water released. This would cause higher adsorption values since the equilibrium concentration would decrease. Mayer et al. (1985) give as trapping volume $5 \mu \mathrm{l}$ per $\mu$ mol lipid for FAT liposomes. This limits the 
$\mathrm{RR}$ concentration change due to trapping in pelleted liposomes to less than $0.7 \%$ per $\mathrm{mg} / \mathrm{ml}$ lipid concentration.

Probably the largest measurement error is caused by competitive adsorption of RR impurities. Our spectrophotometric "window" monitors three molecules besides $\mathrm{RR}$ : adsorption of RV was too small for quantitative measurements; nitrosylruthenium did not seem to adsorb; RB clearly showed adsorption. Apart from differences for very small absorbance values (caused by remaining lipids) the peak-ratio of RR:RB was the same for the initial and the equilibrium RR concentration suggesting that both molecules behave similarly. The structure of $R R$ and $R B$ differs only in valence $(+7$ for $R B,+6$ for RR, Fletcher et al. 1961). We therefore regard RR and RB as one kind of adsorbing molecule. The sum of both molecule concentrations gives the actual concentration of RR-like adsorbing molecules which may be up to $45 \%$ larger than the spectrophotometric determined RR concentration. Similar to the error caused by the spectrophotometer, this effect would shift the adsorption isotherm along the abscissa up to $45 \%$. It is rather probable that other ions compete with RR, too. Ruthenium (III) hexamine trichloride, a comparably weak absorbing substance, might be one of them. Since it is trivalent the adsorption should be smaller for this ion than for RR but its presence might still alter the shape of the adsorption isotherm slightly. Adsorption of monovalent potassium ions (from the $\mathrm{B}^{-3}$ buffer solution) and adsorption of anions are negligible.

Noise in the spectrophotometric measurements, the position of the cell in the cell holder, pipetting of solutions, and the liposome preparation protocol caused some 
statistical errors. The overall statistical error was estimated 15 to $30 \%$, depending on the absorbance value.

\section{ELECTRON MICROGRAPH}

Electron micrographs provided valuable information on shape, size and size distribution of our liposomes. A typical electron micrograph of liposome suspension, shows three different features (Fig. 11): First, dark, mostly spherical or ellipsoidal structures confined by one or two black lines are liposomes. Second, large areas in different grey shades with irregular boundaries are sections with more or less stain. Third, black dots with diameters less than one $\mathrm{mm}$ are impurities. It was a problem to obtain high quality pictures since our preparation method frequently produced layers that were too thin or too thick.

We believe that the liposomes showed here are single layered. According to Johnson et al. (1971), the occurrence of two black lines at the edge of most liposomes could be understood in terms of Fig. 12: a spherical monolayer vesicle in solution (A) collapses during drying of the sample to form a cup-like structure (B) which appears as a particle with a double lined boundary on the micrograph (C). The picture is comparable to pictures of liposomes reported in the literature (Papahadjopoulos and Miller 1967). 


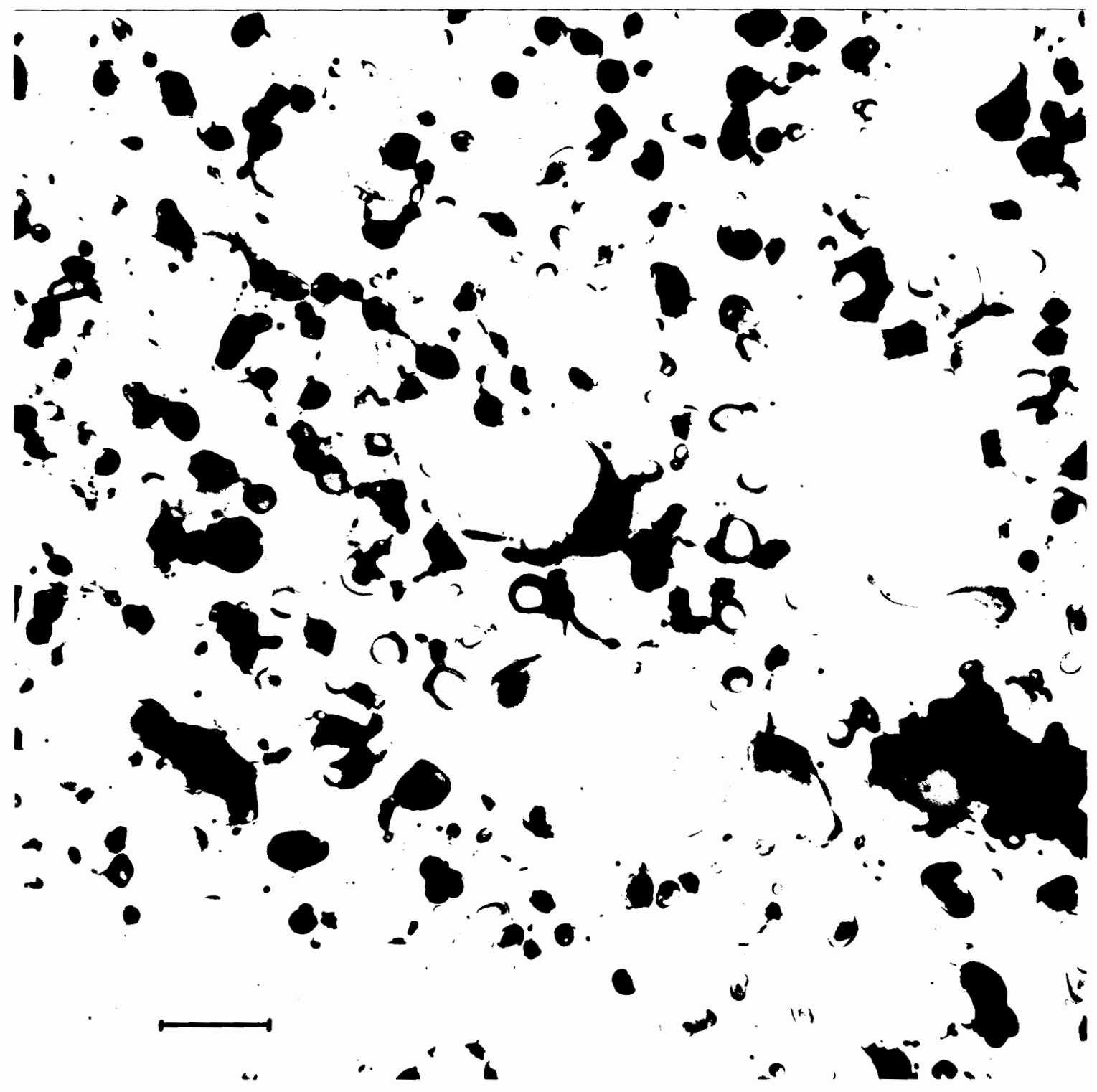

Fig. 11: Electron micrograph of liposome vesicles at $8000 \mathrm{x}$. The bar indicates $2 \mu \mathrm{m}$. 10mg/ml lipids, PC:PS 10:1, $2 \cdot 10^{-5} \mathrm{M}$ RR, 5 FAT cycles.

Winterhalter and Lasic (1993) discuss a theoretical approach to describe the size distribution of lipid vesicles starting from their thermodynamical equilibrium properties

$$
\omega(R)=\frac{R}{R_{m}^{2}} \exp \left[-\left(\frac{R}{2 R_{m}}\right)^{2}\right]
$$




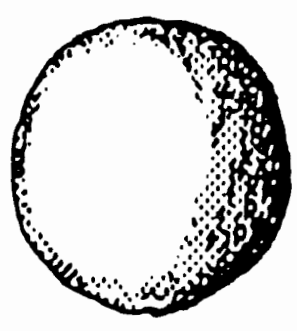

A

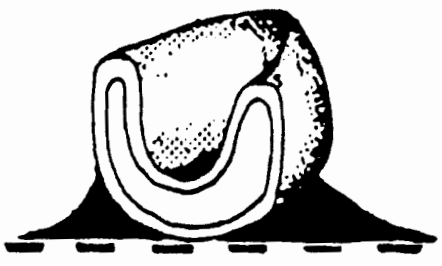

B
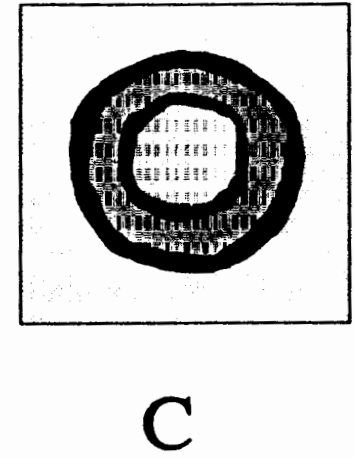

Fig.12: Interpretation of the electron micrograph (after Johnson et al. 1971).

$\omega$ is the probability to find a vesicle with radius $R\left(R\right.$ in $n m$ ) and $R_{m}$ corresponds to the maximum in the distribution (the most probable radius). Size distributions are obtained from this by multiplication with a factor $S$ which has the dimension of a length. A fit of this model to our data is shown in Fig.13. S was found to be $23 \mathrm{~nm}$, $R_{m}$ was found to be $103 \mathrm{~nm}$, and the actual maximum of the theoretical distribution was found to be at about $150 \mathrm{~nm}$. Total number of particles counted was 268 . The experimental distribution shows slightly larger particles than expected from the theoretical distribution. For particle radii greater than $600 \mathrm{~nm}$ the model fails.

Particle sizes for SR vesicles (Scales and Inesi 1976, Arrio et al. 1974) are smaller than our liposomes by a factor of about two . However, particle sizes of liposomes vary with preparation method. Heavy sonication, for example, produces particles with average radii of $12 \mathrm{~nm}$ (Johnson et al. 1971).

Air dried samples are not ideal for size determinations since the drying process may change the structure of the samples. 


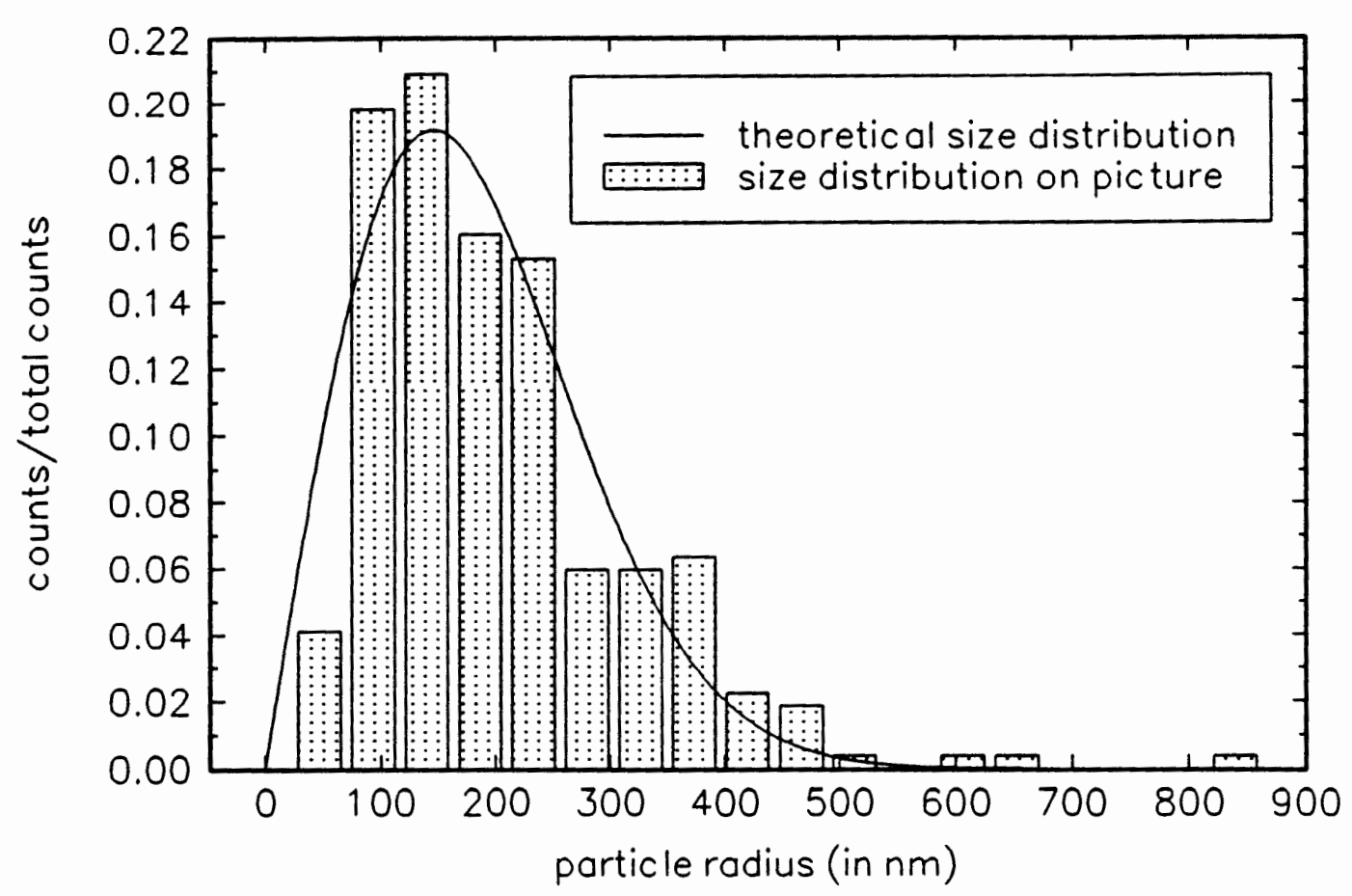

Fig.13: Size distribution of the liposomes showed in Fig. 11 (excluding the three very large liposomes).

\section{MAIN FEATURES OF THE ADSORPTION MODEL}

Our studies of adsorption of RR to liposomes with various surface charge densities and lipid concentrations were based on spectrophotometric measurements of the aqueous concentrations of $R R$ in the absence $\left([R R]_{\text {ini }}\right)$ and in the presence $\left([R R]_{e q}\right)$ of liposomes. Adsorption isotherms are plots of the following ratio $R_{R R}$ as a function of the initial RR concentration. 


$$
R_{R R}=\frac{[R R]_{e q}}{[R R]_{\text {init }}}
$$

$R_{R R}$ varies between 0 and 1; the larger $R_{R R}$ the smaller the adsorption. Experimental data are fitted with theoretical adsorption isotherms by means of two parameters: $q_{\text {eff }}$, the effective valency of a RR molecule, and $\beta_{\mathrm{mRR}}$, the linear partition coefficient. $\beta_{\mathrm{mRR}}$ is the ratio of the association constant $\mathrm{K}_{\mathrm{m}}$ to adsorption site area $\mathrm{P}_{\mathrm{s}}$. The choice of $\beta_{\mathrm{mRR}}$ as a parameter is not ideal since $K_{m}$ is not proportional to $P_{s}$. However, the changes are too small (Fig.14) to allow a simultaneous determination of $K_{m}$ and $P_{S}$ from the fitted curves for the experimental data. The legend in Fig. 14 shows the factor by which $\mathrm{K}_{\mathrm{m}}$ and $\mathrm{P}_{\mathrm{S}}$ are multiplied. All our theoretical adsorption isotherms assume a constant adsorption site area of $5 \mathrm{~nm}^{2}$ and a variable association constant $\mathrm{K}_{\mathrm{m}}$.

Effects of $\mathrm{q}_{\text {eff }}$ and $\beta_{\mathrm{mRR}}$ on the adsorption isotherms are depicted in Fig. 15 and Fig.16. Changes in $q_{\text {eff }}$ drastically changed the adsorption isotherm for low RR concentrations but had less of an effect at high concentrations indicating electrostatically driven adsorption that is limited by available adsorption sites. Changes in $\beta_{\mathrm{mRR}}$ resulted in similar effects at low $R R$ concentrations as the changes in $\mathrm{q}_{\text {eff }}$, but in addition, affected the distribution isotherm close to saturation. 


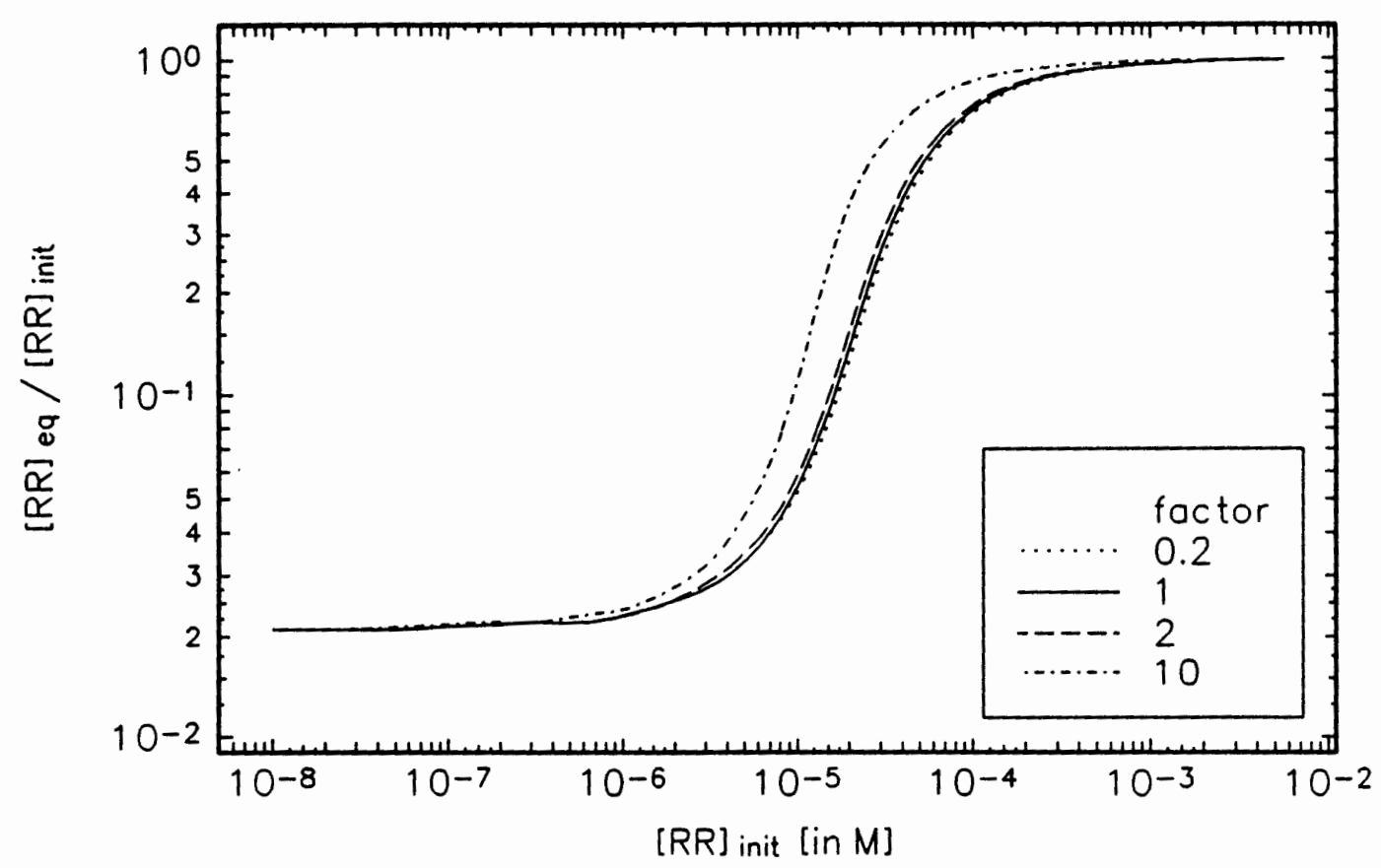

Fig. 14: Effect of simultaneous changes of $K_{m}$ and $\mathrm{P}_{S}$ for a constant $\beta_{\mathrm{mRR}}$ (legend: factor ' 1 ': $\mathrm{K}_{\mathrm{m}}=1.51 / \mathrm{M}, \mathrm{P}_{\mathrm{s}}=5 \mathrm{~nm}^{2}$ )

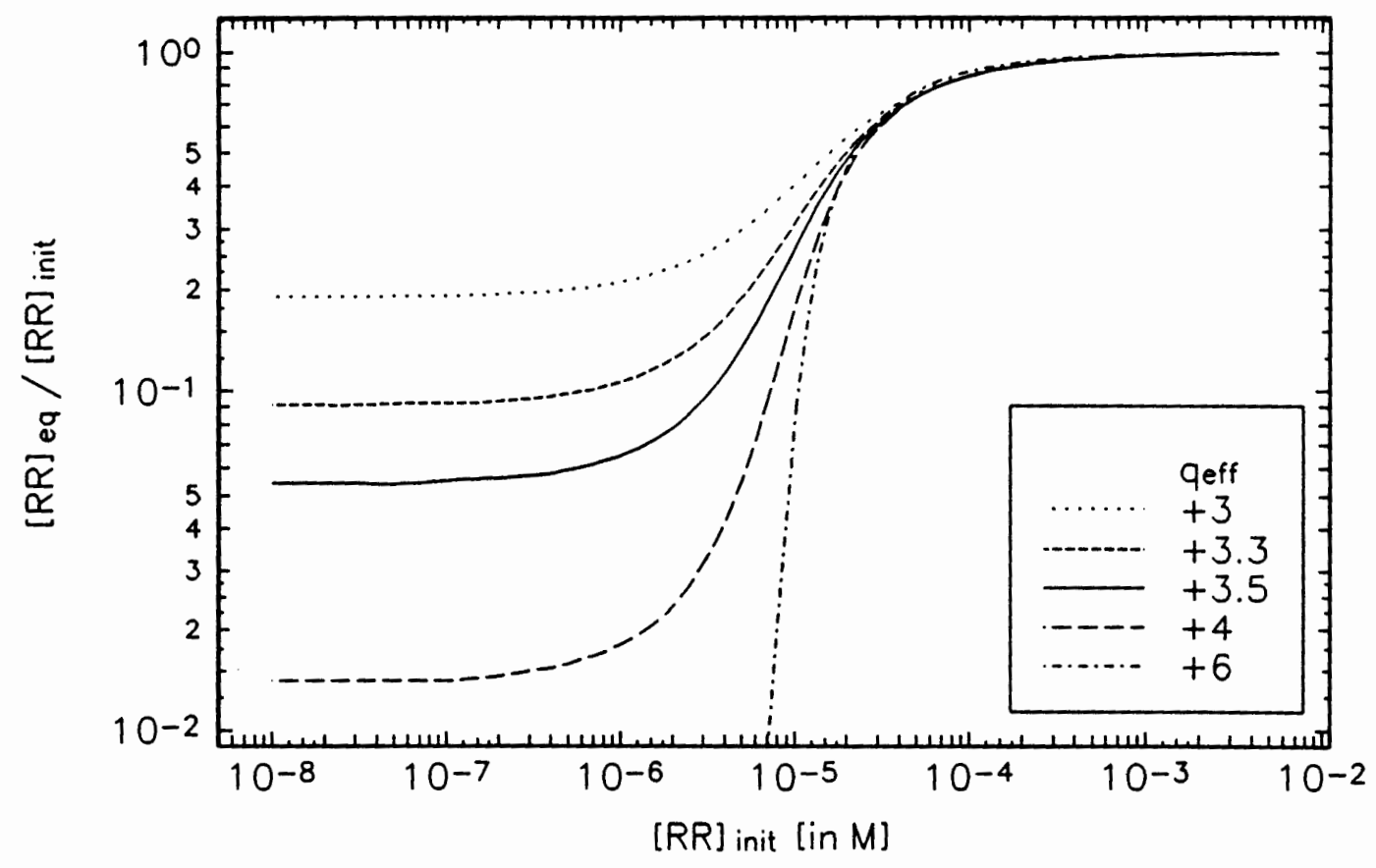

Fig. 15: Dependence of adsorption isotherms on the effective valency $q_{\text {eff }}$ $\left(\beta_{\mathrm{mRR}}=1\left(\mathrm{Mnm}^{2}\right)^{-1}, 1 \mathrm{mg} / \mathrm{ml} \mathrm{PC:PS} \mathrm{10:1).}\right.$ 


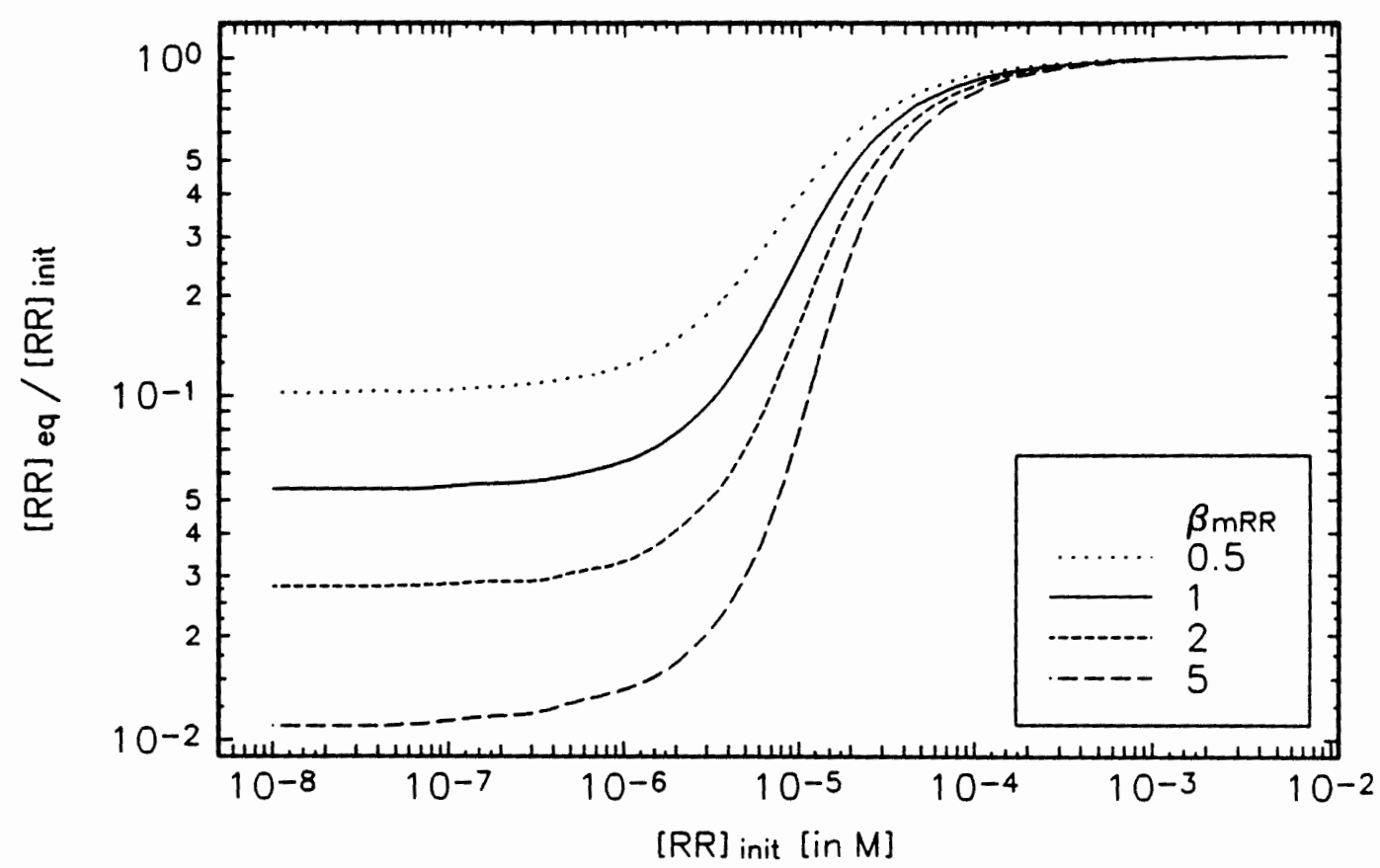

Fig. 16: Dependence of adsorption isotherms on the linear partition coefficient $\beta_{\mathrm{mRR}}$ [in $\left.M^{-1} \mathrm{~nm}^{-2}\right],\left(\mathrm{q}_{\text {eff }}=3.5,1 \mathrm{mg} / \mathrm{mlPC}:\right.$ PS $\left.10: 1\right)$.

\section{ADSORPTION TO LIPOSOMES}

We determined adsorption of RR to PC, PC:PS, and PC:PI membranes in various lipid concentrations $(0.3,1.0,3.0,10 \mathrm{mg} / \mathrm{ml}$ at a ratio $10: 1$ of uncharged to charged lipids) and various ratios of uncharged to charged lipids $(20: 1,10: 1,5: 1$ at $1 \mathrm{mg} / \mathrm{ml}$ lipid concentration). Buffer solution was $\mathrm{B}^{-3}$ at $\mathrm{pH} 7.3$. No salt was added to the solution. Concentrations were calculated from the absorbance data using Luft's 
formula (Eq.17) for RR solutions and the modified formula (Eq.18) for lipid containing solutions. Fits of the experimental data were done numerically with a computer program written by Dr. Smejtek and the quality of the fits was checked visually and by minimizing a weighted $\chi^{2} . R_{n}$ is the ratio of $[R R]_{e q}$ over $[R R]_{\text {init }}$ for the datapoint $n$.

$$
\chi^{2}=\frac{1}{N-1} \sum_{n=1}^{N}\left(\frac{R_{n}^{\exp }-R_{n}^{\text {th }}}{R_{n}^{\exp }}\right)^{2}
$$

It was not possible to fit the data only by means of adsorption site area $P_{S}$ and association constant $K_{m}$, even when all possible systematic errors were considered. To solve this problem we introduced an effective valency $\mathrm{q}_{\mathrm{eff}}$ of $\mathrm{RR}$ ions. We also used the linear partition coefficient $\beta_{\mathrm{mRR}}$, the ratio of $\mathrm{K}_{\mathrm{m}}$ to $\mathrm{P}_{\mathrm{s}}$, to reduce the number of parameters. Smejtek and Wang (1990) give values of $P_{S} \approx 5 \mathrm{~nm}^{2}$ for some lipophilic monovalent ions that adsorb below the surface of the lipid bilayer; RR most probably adsorbs to the surface. Adsorption site areas for monovalent lipophilic ions are comparable to adsorption site areas of about trivalent ions that adsorb to the surface if one accounts for the changes in the dielectric constant (about 8:1 for $\epsilon_{\mathrm{w}}: \epsilon_{\mathrm{m}}$ ). Lower limit for $P_{S}$ should be the size of the $R R$ molecule (about $0.3 \mathrm{~nm}^{2}$ ). Higher valencies should produce larger exclusion disks. We chose $5 \mathrm{~nm}^{2}$ for $\mathrm{P}_{\mathrm{S}}$ in all fits. Values for $\beta_{\mathrm{mRR}}$ are only comparable for constant $\mathrm{q}_{\mathrm{eff}}$ since both parameters are strongly related. Errors for $\mathrm{q}_{\mathrm{eff}}$ represent the range of valencies for which fits with comparable low $\chi^{2}$ were obtained; for the optimum $\mathrm{q}_{\mathrm{eff}}$ variation of $\beta_{\mathrm{mRR}}$ within the given error bars was 10 to $20 \%$. 


\section{PC:PS Ratio Effects}

Fig. 17 shows the dependence of the adsorption isotherm on the ratio of charged to uncharged lipids composed from PS and PC; fit-parameters are given in Table IV. Tabels VIII, IX, and X in the appendix give additional data. The GCS theory was able to describe the adsorption isotherms if the effective valency was allowed to vary. Effective valencies decreased with increasing surface charge density. We could not obtain realistic fit-parameters for pure PC membranes since the adsorption was too small when compared to the measurement errors. Experiments with higher lipid concentrations may provide better experimental data.

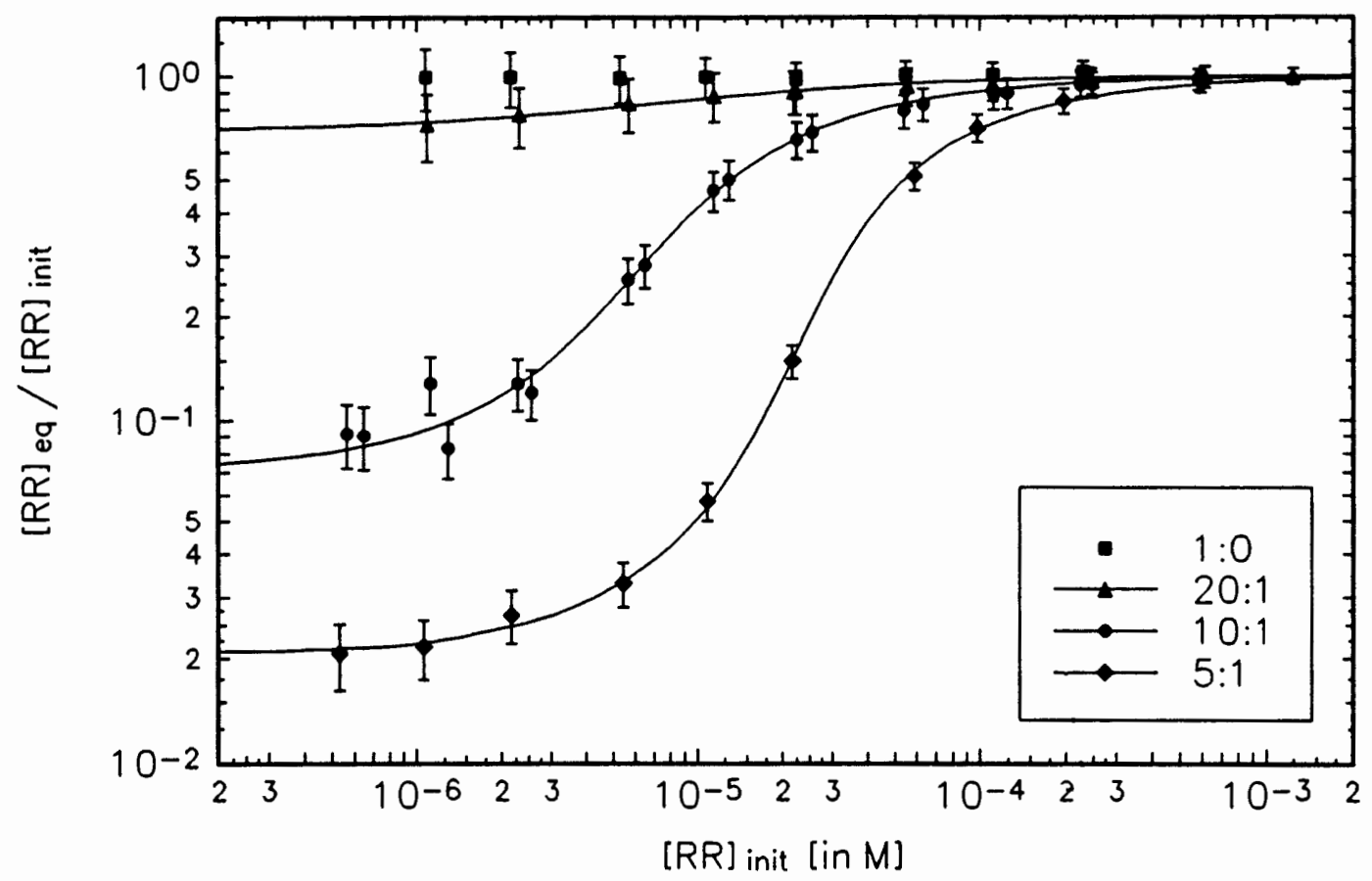

Fig.17: Adsorption isotherms for different ratios PC:PS (lipid conc. $1 \mathrm{mg} / \mathrm{ml}$ ). 
Table IV: Fit parameter for the PC:PS ratio dependence (Fig.17). Lipid conc. $1 \mathrm{mg} / \mathrm{ml}$.

\begin{tabular}{|c||c|c|c||}
\hline PC:PS & $\mathrm{q}_{\text {eff }}$ & $\beta_{\mathrm{mRR}}[\mathrm{nm}]$ & $\chi^{2}\left[\cdot 10^{-2}\right]$ \\
\hline \hline $1: 0$ & n. a. & n. a. & n. a. \\
\hline $20: 1$ & $4.1 \pm 0.3$ & 0.89 & 0.019 \\
\hline $10: 1$ & $3.8 \pm 0.2$ & 0.54 & 0.778 \\
\hline $5: 1$ & $2.9 \pm 0.1$ & 0.52 & 0.130 \\
\hline
\end{tabular}

\section{PC:PS Lipid Concentration Effects}

Fig.18 shows the dependence of the adsorption isotherm on the lipid concentration of PC:PS 10:1 liposomes; fit-parameters are given in Table V (Tables IX, XI, XII and XIII in the appendix for additional data). Experimental data are correctly described by the GCS theory for a fixed $\mathrm{q}_{\text {eff }}=3.8$. The optimum values for $\mathrm{q}_{\text {eff }}$ varied slightly but $\mathrm{q}_{\text {eff }}=3.8$ was always within the measurement error.

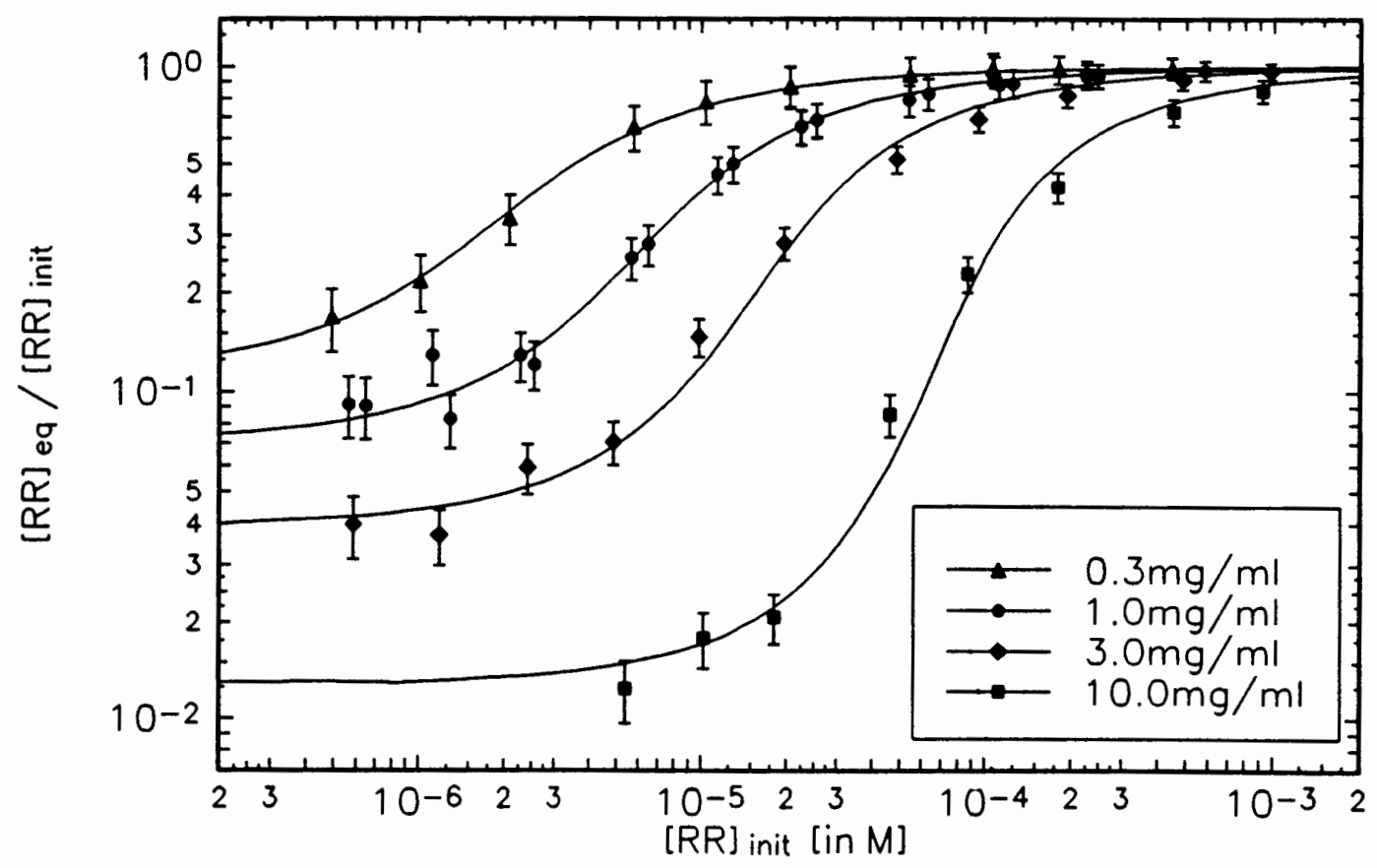

Fig.18: Adsorption isotherms for different lipid concentrations (PC:PS 10:1). 
Table V: Fit parameter for the lipid concentration dependence (Fig.18). PC:PS 10:1; $[\ldots]$ are values for $\mathrm{q}_{\text {eff }}=3.8$

\begin{tabular}{|c||c|c|c|}
\hline $\begin{array}{c}\text { lipid conc. } \\
{[\mathrm{mg} / \mathrm{ml}]}\end{array}$ & $\mathrm{q}_{\mathrm{eff}}$ & $\beta_{\mathrm{mRR}}[\mathrm{nm}]$ & $\chi^{2}\left[\cdot 10^{-2}\right]$ \\
\hline \hline 0.3 & $3.9 \pm 0.2$ & $0.81[0.99]$ & $0.079[0.090]$ \\
\hline 1.0 & $3.8 \pm 0.2$ & 0.54 & 0.778 \\
\hline 3.0 & $3.8 \pm 0.2$ & 0.33 & 1.42 \\
\hline 10.0 & $3.7 \pm 0.2$ & $0.43[0.34]$ & $2.73[5.09]$ \\
\hline
\end{tabular}

\section{PC:PI Ratio Effects}

Mixtures of PC and PI showed the same features as mixtures of PC and PS (Fig.19, Table VI for fit-parameter, Tables XIV and XV in the appendix for additional data). The effective valency also decreases with increasing surface charge density.

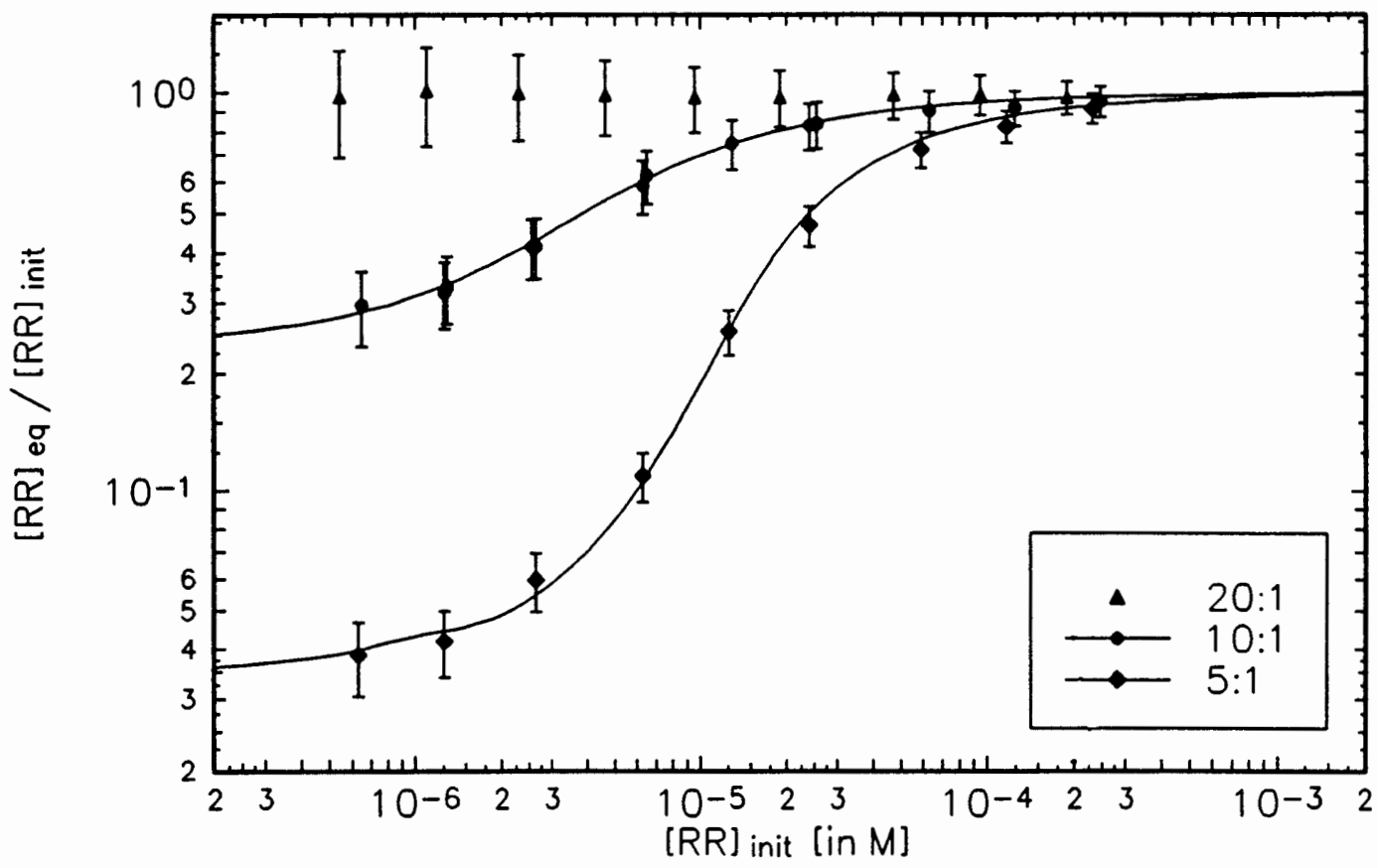

Fig.19: Adsorption isotherms for different ratios PC:PI (lipid conc. $1 \mathrm{mg} / \mathrm{ml}$ ). 
Table VI: Fit parameter for the PC:PI ratio dependence (Fig.19). Lipid conc. $1 \mathrm{mg} / \mathrm{mi}$.

\begin{tabular}{|c||c|c|c|}
\hline \hline PC:PI & $\mathrm{q}_{\text {eff }}$ & $\beta_{\mathrm{mRR}}[\mathrm{nm}]$ & $\chi^{2}\left[\cdot 10^{-2}\right]$ \\
\hline $20: 1$ & n. a. & n. a. & n. a. \\
\hline $10: 1$ & $3.9 \pm 0.2$ & 0.21 & 0.071 \\
\hline $5: 1$ & $3.2 \pm 0.1$ & 0.16 & 0.258 \\
\hline
\end{tabular}

Values for the effective valencies are slightly larger compared to PC:PS membranes. The differences are probably caused by the experimental protocol: PI has an about $12 \%$ larger molecular weight than PS; PC:PI mixtures for a certain mass ratio contain, therefore, less charged phospholipids than PC:PS mixtures. The resulting lower surface charge density causes a larger effective valency.

\section{PC:PI Lipid Concentration Effects}

Lipid concentration dependence of adsorption to PC:PI membranes is similar as found for PC:PS membranes (Fig.20, Table VII for fit-parameter, Tables XIV, XVI,

Table VII: Fit parameter for the lipid concentration dependence (Fig.20). PC:PI 10:1; $[\ldots]$ are values for $\mathrm{q}_{\mathrm{eff}}=3.8$

\begin{tabular}{|c||c|c|c||}
\hline $\begin{array}{c}\text { lipid conc. } \\
{[\mathrm{mg} / \mathrm{ml}]}\end{array}$ & $\mathrm{q}_{\text {eff }}$ & $\beta_{\mathrm{mRR}}[\mathrm{nm}]$ & $\chi^{2}\left[\cdot 10^{-2}\right]$ \\
\hline \hline 0.3 & $3.9 \pm 0.3$ & $0.08[0.10]$ & $0.099[0.124]$ \\
\hline 1.0 & $3.9 \pm 0.2$ & $0.21[0.25]$ & $0.071[0.073]$ \\
\hline 3.0 & $3.9 \pm 0.2$ & $0.18[0.23]$ & $0.690[0.360]$ \\
\hline 10.0 & $3.6 \pm 0.2$ & $0.24[0.17]$ & $1.09[2.10]$ \\
\hline
\end{tabular}




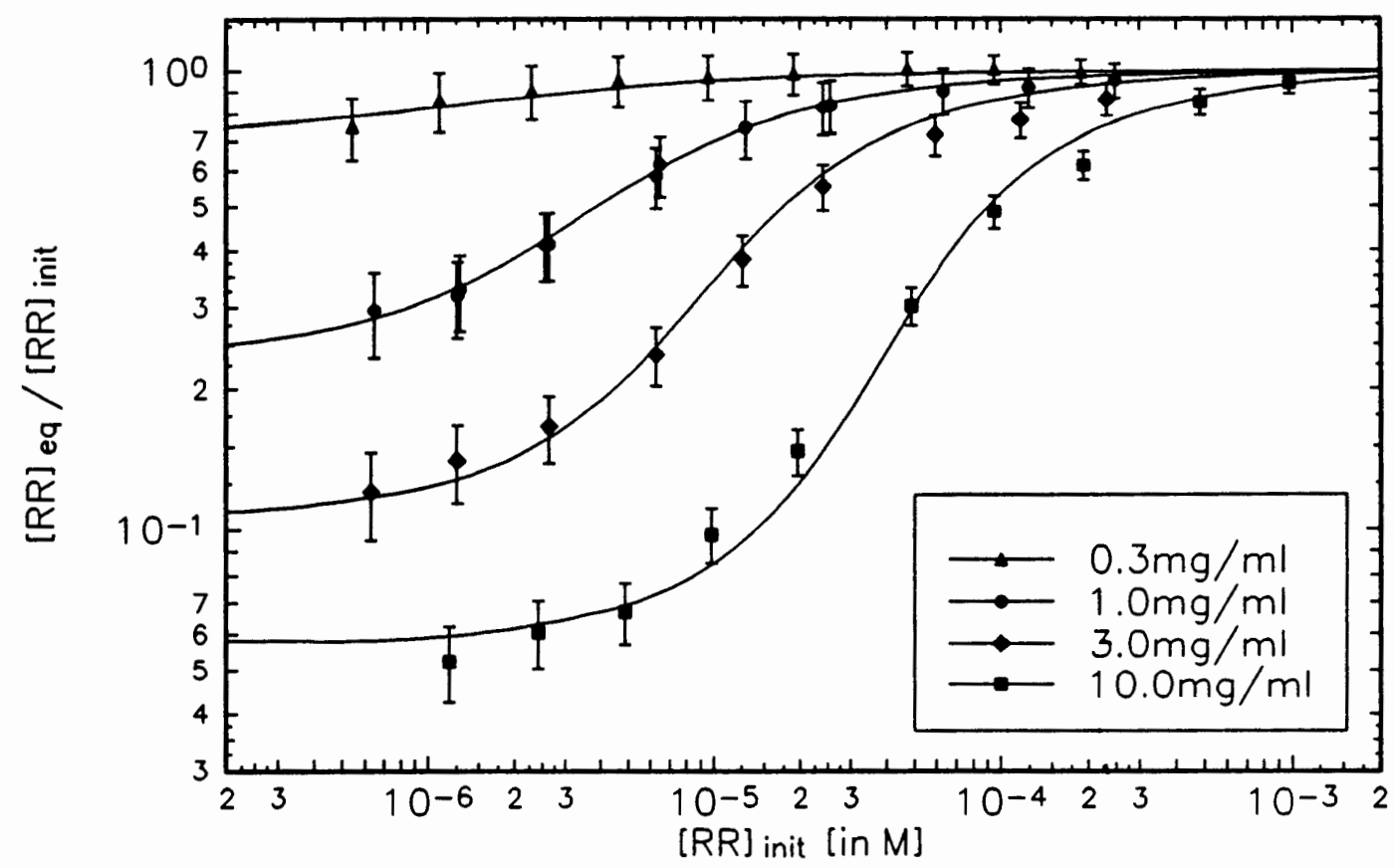

Fig.20: Adsorption isotherms for different lipid concentrations (PC:PI 10:1).

XVII, and XVIII in the appendix for additional data). The linear partition coefficient is significantly smaller than for PC:PS membranes, indicating less adsorption.

\section{Discussion}

Our data show that the simple GCS theory describes, surprisingly well, adsorption isotherms of the hexavalent ion RR when an effective valency is introduced. The questions are why it is necessary to introduce an effective valency and why is this valency dependent on the membrane composition? 
As follows from the Boltzmann factor in Eq.(9), $q_{\text {eff }}$ mainly controls the concentration of $\mathrm{RR}$ at the aqueous side of the membrane-water interface. For a surface potential of $70 \mathrm{mV}$ (that is e.g. the value for PC:PS 10:1 at low RR concentrations) $\mathrm{q}_{\text {eff }}=6$ means an increase by a factor of about $20 \cdot 10^{6}$ of the RR concentration at the interface compared to the bulk aqueous concentration. If the RR ions could fulfill this prediction they had to be packed denser than in the solid state. The finite size of the ions (which is not accounted for in our theory) is therefore one reason why an effective valency had to be introduced; screening of RR ions by buffer ions may be another. Furthermore, ion-ion repulsion which may be important at high local RR concentration is not accounted for by our theory.

An increase of the surface charge density also increases the membrane surface potential. Finite size and ion-ion repulsion limit the available space in front of the membrane. For this reason the dependence of the ion concentration on the surface potential more probably obeys a saturation curve than an exponential increase (as produced by the increasing surface potential in the Boltzmann factor). A decrease of $\mathrm{q}_{\text {eff }}$ is associated with an increase of the surface potential produced by an increasing concentration of charged phospholipids. Effective valencies are therefore one possibility to account for finite size effects and ion-ion interactions. Carnie and McLaughlin (1983) calculated and Alvarez et al. (1983) measured the adsorption of large divalent cations including finite size effects. In agreement with our results they found less adsorption for high ion concentrations than predicted by the GCS theory. 
Changes in the lipid concentration do not change the surface potential; no changes in the effective valency were therefore expected nor found.

Values for the linear partition coefficient can hardly be compared to values given in the literature for other ions since $\beta_{\mathrm{mRR}}$ and $\mathrm{q}_{\text {eff }}$ are strongly related. We found that PC:PI liposomes adsorb significantly less than PC:PS liposomes for a constant $\mathrm{q}_{\mathrm{eff}}$. This result disagrees with data presented previously: Eisenberg et al. (1979) found larger adsorption to PI liposomes than to PS liposomes for several monovalent ions; Chung et al. (1985) also found slightly larger adsorption of the tetravalent ion Gentamicin; Langner et al. (1990) found an equivalent electrostatic potential profile for PC:PI 5:1 and PC:PS 5:1 membranes. Our result may suggest some specific interactions of RR with PS. Luft (1971a) found different staining reactions of RR with PS and PI but he did no adsorption measurements.

Accounting for possible systematic measurement errors (e.g. additional adsorption of RB as a RR-like molecule) would yield higher values of the linear partition coefficient and lower values of the effective valency.

\section{Biological Importance}

We have shown that RR ions adsorb to phospholipids and that their adsorption is strongly affected by electrostatic interactions. The main electrostatic effect is the increase of the ion concentration at the membrane-water interface. The adsorbance saturation occurring for high $\mathrm{RR}$ concentrations allows some estimates about the 
maximum binding of RR to lipid membranes to be made. For PC:PS 20:1 this is about $9 \pm 3 \mathrm{nmol}$ per $\mathrm{mg}$ of lipid (PC:PS 10:1 about $16 \mathrm{nmol} / \mathrm{mg}$; PC:PI 10:1 about $8 \mathrm{nmol} / \mathrm{mg}$ ). These interactions should be considered in adsorption studies of biological membranes since a significant percentage of the phospholipids in biological membranes are charged. PS is the predominant charged phospholipid for many mammalian cells (White 1973).

SR vesicles contain about $0.45 \mathrm{mg}$ of phospholipids per $\mathrm{mg}$ protein (Scales and Inesi 1976) and the surface charge densities of SR vesicles range from $-5.4 \cdot 10^{3}$ to $-9.2 \cdot 10^{-3} \mathrm{C} / \mathrm{m}^{2}$ (Arrio 1984 , Liu and Oba 1990) which is comparable to membranes made from 20:1 mixtures of uncharged to charged phospholipids. Corbalan-Garcia (1992) found a RR binding of 6nmol per mg protein to rabbit skeletal SR vesicles; Moutin et al (1992) found two RR binding sites on rabbit skeletal SR vesicles, one binds $10 \mathrm{nmol}$ per $\mathrm{mg}$ protein and may represent the high affinity $\mathrm{Ca}^{2+}$ transport sites of the $\mathrm{Ca}^{2+}$-ATPase, the other binds $15-17 \mathrm{nmol}$ per mg protein and represents "nonspecific cation binding sites of the SR $\mathrm{Ca}^{2+}$-ATPase or of a closely associated element". It is very probable that a significant part of the reported binding is due to negatively charged phospholipids present in the SR membrane. For a quantitative analysis the exact surface charge and the phospholipid composition have to be known. 


\section{CHAPTER V}

\section{CONCLUSIONS}

In this study we investigated interaction of the commercially available stain Ruthenium Red (RR) with phospholipid bilayer vesicles by means of spectrophotometric absorption measurements. Adsorption of $R R$ to liposomes made from phosphatidylcholine and phosphatidylserine or phosphatidylinositol in various compositions and concentrations was measured. Experimental adsorption isotherms were fitted with the Gouy-Chapman-Stern adsorption model from which the linear partition coefficient and an effective valency of the Ruthenium Red ion were determined. Furthermore, Ruthenium Red solutions and freeze-and-thawing of liposomes were characterized and electron micrographs of liposomes were taken. Major findings are:

1) The Gouy-Chapman-Stern theory is able to describe adsorption of a hexavalent ion to charged phospholipid bilayer vesicles if an effective ion valency is introduced which takes care of the finite size of the ion and ion-ion repulsion.

2) Ruthenium Red adsorbs to phospholipid vesicles and its adsorption is larger for PC:PS membranes than for PC:PI membranes. Attractive electrostatic interactions between RR ions and negatively charged membranes strongly increase adsorption by increasing the ion concentration at the membrane-water interface. These 
interactions have to be considered in studies of RR adsorption to biological membranes and membrane proteins due to the presence of negatively charged phospholipids in most membrane systems.

3) Five freeze-and-thaw cycles are sufficient to obtain an equilibrium distribution of large ions at the membrane-water interface of liposomes. The diameter of vesicles produced by this procedure is typically 200 to $300 \mathrm{~nm}$.

The significance of this study is that we have developed understanding of adsorption of RR to well defined artificial lipid membranes. Results of this work provide a basis for the understanding of interactions between $R R$ and biological membranes. 


\section{REFERENCES}

Gmelins Handbuch der Anorganischen Chemie. 1938. 8. Auflage

Abraham-Shrauner, B. 1975. Generalized Gouy-Chapman potential of charged phospholipid membranes with divalent cations. Journ. Math. Biol. 2:333-339

Abramson, J.J., Cronin, J.R., Salama, G. 1988. Oxidation induced by phthalocyanine dyes causes rapid calcium release from sarcoplasmic reticulum vesicles. Arch. Biochem. Biophys. 263(2):245-255

Alvarez, O., Brodwick, M., Latorre, R., McLaughlin, A., McLaughlin, S., Szabo, G. 1983. Large divalent cations and electrostatic potentials adjacent to membranes. Experimental results with hexamethonium. Biophys. J. 44:333-342

Amann, R., Maggi, C.A. 1991. Ruthenium Red as a capsaicin antagonist. Life Sci. 49(12):849-856

Anghileri, L.J., Marchal, C., Matrat, M., Crone-Escanye, M.C., Robert, J. 1986. Hyperthermia inhibition of tumor cells growth in the presence of Ruthenium red. Neoplasma. 33(5):603-608

Angström, A. 1929. Geograf. Ann. 11:156

Antoniu, B., Kim, D.H., Morii, M., Ikemoto, N. 1985. Inhibitors of $\mathrm{Ca}^{2+}$. Biochim. Biophys. Acta 816(1):9-17 release from the isolated sarcoplasmic reticulum. $\quad$. $\mathrm{Ca}^{2+}$ channel blockers.

Arrio, B., Johannin, G., Carette, A., Chevalier, J., Brethes, D. 1984. Electrokinetic and hydrodynamic properties of sarcoplasmic reticulum vesicles: a study by laser doppler electrophoresis and quasi-elestic light scattering. Arch. Biochem. Biophys. 228(1):220-229

Arrio, B., Chevallier, J., Jullien, M., Yon, J., Calvayrac, R. 1974. Description by quasi elastic light scattering of a biological preparation: sarcoplasmic reticulum vesicles. J. Membrane Biol. 18:95-112

Aveyard, R., Haydon, D.A. 1973. An introduction to the principles of surface chemistry. 
Bangham, A.D., Standish, M.M., Miller, N. 1965. Cation permeability of phospholipid model membranes; effect of narcotics. Nature (London) 208:1295-1297

Bangham, A.D. 1972. Model membranes. Chem. Phys. Lipids 8:386-392

Beiser, A. 1969. Perspectives of Modern Physics. pp. 419. McGraw-Hill,NY

Benz, R. 1985. Structure and dynamics of nerve membranes. Festkörperprobleme 25:747-756

Benz, R., Läuger, P., Janko, K. 1976. Transport kinetics of hydrophobic ions in lipid bilayer membranes. Charge pulse relaxation studies. Biochim. Biophys. Acta. 455:701-720

Bick, R.J., Youker, K.A., Pownall, H.J., van Winkle, W.B., Entman, M.L. 1991. Unsaturated aminophospholipids are preferentially retained by the fast skeletal muscle calcium ATPase during detergent solubilization. Evidence for a specific association between aminophospholipids and the calcium pump protein. Arch. Biochem. Biophys. 286:346-352

Bohren, C.F., Huffman, D.R. 1983. Absorption and scattering of light by small particles.

Carnie, S., McLaughlin, S. 1983. Large divalent cations and electrostatic potentials adjacent to membranes, a theoretical calculation. Biophys. J. 44:325-332

Carrondo, M.A.A.F.d.C.T., Griffith, W.P., Hall, J.P., Skapski, A.C. 1980. X-ray structure of $\left[\mathrm{Ru}_{3} \mathrm{O}_{2}\left(\mathrm{NH}_{3}\right)_{14}\right]^{6+}$. Biochim. Biophys. Acta 627:332-334, cation of the cytological reagent Ruthenium red.

Chapman, D.L. 1913. A contribution to the theory of electrocapillarity. Philos. Mag. 25:475-481

Charuk, J.H.M., Pirraglia, C.A., Reithmeier, R.A.F. 1990. Interaction of Ruthenium Red with $\mathrm{Ca}^{2+}$-binding proteins. Analytical Biochemistry 188:123-131

Chiesi, M., Scwaller, R., Calviello, G. 1988. Inhibition of rapid Ca-release from isolated skeletal and cardiac sarcoplasmic reticulum membranes. Biocem. Biophys. Res. Commun. 154(1):1-8

Chu, A., Sumbilla, C., Scales, D., Piazza, A., Inesi, G. 1988. trypsin digestion of junctional sarcoplasmic reticulum vesicles. Biochem. 27:2827-33 
Chung, L., Kaloyanides, G., McDaniel, R., McLaughlin, A., McLaughlin, S. 1985. Ineraction of Gentamicin and Spermine with bilayer membranes containing negatively charged phospholipids. Biochemistry 24(2):442-452

Corbalan-Garcia, S., Teruel, J., Gomez-Fernandez, J. 1992. Characterization of ruthenium red-binding sites of the calcium-ATPase from sracoplasmic reticulum and their interaction with Ca-binding sites. Biochem. J. 287:767-774.

Dierichs, R. 1979. Ruthenium Red as a stain for electron microscopy. Some new aspects of its application and mode of action. Histochemistry 64(2):171-187

Eisenberg, M., Gresalfi, T., Riccio, T., McLaughlin, S. 1979. Adsorption of monovalent cations to bilayermembranes containing negative phospholipids. Biochemistry 18(23):5213-5223

Emerson, J., Clarke, M.J., Ying W. L., Sanadi, D.R. 1993. The component of "Ruthenium red" responsible for inhibition of mitochondrial calcium ion transport. Spectra, electrochemistry, and aquation kinetics. Crystal Structure of $\mu$-O$\left[\left(\mathrm{HCO}_{2}\right)\left(\mathrm{NH}_{3}\right)_{4} \mathrm{Ru}\right]_{2} \mathrm{Cl}_{3}$. J. Am. Chem. Soc. 115:11799-805

Fletcher, J.M., Greenfield, B.F., Hardy, C.J., Scargil, D., Woodhead, J.L. 1961. Ruthenium Red. J. Chem. Soc.:2000-2006

Flewelling, R., Hubbell, W. 1986. The membrane dipole potential in a total membrane potential model. Biophys. J. 49:541-552

Gouy, M. 1910. Sur la constitution de la charge électrique a la surface d'un électrolyte. J. Phys. Radium 9:457

Grahame, D.C. 1947. Chem. Rev. 41:441

Gregoriadis, G., Florence, A.T. 1993. Liposomes in drug delivery. Clinical, diagnostic and ophthalmic potential. Drugs 45(1):15-28

Gruner, S.M., Lenk, R.P., Janoff, A.S., Ostro, M.J. 1985. Novel multilayered lipid vesicles: comparison of physical characteristics of multilamellar liposomes and stable plurilamellar vesicles. Biochemistry 24:2833-2842

Hirabayashi, Y., Sakagami, T., Yamada, K. 1990. Acta Histochem. Cytochem. 23:165175

Hochman, J.H., Partridge, B., Ferguson-Miller, S. 1981. An effective electron donor to cytochrome oxidase. Purification, identification, and kinetic characterization of 
a contaminant of Ruthenium Red, hexaamineruthenium II/III. J. biol. chem. 256(16):8693-8698

Howell, J.N. 1982. The interaction between ruthenium red and the isolated sarcoplasmic reticulum. Membrane Biochem. 4:235-245.

Hulst, H.C.v.d. 1981. Light scattering by small particles.

Inesi, G., Sumbilla, C., Kirtley, M.E. 1990. Relationships of molecular structure and function in $\mathrm{Ca}^{2+}$-transport ATPase. Physiol. Rev. 70(3):749-760

Johnson, N.W., Kaler, E.W. 1986. Size disproportionation in vesicular dispersions. $J$. Colloid Interface Sc. 116(2):444-457

Johnson, S.M., Bangham, A.D., Hill, M.W., Korn, E.D. 1971. single bilayer liposomes. Biochim. Biophys. Acta 233:820-826

Joly, A. 1892. Composés ammoniacaux dérivés du sesquichlorue de ruthénium. $C$. $R$. Acad. Sci. 115:1299-1301

Jørgensen, C.K., Orgel, L.E. 1961. Energy levels and $\pi$ bonding in polynuclear complexes. Mol. Phys. 4:215-218

Kashiwayanagi, M., Suenaga, A., Enomoto, S., Kurihara, K. 1990. Membrane fluidity changes of liposomes in response to various odorants. Biophys. J. 58:887-895

Kortüm, G. 1962. Kolorimetrie, Photometrie und Spektrometrie. 4. Aufl.

Kreimer, G., Melkonian, M., Latzko, E. 1985. An electrogenic uniport mediates lightdependent $\mathrm{Ca}^{2+}$ influx into intact spinach chloroplasts. FEBS-Lett. 180(2):253-258

Langner, M., Cafiso, D., Marcelja, S., McLaughlin, S. 1990. Electrostatics of phosphoinositide bilayer membranes. Biophys. J. 57:335-349

Lau, A., McLaughlin, A., McLaughlin, S. 1981. The adsorption of divalent cations to phosphatidylglycerol bilayer membranes. Biochim. Biophys. Acta 645(2):279-292

Liu, G., Oba, T. 1990. Effects of tetraphenylboron-induced increase in inner surface charge on $\mathrm{Ca}^{2+}$ release from sarcoplasmic reticulum. Jap. Journal. Physiol 40:723736

Luft, J.H. 1971a. Ruthenium Red and Violet I. Chemistry, purification, methods of use for electron microscopy and mechanism of action. Anat. Rec. 171:347-368 
Luft, J. 1971b. Ruthenium Red and Violet II. Fine structural localization in animal tissues. Anat. Rec. 171:369-416

Luthra, R., Olson, M.S. 1977. The inhibition of calcium uptake and release by rat liver mitrochondria by Ruthenium Red. FEBS-Lett. 81(1):142-146

M'esz'aros, L.G., Ikemoto, N. 1985. Ruthenium Red and caffeine affect the $\mathrm{Ca}^{2+}$ ATPase of the sarcoplasmic reticulum. Biochem. Biophys. Res. Commun. 127(3):836-842

MacDonald, R.C., MacDonald, R.I., Menco, B.P.M., Takeshita, K., Subbarao, N.K., $\mathrm{Hu}$, L.R. 1991. Small-volume extrusion apparatus for preparation of large, unilamellar vesicles. Biochim. Biophys. Acta. 1061:297-303

Mangin, L. 1893. Sur l'emploi du rouge de ruthénium en anatomie végétale. $C . R$. Acad. Sci. 116:653-656

Mayer, L.D., Hope, M.J., Cullis, P.R., Lanoff, A.S. 1985. Solute distributions and trapping efficiencies observed in freeze-thawed multilamellar vesicles. Biochim. Biophys. Acta 817:193-196

McLaughlin, S. 1977. Electrostatic potentials at membrane -solution interfaces. Current topics in Membranes and Transport. 9:71-144. F. Bronner A. Kleinzeller, editors

McLaughlin, S. 1989. The electrostatic properties of membranes. Annu. Rev. Biophys. Chem. 18:113-136

McLaughlin, S., Harary, H. 1976. The hydrophobic adsorption of charged molecules to bilayer membranes: a test of the applicability of the Stern equation. Biochemistry 15:1941-1948

Mobed, M., Nishiya, T., Chang, T.M.S. 1992. Purification and characterization of liposomes encapsulating hemoglobin as potential blood substitutes. Biomaterials Artificial Cells and Immobilization Biotechnology 20(1):53-70

Moore, C.L. 1971. Secific inhibition of mitochondrial $\mathrm{Ca}^{2+}$ transport by Ruthenium Red. Biochem. Biophys. Res. Commun. 42(2):298-305

Moutin, M., Rapin, C., Dupont, Y. 1992. Ruthenium red affects the intrinsic fluorescence of the calcium-ATPase of skeletal sarcoplasmic reticulum. Biochim. Biophys. Acta 1100:321-328. 
Murano, E., Paoletti, S., Cesaro, A., Rizzo, R. 1990. Ruthenium red complexation with ionic polysaccharides in dilute aqueous solutions: chirooptical evidence of stereospecific interaction. Anal. Biochem. 187(1):120-123.

Niesman, M.R. 1992. The use of liposomes as drug carriers in ophthalmology. Crit. Rev. Ther. Drug. Carrier Syst. 9(1):1-38

Oberc-Greenwood, M.A., Muul, L.M., Gately, M.K., Kornblith, P.L., Smith, B.H. 1986. Ultrastructural features of the lymphocyte-stimulated halos produced by human glioma-derived cells in vitro. J. Neurooncol. 3(4):387-396

Papahadjopoulos, D., Miller, N. 1967. Phospholipid model membranes, I. Structural characteristics of hydrated liquid crystals. Biochim. Biophys. Acta 135(4):624-638

Papahadjopoulos, D., Poste, G., Schaeffer, B.E., Vail, W.J. 1974. Membrane fusion and molecular segregation in phospholipid vesicles. Biochim. Biophys. Acta 352: $10-28$

Parsegian, V.A. 1981. Perturbation of membrane structure by uranyl acetate labeling. Biophys. J. 33:475-478.

Perkampus, H.H. 1992. UV-VIS spectroscopy and its applications.

Pickering, J.G., Jekanowski, J., Weir, L., Takeshita, S., Losordo, D.W., Isner, J.M. 1994. Liposome-mediated gene transfer into human vascular smooth muscle cells. Circulation 89(1):13-21

Reed, K.C., Bygrave, F.L. 1974. A low molecular weight ruthenium complex inhibitory to mitochondrial $\mathrm{Ca}^{2+}$ transport. FEBS Lett. 46(1):109-114

Reimann, B. 1961. Zur Verwendbarkeit von Rutheniumrot als elektronenmikroskopisches Kontrastierungsmittel. Mikroskopie 16:224-226

Sasaki, T., Naka, M., Nakamura, F., Tanaka, T. 1992. Ruthenium red inhibits the binding of $\mathrm{Ca}$ to calmodulin required for enzyme activation. J. Biol. Chem. 267:21518-523.

Scales, D., Inesi, G. 1976. Assembly of ATPase protein in sarcoplasmic reticulum membranes. Biophys. J. 16:735-751

Seiler, S., Wegener, A.D., Whang, D.D., Hathaway, D.R., Jones, L.R. 1984. High molecular weight proteins in cardiac and sceletal muscle junctional sarcoplasmic 
reticulum vesicles bind calmodulin, are phosphorylated, and are degraded by $\mathrm{Ca}^{2+}$ activated protease. J. Biol. Chem. 259:8550-8557

Singer, S.J., Nicolson, G.L. 1072. The fluid mosaic model of the structure of cell membranes. Science 175:720-731

Sloan, P. 1990. L'Oreal Banks on Rising "Star". Advertising Age 61(14):47

Small, D. 1986. Handbook of lipid research. The physical chemistry of lipids. pp. 512. Plenum Press, NY

Smejtek, P., Wang, S. 1993. Distribution of hydrophobic ionizable xenobiotics between water and lipid membranes: pentachlorophenol and pentachlorophenate. A comparison with octanol-water partition. Arch. Environ. Contam. Toxicol. 25:394404

Smejtek, P., Wang, S. 1991. Domains and anomalous adsorption isotherms of dipalmitoylphosphatidylcholine membranes and lipophilic ions: pentachlorophenolate, tetraphenylborate, and dipicrylamine. Biophys. J. 59:10641073

Smejtek, P., Wang, S. 1990. Adsorption of dipalmitoylphosphatidylcholine membranes in gel and fluid state: pentachlorophenolate, dipicrylamine, and tetraphenylborate. Biophys. J. 58:1285-1294

Smith, P.M., Fealey, T., Earley, J.E., Silverton, J.V. 1971. The crystal and molecular structure of Di- $\mu$-oxo bis(pentaamineruthenium)bis(ethylenediamine)ruthenium hexachloride. The ethylenediamine analog of ruthenium red. Inorg. Chem. 10:1943-47

Stern, O. 1924. Zeit.f. Elektrochem. 30:508

Stryer, L. 1981. Biochemistry. 2nd ed.

Stuart, J., Pessah, I.N., Favero, T.G., Abramson, J.J. 1992. Photooxidation of seletal muscle sarcoplasmic reticulum induces rapid calcium release. Arch. Biochem. Biophys. 292(2):512-521

Sugarman S. M., Perez-Soler, R. 1992. Liposomes in the treatment of malignancy: a clinical perspective. Crit. Rev. Oncol. Hematol. 12(3):231-242 
Tortorella, D., Ulbrandt, N.D., London, E. 1993. Simple centrifugation method for efficient pelleting of both small and large unilamellar vesicles that allows convenient measurement of protein binding. Biochemistry 32:9181-9188

Vasington, F.D., Gazzotti, P., Tiozzo, R., Carafoli, E. 1972. The effect of Ruthenium Red on $\mathrm{Ca}^{2+}$ transport and respiration in rat liver mitrochondria. Biochim. Biophys. Acta 256(1):43-54

Vuillemard, J.C. 1991. Recent advances in the large-scale production of lipid vesicles for use in food products: microfluidization. J. Microencapsul. 8(4):547-562

Watson, E.L., Vincenzi, F.F., Davis, P.W. 1971. $\mathrm{Ca}^{2+}$-activated membrane ATPase: selective inhibition by Ruthenium Red. Biochim. Biophys. Acta 249(2):606-610

Westman, J., Boulanger, Y., Ehrenberg, A., Smith I. C. P. 1982. Charge and pH dependent drug binding to model membranes, a ${ }^{2} \mathrm{H}-\mathrm{NMR}$ and light adsorption study. Biochim. Biophys. Acta 685:315-328

White, D.A. 1973. Form and function of phospholipids. G.B. Ansell, J.N. Hawthorne J.T.G. Dawson, editors. pp. 441-482

Winiski, A.P., McLaughlin, A., McDaniel R. V., Eisenberg, M., McLaughlin, S. 1986. An experimental test of the discteteness-of-charge effect in positive and negative lipid bilayers. Biochemistry 25:8206-8214

Winterhalter, M., Lasic, D.D. 1993. Liposome stability and formation: experimental parameters and theories on the size distribution. Chem. Phys. Lipids 64:35-43

Xiong, H., Buck, E., Stuart, J., Pessah, I.N., Salama, G., Abramson, J.J. 1992. Rose Bengal activates the $\mathrm{Ca}^{2+}$ release channel from skeletal muscle sarcoplasmic reticulum vesicles. Arch. Biochem. Biophys. 292(2):522-528. 


\section{APPENDIX}

\section{A: Glossary}

$\varepsilon \quad$ molar decadic extinction coefficient

$\alpha \quad$ wavelength exponent (see Eq.(16))

$\beta_{\mathrm{mRR}}$ linear partition coefficient

$\epsilon_{0} \quad$ permittivity of free space $\left(=8.85419 \cdot 10^{-12} \mathrm{As}(\mathrm{Vm})^{-1}\right)$

$\epsilon_{\mathrm{m}}$ dielectric constant of the membrane interior

$\epsilon_{\mathrm{w}} \quad$ dielectric constant of the electrolyte

$\lambda \quad$ wavelength

$\rho \quad$ volume charge density

$\sigma_{0} \quad$ native membrane surface charge density

$\sigma_{\mathrm{T}}, \sigma_{\mathrm{R}}, \sigma_{\mathrm{M}} \quad$ scattering cross sections

$\sigma_{\mathrm{m}} \quad$ membrane surface charge density

$\Phi \quad$ electrostatic potential

$\Phi_{0} \quad$ electrostatic surface potential

A absorbance

$\mathrm{B}^{-3}$ phosphate-citrate-borate buffer $(0.002: 0.002: 0.0005 \mathrm{M})$

FAT freeze-and-thaw

GCS Gouy-Chapman-Stern

I intensity of monochromatic light emerging from the sample

$I_{0} \quad$ intensity of monochromatic light entering the sample

$\mathrm{I}_{\mathrm{F}} \quad$ interception point of two fits in Table II

$\mathrm{k}_{\mathrm{B}} \quad$ Boltzmann constant $\left(=1.380662 \cdot 10^{-23} \mathrm{JK}^{-1}\right)$

$\mathrm{K}_{\mathrm{m}} \quad$ intrinsic association constant

LUV large unilamellar vesicle

MLV multilamellar vesicle 
PC Phosphatidylcholine

PI Phosphatidylinositol

$\mathrm{P}_{\mathrm{L}} \quad$ membrane surface area per lipid

PS Phosphatidylserine

$P_{s} \quad$ surface area per adsorbed $R R$ ion

$\mathrm{q} \quad$ ion charge including the sign

$\mathrm{q}_{\text {eff }}$ effective charge of the RR ion including the sign

RB Ruthenium Browne

RR Ruthenium Red

RV Ruthenium Violett

SFF space filling factor

SR sarcoplasmic reticulum

SUV small unilamellar vesicle

$\mathrm{T}$ temperature

$\mathrm{V}_{\mathrm{m}}$ membrane surface potential

[L] volume density of lipids

$(R R)_{m}$ membrane surface density of adsorbd RR

$[R R]_{\text {eq }}$ bulk aqueous concentration of RR after adsorption of the ions to the membrane (equilibrium concentration)

$[R R]_{\text {if }} R R$ volume concentration at the aqueous side of the membrane-solution interface $[R R]_{\text {init }} \quad$ bulk aqueous concentration of $R R$ before adsorption of the ions to the membrane (initial concentration)

$\mathrm{X}: \mathrm{Y} 10: 1 \quad 9$ mass parts $\mathrm{X}$ and 1 mass part $\mathrm{Y}$ 
B: Tables

Table VIII: Experimental data and fitted data for PC:PS 20:1; lipid conc. $1 \mathrm{mg} / \mathrm{ml}$

\begin{tabular}{|c|c|c|c|c|c|}
\hline \multicolumn{2}{|c|}{ experiment data } & \multicolumn{3}{|c|}{ fit data } & \multirow[b]{2}{*}{$\begin{array}{c}\text { surf. pot. } \\
{[\mathrm{mV}]}\end{array}$} \\
\hline $\begin{array}{c}\text { RR conc. } \\
{[\mu \mathrm{M}]}\end{array}$ & $\begin{array}{l}{[R R]_{\text {eq }} /} \\
{[R R]_{\text {init }}}\end{array}$ & $\begin{array}{c}\mathrm{RR} \text { conc. } \\
{[\mu \mathrm{M}]}\end{array}$ & $\begin{array}{l}{[R R]_{\text {eq }} /} \\
{[R R]_{\text {init }}}\end{array}$ & $\begin{array}{c}(\mathrm{RR})_{\mathrm{m}} \\
{\left[\mathrm{nmol} / \mathrm{m}^{2}\right]}\end{array}$ & \\
\hline 0.510 & 0.858 & 0.010 & 0.698 & 0.005 & -42.4 \\
\hline 1.09 & 0.721 & 0.100 & 0.701 & 0.053 & -42.3 \\
\hline 2.31 & 0.770 & 0.178 & 0.704 & 0.094 & -42.3 \\
\hline 5.69 & 0.831 & 0.316 & 0.709 & 0.164 & -42.1 \\
\hline 11.4 & 0.874 & 0.562 & 0.717 & 0.284 & -41.9 \\
\hline 22.3 & 0.901 & 1.00 & 0.730 & 0.481 & -41.5 \\
\hline 55.2 & 0.933 & 1.78 & 0.751 & 0.791 & -40.8 \\
\hline 110. & 0.944 & 3.16 & 0.779 & 1.25 & -39.8 \\
\hline 246. & 0.964 & 5.62 & 0.815 & 1.86 & -38.4 \\
\hline 609. & 0.993 & 10.0 & 0.854 & 2.61 & -36.7 \\
\hline 1230 & 0.994 & 17.8 & 0.891 & 3.46 & -34.6 \\
\hline \multirow[t]{7}{*}{ additional } & data: & 31.6 & 0.923 & 4.37 & -32.2 \\
\hline & & 56.2 & 0.947 & 5.28 & -29.7 \\
\hline & & 100. & 0.965 & 6.20 & -27.0 \\
\hline & & 178. & 0.978 & 7.10 & -24.1 \\
\hline & & 316. & 0.986 & 8.00 & -21.3 \\
\hline & & 562. & 0.991 & 8.93 & -18.3 \\
\hline & & 1000. & 0.994 & 9.94 & -15.4 \\
\hline
\end{tabular}

$\mathrm{q}_{\mathrm{eff}}=4.1 ; \quad \beta_{\mathrm{mRR}}=0.886 \mathrm{~nm} ; \quad \chi^{2}=0.192 \cdot 10^{-3}$ 
Table IX: Experimental data and fitted data for PC:PS 10:1; lipid conc. $1 \mathrm{mg} / \mathrm{ml}$

\begin{tabular}{|c|c|c|c|c|c|}
\hline \multirow{2}{*}{$\begin{array}{l}\text { experiment } \\
\text { RR conc. } \\
{[\mu \mathrm{M}]}\end{array}$} & \multirow{2}{*}{$\begin{array}{l}\text { data } \\
\qquad[R R]_{\text {eq }} / \\
{[R R]_{\text {init }}}\end{array}$} & \multicolumn{2}{|c|}{ fit data } & \multirow[b]{2}{*}{$\begin{array}{c}(\mathrm{RR})_{\mathrm{m}} \\
{\left[\mathrm{nmol} / \mathrm{m}^{2}\right]}\end{array}$} & \multirow[b]{2}{*}{$\begin{array}{c}\text { surf. pot. } \\
\text { [mV] }\end{array}$} \\
\hline & & $\begin{array}{c}\text { RR conc. } \\
{[\mu \mathrm{M}]}\end{array}$ & $\begin{array}{l}{[R R]_{\text {eq }} /} \\
{[R R]_{\text {init }}}\end{array}$ & & \\
\hline 0.56 & 0.912 & 0.010 & 0.071 & 0.017 & -72.3 \\
\hline 1.11 & 0.128 & 0.100 & 0.072 & 0.166 & -72.1 \\
\hline 2.27 & 0.128 & 0.178 & 0.074 & 0.295 & -72.0 \\
\hline 5.66 & 0.255 & 0.316 & 0.077 & 0.522 & -71.7 \\
\hline 11.3 & 0.462 & 0.562 & 0.082 & 0.924 & -71.3 \\
\hline 22.4 & 0.654 & 1.00 & 0.092 & 1.63 & -70.4 \\
\hline 53.7 & 0.789 & 1.78 & 0.112 & 2.83 & -68.9 \\
\hline 111. & 0.881 & 3.16 & 0.156 & 4.78 & -66.4 \\
\hline 224. & 0.938 & 5.62 & 0.251 & 7.53 & -62.4 \\
\hline \multirow[t]{2}{*}{578.} & 0.973 & 10.0 & 0.413 & 10.5 & -57.5 \\
\hline & & 17.8 & 0.592 & 13.0 & -52.6 \\
\hline additional & data: & 31.6 & 0.737 & 14.9 & -48.2 \\
\hline 0.65 & 0.090 & 56.2 & 0.836 & 16.5 & -44.2 \\
\hline 1.29 & 0.083 & 100. & 0.901 & 17.8 & -40.3 \\
\hline 2.55 & 0.120 & 178. & 0.941 & 18.9 & -36.6 \\
\hline 6.45 & 0.281 & 316. & 0.965 & 19.9 & -32.9 \\
\hline 12.8 & 0.499 & 562. & 0.979 & 20.9 & -29.2 \\
\hline 25.4 & 0.686 & 1000. & 0.988 & 21.8 & -25.6 \\
\hline 63.1 & 0.826 & & & & \\
\hline 124. & 0.888 & & & & \\
\hline
\end{tabular}

$\mathrm{q}_{\mathrm{eff}}=3.8 ; \quad \beta_{\mathrm{mRR}}=0.536 \mathrm{~nm} ; \quad \chi^{2}=0.778 \cdot 10^{-2}$ 
Table X: Experimental data and fitted data for PC:PS 5:1; lipid conc. $1 \mathrm{mg} / \mathrm{ml}$

\begin{tabular}{|c|c|c|c|c|c|}
\hline \multicolumn{2}{|c|}{ experiment data } & \multicolumn{3}{|c|}{ fit data } & \multirow[b]{2}{*}{$\begin{array}{c}\text { surf. pot. } \\
{[\mathrm{mV}]}\end{array}$} \\
\hline $\begin{array}{c}\mathrm{RR} \text { conc. } \\
{[\mu \mathrm{M}]}\end{array}$ & $\begin{array}{l}{[R R]_{\text {eq }}} \\
{[R R]_{\text {init }}}\end{array}$ & $\begin{array}{c}\mathrm{RR} \text { conc. } \\
{[\mu \mathrm{M}]}\end{array}$ & $\begin{array}{l}{[R R]_{\text {eq }} /} \\
{[R R]_{\text {init }}}\end{array}$ & $\begin{array}{c}(\mathrm{RR})_{\mathrm{m}} \\
{\left[\mathrm{nmol} / \mathrm{m}^{2}\right]}\end{array}$ & \\
\hline 0.531 & 0.021 & 0.010 & 0.020 & 0.018 & -106.5 \\
\hline 1.06 & 0.022 & 0.100 & 0.021 & 0.176 & -106.5 \\
\hline 2.16 & 0.027 & 0.178 & 0.021 & 0.314 & -106.4 \\
\hline 5.43 & 0.033 & 0.316 & 0.021 & 0.557 & -106.3 \\
\hline 10.8 & 0.057 & 0.562 & 0.021 & 0.991 & -106.1 \\
\hline 21.6 & 0.149 & 1.00 & 0.022 & 1.76 & -105.8 \\
\hline 58.6 & 0.509 & 1.78 & 0.024 & 3.13 & -105.2 \\
\hline 97.5 & 0.704 & 3.16 & 0.027 & 5.54 & -104.1 \\
\hline 196. & 0.842 & 5.62 & 0.034 & 9.78 & -102.2 \\
\hline \multirow[t]{2}{*}{591.} & 0.956 & 10.0 & 0.051 & 17.1 & -98.5 \\
\hline & & 17.8 & 0.108 & 28.5 & -91.7 \\
\hline \multirow[t]{7}{*}{ additional } & data: & 31.6 & 0.278 & 41.1 & -81.8 \\
\hline & & 56.2 & 0.514 & 49.2 & -73.1 \\
\hline & & 100. & 0.700 & 54.0 & -66.3 \\
\hline & & 178. & 0.821 & 57.3 & -60.4 \\
\hline & & 316. & 0.895 & 59.8 & -55.0 \\
\hline & & 562. & 0.939 & 61.8 & -49.8 \\
\hline & & 1000. & 0.965 & 63.5 & -44.8 \\
\hline
\end{tabular}

$\mathrm{q}_{\mathrm{eff}}=2.9 ; \quad \beta_{\mathrm{mRR}}=0.521 \mathrm{~nm} ; \quad \chi^{2}=0.129 \cdot 10^{-2}$ 
Table XI: Experimental data and fitted data for PC:PS 10:1; lipid conc. $0.3 \mathrm{mg} / \mathrm{ml}$

\begin{tabular}{|c|c|c|c|c|c|}
\hline \multicolumn{2}{|c|}{ experiment data } & \multicolumn{3}{|c|}{ fit data } & \multirow[b]{2}{*}{$\begin{array}{c}\text { surf. pot. } \\
{[\mathrm{mV}]}\end{array}$} \\
\hline $\begin{array}{c}\text { RR conc. } \\
{[\mu \mathrm{M}]}\end{array}$ & $\begin{array}{l}{[R R]_{\text {eq }} /} \\
{[R R]_{\text {init }}}\end{array}$ & $\begin{array}{c}\text { RR conc. } \\
{[\mu \mathrm{M}]}\end{array}$ & $\begin{array}{l}{[R R]_{e q} /} \\
{[R R]_{\text {init }}}\end{array}$ & $\begin{array}{c}(\mathrm{RR})_{\mathrm{m}} \\
{\left[\mathrm{nmol} / \mathrm{m}^{2}\right]}\end{array}$ & \\
\hline 0.491 & 0.168 & 0.010 & 0.113 & 0.053 & -72.3 \\
\hline 1.01 & 0.217 & 0.100 & 0.121 & 0.524 & -71.8 \\
\hline 2.08 & 0.338 & 0.178 & 0.129 & 0.924 & -71.3 \\
\hline 5.73 & 0.652 & 0.316 & 0.142 & 1.62 & -70.6 \\
\hline 10.3 & 0.780 & 0.562 & 0.169 & 2.79 & -69.3 \\
\hline 20.6 & 0.874 & 1.00 & 0.221 & 4.64 & -67.1 \\
\hline 54.0 & 0.944 & 1.78 & 0.319 & 7.22 & -63.8 \\
\hline 106. & 0.987 & 3.16 & 0.466 & 10.1 & -59.8 \\
\hline 180. & 0.984 & 5.62 & 0.622 & 12.7 & -55.7 \\
\hline \multirow[t]{2}{*}{446.} & 0.991 & 10.0 & 0.750 & 14.9 & -51.8 \\
\hline & & 17.8 & 0.842 & 16.8 & -48.0 \\
\hline \multirow[t]{7}{*}{ additional } & data: & 31.6 & 0.903 & 18.4 & -44.4 \\
\hline & & 56.2 & 0.941 & 19.8 & -40.9 \\
\hline & & 100. & 0.965 & 21.1 & -37.3 \\
\hline & & 178. & 0.979 & 22.2 & -33.8 \\
\hline & & 316. & 0.988 & 23.3 & -30.3 \\
\hline & & 562. & 0.993 & 24.3 & -26.8 \\
\hline & & 1000. & 0.996 & 25.4 & -23.3 \\
\hline
\end{tabular}

$\mathrm{q}_{\mathrm{eff}}=3.9 ; \quad \beta_{\mathrm{mRR}}=0.805 \mathrm{~nm} ; \quad \chi^{2}=0.763 \cdot 10^{-3}$ 
Table XII: Experimental data and fitted data for PC:PS 10:1; lipid conc. $3 \mathrm{mg} / \mathrm{ml}$

\begin{tabular}{|c|c|c|c|c|c|}
\hline \multirow{2}{*}{$\begin{array}{l}\text { experiment } \\
\text { RR conc. } \\
{[\mu \mathrm{M}]}\end{array}$} & \multirow{2}{*}{$\begin{array}{l}\text { data } \\
\qquad[R R]_{\mathrm{eq}} / \\
{[\mathrm{RR}]_{\text {init }}}\end{array}$} & \multicolumn{2}{|c|}{ fit data } & \multirow[b]{2}{*}{$\begin{array}{c}(\mathrm{RR})_{\mathrm{m}} \\
{\left[\mathrm{nmol} / \mathrm{m}^{2}\right]}\end{array}$} & \multirow[b]{2}{*}{$\begin{array}{c}\text { surf. pot } \\
{[\mathrm{mV}]}\end{array}$} \\
\hline & & $\begin{array}{c}\text { RR conc. } \\
{[\mu \mathrm{M}]}\end{array}$ & $\begin{array}{l}{[\mathrm{RR}]_{\mathrm{eq}} /} \\
{[\mathrm{RR}]_{\text {init }}}\end{array}$ & & \\
\hline 0.59 & 0.040 & 0.010 & 0.039 & 0.006 & -72.3 \\
\hline 1.18 & 0.037 & 0.100 & 0.040 & 0.057 & -72.2 \\
\hline 2.42 & 0.059 & 0.178 & 0.040 & 0.102 & -72.2 \\
\hline 4.87 & 0.070 & 0.316 & 0.041 & 0.181 & -72.1 \\
\hline 9.76 & 0.146 & 0.562 & 0.042 & 0.321 & -71.9 \\
\hline 19.6 & 0.282 & 1.00 & 0.044 & 0.570 & -71.6 \\
\hline 48.7 & 0.515 & 1.78 & 0.048 & 1.01 & -70.9 \\
\hline 94.3 & 0.690 & 3.16 & 0.056 & 1.78 & -69.8 \\
\hline 193. & 0.818 & 5.62 & 0.074 & 3.11 & -67.8 \\
\hline 486. & 0.915 & 10.0 & 0.119 & 5.25 & -64.3 \\
\hline 975. & 0.967 & 17.8 & 0.236 & 8.11 & -58.8 \\
\hline \multicolumn{2}{|c|}{ additional data: } & 31.6 & 0.433 & 10.7 & -52.7 \\
\hline 1.04 & 0.024 & 56.2 & 0.627 & 12.5 & -47.4 \\
\hline 2.12 & 0.033 & 100. & 0.768 & 13.9 & -42.9 \\
\hline 5.62 & 0.022 & 178. & 0.859 & 14.9 & -38.7 \\
\hline 10.8 & 0.061 & 316. & 0.916 & 15.8 & -34.8 \\
\hline 22.5 & 0.140 & 562. & 0.950 & 16.6 & -31.1 \\
\hline 55.3 & 0.361 & 1000. & 0.971 & 17.4 & -27.3 \\
\hline 110. & 0.517 & & & & \\
\hline 185. & 0.613 & & & & \\
\hline
\end{tabular}

The additional data were not used for the fit.

$\mathrm{q}_{\mathrm{eff}}=3.8 ; \quad \beta_{\mathrm{mRR}}=0.332 \mathrm{~nm} ; \quad \chi^{2}=0.142 \cdot 10^{-1}$ 
Table XIII: Experimental data and fitted data for PC:PS 10:1; lipid conc. $10 \mathrm{mg} / \mathrm{ml}$

\begin{tabular}{|c|c|c|c|c|c|}
\hline \multicolumn{2}{|c|}{ experiment data } & \multicolumn{3}{|c|}{ fit data } & \multirow[b]{2}{*}{$\begin{array}{l}\text { surf. pot. } \\
{[\mathrm{mV}]}\end{array}$} \\
\hline $\begin{array}{l}\text { RR conc. } \\
{[\mu \mathrm{M}]}\end{array}$ & $\begin{array}{l}{[R R]_{e q} /} \\
{[R R]_{\text {init }}}\end{array}$ & $\begin{array}{c}\text { RR conc. } \\
{[\mu \mathrm{M}]}\end{array}$ & $\begin{array}{l}{[R R]_{e q} /} \\
{[R R]_{\text {init }}}\end{array}$ & $\begin{array}{c}(\mathrm{RR})_{\mathrm{m}} \\
{\left[\mathrm{nmol} / \mathrm{m}^{2}\right]}\end{array}$ & \\
\hline & & 0.010 & 0.013 & 0.002 & -72.3 \\
\hline & & 0.100 & 0.013 & 0.018 & -72.3 \\
\hline & & 0.178 & 0.013 & 0.031 & -72.3 \\
\hline 5.37 & 0.012 & 0.316 & 0.013 & 0.056 & -72.3 \\
\hline 10.2 & 0.018 & 0.562 & 0.013 & 0.099 & -72.2 \\
\hline 18.1 & 0.021 & 1.00 & 0.013 & 0.177 & -72.1 \\
\hline 46.1 & 0.085 & 1.78 & 0.013 & 0.314 & -71.9 \\
\hline 86.5 & 0.228 & 3.16 & 0.014 & 0.558 & -71.6 \\
\hline 179. & 0.423 & 5.62 & 0.015 & 0.991 & -71.1 \\
\hline 451. & 0.726 & 10.0 & 0.017 & 1.76 & -70.1 \\
\hline 917. & 0.846 & 17.8 & 0.022 & 3.11 & -68.3 \\
\hline \multirow[t]{7}{*}{ additional } & data: & 31.6 & 0.036 & 5.46 & -65.0 \\
\hline & & 56.2 & 0.085 & 9.20 & -58.6 \\
\hline & & 100. & 0.256 & 13.3 & -49.7 \\
\hline & & 178. & 0.501 & 15.9 & -42.3 \\
\hline & & 316. & 0.692 & 17.4 & -36.7 \\
\hline & & 562. & 0.815 & 18.6 & -32.1 \\
\hline & & 1000. & 0.890 & 19.7 & -27.9 \\
\hline
\end{tabular}

$\mathrm{q}_{\mathrm{eff}}=3.7 ; \quad \beta_{\mathrm{mRR}}=0.425 \mathrm{~nm} ; \quad \chi^{2}=0.273 \cdot 10^{-1}$ 
Table XIV: Experimental data and fitted data for PC:PI 10:1; lipid conc. $1 \mathrm{mg} / \mathrm{ml}$

\begin{tabular}{|c|c|c|c|c|c|}
\hline \multicolumn{2}{|c|}{ experiment data } & \multicolumn{3}{|c|}{ fit data } & \multirow[b]{2}{*}{$\begin{array}{c}\text { surf. pot. } \\
{[\mathrm{mV}]}\end{array}$} \\
\hline $\begin{array}{l}\text { RR conc. } \\
{[\mu \mathrm{M}]}\end{array}$ & $\begin{array}{l}{[\mathrm{RR}]_{\mathrm{eq}} /} \\
{[\mathrm{RR}]_{\text {init }}}\end{array}$ & $\begin{array}{c}\text { RR conc. } \\
{[\mu \mathrm{M}]}\end{array}$ & $\begin{array}{l}{[R R]_{\text {eq }}{ }^{2}} \\
{[R R]_{\text {init }}}\end{array}$ & $\begin{array}{c}(\mathrm{RR})_{\mathrm{m}} \\
{\left[\mathrm{nmol} / \mathrm{m}^{2}\right]}\end{array}$ & \\
\hline 0.65 & 0.296 & 0.010 & 0.236 & 0.014 & -67.4 \\
\hline 1.29 & 0.328 & 0.100 & 0.243 & 0.137 & -67.2 \\
\hline 2.55 & 0.412 & 0.178 & 0.249 & 0.242 & -67.0 \\
\hline 6.45 & 0.619 & 0.316 & 0.259 & 0.424 & -66.6 \\
\hline 12.8 & 0.747 & 0.562 & 0.278 & 0.734 & -66.0 \\
\hline 25.4 & 0.835 & 1.00 & 0.311 & 1.25 & -64.9 \\
\hline 63.1 & 0.902 & 1.78 & 0.369 & 2.03 & -63.3 \\
\hline 124. & 0.918 & 3.16 & 0.460 & 3.08 & -60.8 \\
\hline \multirow[t]{3}{*}{247.} & 0.953 & 5.62 & 0.578 & 4.29 & -57.7 \\
\hline & & 10.0 & 0.698 & 5.46 & -54.3 \\
\hline & & 17.8 & 0.797 & 6.52 & -50.8 \\
\hline additional & data: & 31.6 & 0.870 & 7.45 & -47.3 \\
\hline 1.26 & 0.317 & 56.2 & 0.919 & 8.27 & -43.9 \\
\hline 2.63 & 0.413 & 100. & 0.950 & 8.99 & -40.4 \\
\hline 6.27 & 0.584 & 178. & 0.970 & 9.64 & -37.0 \\
\hline \multirow[t]{3}{*}{24.0} & 0.828 & 316. & 0.982 & 10.2 & -33.5 \\
\hline & & 562. & 0.989 & 10.8 & -30.0 \\
\hline & & 1000. & 0.994 & 11.4 & -26.6 \\
\hline
\end{tabular}

$\mathrm{q}_{\mathrm{eff}}=3.9 ; \quad \beta_{\mathrm{mRR}}=0.211 \mathrm{~nm} ; \quad \chi^{2}=0.713 \cdot 10^{-3}$ 
Table XV: Experimental data and fitted data for PC:PI 5:1; lipid conc. $1 \mathrm{mg} / \mathrm{ml}$

\begin{tabular}{|c|c|c|c|c|c|}
\hline \multirow{2}{*}{$\begin{array}{c}\text { experimen } \\
\text { RR conc. } \\
{[\mu \mathrm{M}]}\end{array}$} & \multirow{2}{*}{$\begin{array}{l}\text { data } \\
\qquad[R R]_{\text {eq }} / \\
{[R R]_{\text {init }}}\end{array}$} & \multicolumn{3}{|c|}{ fit data } & \multirow[b]{2}{*}{$\begin{array}{c}\text { surf. pot. } \\
{[\mathrm{mV}]}\end{array}$} \\
\hline & & $\begin{array}{c}\mathrm{RR} \text { conc. } \\
{[\mu \mathrm{M}]}\end{array}$ & $\begin{array}{l}{[R R]_{\text {eq }} /} \\
{[R R]_{\text {init }}}\end{array}$ & $\begin{array}{c}(\mathrm{RR})_{\mathrm{m}} \\
{\left[\mathrm{nmol} / \mathrm{m}^{2}\right]}\end{array}$ & \\
\hline 0.63 & 0.039 & 0.010 & 0.035 & 0.018 & -101.8 \\
\hline 1.26 & 0.042 & 0.100 & 0.036 & 0.177 & -101.7 \\
\hline 2.63 & 0.059 & 0.178 & 0.036 & 0.315 & -101.6 \\
\hline 6.27 & 0.109 & 0.316 & 0.037 & 0.560 & -101.4 \\
\hline 12.5 & 0.254 & 0.562 & 0.039 & 0.994 & -101.0 \\
\hline 24.0 & 0.465 & 1.00 & 0.043 & 1.76 & -100.1 \\
\hline 58.8 & 0.721 & 1.78 & 0.047 & 3.11 & -99.4 \\
\hline 116. & 0.823 & 3.16 & 0.060 & 5.46 & -97.4 \\
\hline \multirow[t]{3}{*}{231.} & 0.915 & 5.62 & 0.094 & 9.37 & -93.6 \\
\hline & & 10.0 & 0.189 & 14.9 & -87.3 \\
\hline & & 17.8 & 0.385 & 20.1 & -79.5 \\
\hline \multirow[t]{7}{*}{ additional } & data: & 31.6 & 0.595 & 23.5 & -72.7 \\
\hline & & 56.2 & 0.751 & 25.8 & -67.0 \\
\hline & & 100. & 0.851 & 27.4 & -61.9 \\
\hline & & 178. & 0.912 & 28.7 & -57.1 \\
\hline & & 316. & 0.949 & 29.8 & -52.5 \\
\hline & & 562. & 0.970 & 30.7 & -47.9 \\
\hline & & 1000. & 0.983 & 31.5 & -43.5 \\
\hline
\end{tabular}

$\mathrm{q}_{\mathrm{eff}}=3.2 ; \quad \beta_{\mathrm{mRR}}=0.158 \mathrm{~nm} ; \quad \chi^{2}=0.258 \cdot 10^{-2}$ 
Table XVI: Experimental data and fitted data for PC:PI 10:1; lipid conc. $0.3 \mathrm{mg} / \mathrm{ml}$

\begin{tabular}{|c|c|c|c|c|c|}
\hline \multicolumn{2}{|c|}{ experiment data } & \multicolumn{3}{|c|}{ fit data } & \multirow[b]{2}{*}{$\begin{array}{c}\text { surf. pot. } \\
{[\mathrm{mV}]}\end{array}$} \\
\hline $\begin{array}{c}\text { RR conc. } \\
{[\mu \mathrm{M}]}\end{array}$ & $\begin{array}{l}{[R R]_{\text {eq }} /} \\
{[R R]_{\text {init }}}\end{array}$ & $\begin{array}{c}\mathrm{RR} \text { conc. } \\
{[\mu \mathrm{M}]}\end{array}$ & $\begin{array}{l}{[R R]_{\text {eq }} /} \\
{[R R]_{\text {init }}}\end{array}$ & $\begin{array}{c}(\mathrm{RR})_{\mathrm{m}} \\
{\left[\mathrm{nmol} / \mathrm{m}^{2}\right]}\end{array}$ & \\
\hline 0.54 & 0.750 & 0.010 & 0.723 & 0.017 & -67.4 \\
\hline 1.09 & 0.860 & 0.100 & 0.738 & 0.158 & -66.9 \\
\hline 2.29 & 0.902 & 0.178 & 0.749 & 0.269 & -66.5 \\
\hline 4.64 & 0.950 & 0.316 & 0.767 & 0.444 & -65.9 \\
\hline 9.49 & 0.968 & 0.562 & 0.793 & 0.703 & -64.9 \\
\hline 19.0 & 0.985 & 1.00 & 0.825 & 1.05 & -63.5 \\
\hline 47.1 & 1.010 & 1.78 & 0.861 & 1.49 & -61.7 \\
\hline 94.7 & 1.005 & 3.16 & 0.896 & 1.97 & -59.5 \\
\hline \multirow[t]{3}{*}{188.} & 0.993 & 5.62 & 0.927 & 2.48 & -57.0 \\
\hline & & 10.0 & 0.951 & 2.98 & -54.3 \\
\hline & & 17.8 & 0.968 & 3.46 & -51.4 \\
\hline \multirow[t]{7}{*}{ additional } & data: & 31.6 & 0.979 & 3.91 & -48.3 \\
\hline & & 56.2 & 0.987 & 4.33 & -45.1 \\
\hline & & 100. & 0.992 & 4.71 & -41.9 \\
\hline & & 178. & 0.995 & 5.06 & -38.5 \\
\hline & & 316. & 0.997 & 5.39 & -35.2 \\
\hline & & 562. & 0.998 & 5.70 & -31.7 \\
\hline & & 1000. & 0.999 & 6.02 & -28.3 \\
\hline
\end{tabular}

$\mathrm{q}_{\mathrm{eff}}=3.9 ; \quad \beta_{\mathrm{mRR}}=0.084 \mathrm{~nm} ; \quad \chi^{2}=0.988 \cdot 10^{-3}$ 
Table XVII: Experimental data and fitted data for PC:PI 10:1; lipid conc. $3 \mathrm{mg} / \mathrm{ml}$

\begin{tabular}{|c|c|c|c|c|c|}
\hline \multicolumn{2}{|c|}{ experiment data } & \multicolumn{2}{|c|}{ fit data } & \multirow[b]{2}{*}{$\begin{array}{c}(\mathrm{RR})_{\mathrm{m}} \\
{\left[\mathrm{nmol} / \mathrm{m}^{2}\right]}\end{array}$} & \multirow[b]{2}{*}{$\begin{array}{c}\text { surf. pot. } \\
{[\mathrm{mV}]}\end{array}$} \\
\hline $\begin{array}{c}\text { RR conc. } \\
{[\mu \mathrm{M}]}\end{array}$ & $\begin{array}{l}{[R R]_{\text {eq }} /} \\
{[R R]_{\text {init }}}\end{array}$ & $\begin{array}{c}\mathrm{RR} \text { conc. } \\
{[\mu \mathrm{M}]}\end{array}$ & $\begin{array}{l}{[R R]_{\text {eq }} /} \\
{[R R]_{\text {init }}}\end{array}$ & & \\
\hline 0.63 & 0.120 & 0.010 & 0.106 & 0.005 & -67.4 \\
\hline 1.26 & 0.140 & 0.100 & 0.108 & 0.054 & -67.3 \\
\hline 2.63 & 0.165 & 0.178 & 0.109 & 0.096 & -67.2 \\
\hline 6.27 & 0.237 & 0.316 & 0.111 & 0.169 & -67.1 \\
\hline 12.5 & 0.382 & 0.562 & 0.116 & 0.300 & -66.8 \\
\hline 24.0 & 0.553 & 1.00 & 0.123 & 0.528 & -66.3 \\
\hline 58.8 & 0.719 & 1.78 & 0.138 & 0.923 & -65.5 \\
\hline 116. & 0.777 & 3.16 & 0.169 & 1.58 & -63.9 \\
\hline \multirow[t]{3}{*}{230.} & 0.865 & 5.62 & 0.230 & 2.61 & -61.4 \\
\hline & & 10.0 & 0.345 & 3.95 & -57.7 \\
\hline & & 17.8 & 0.505 & 5.30 & -53.4 \\
\hline \multirow[t]{7}{*}{ additional } & data: & 31.6 & 0.662 & 6.44 & -49.1 \\
\hline & & 56.2 & 0.783 & 7.35 & -45.1 \\
\hline & & 100. & 0.866 & 8.10 & -41.3 \\
\hline & & 178. & 0.918 & 8.75 & -37.6 \\
\hline & & 316. & 0.951 & 9.33 & -34.0 \\
\hline & & 562. & 0.971 & 9.87 & -30.5 \\
\hline & & 1000. & 0.983 & 10.4 & -27.0 \\
\hline
\end{tabular}

$\mathrm{q}_{\mathrm{eff}}=3.9 ; \quad \beta_{\mathrm{mRR}}=0.183 \mathrm{~nm} ; \quad \chi^{2}=0.690 \cdot 10^{-2}$ 
Table XVIII: Experimental data and fitted data for PC:PI 10:1; lipid conc. 10mg/ml

\begin{tabular}{|c|c|c|c|c|c|}
\hline \multicolumn{2}{|c|}{ experiment data } & \multicolumn{3}{|c|}{ fit data } & \multirow[b]{2}{*}{$\begin{array}{c}\text { surf. pot. } \\
{[\mathrm{mV}]}\end{array}$} \\
\hline $\begin{array}{c}\mathrm{RR} \text { conc. } \\
{[\mu \mathrm{M}]}\end{array}$ & $\begin{array}{l}{[R R]_{\text {eq }} /} \\
{[R R]_{\text {init }}}\end{array}$ & $\begin{array}{c}\mathrm{RR} \text { conc. } \\
{[\mu \mathrm{M}]}\end{array}$ & $\begin{array}{l}{[R R]_{\text {eq }} /} \\
{[R R]_{\text {init }}}\end{array}$ & $\begin{array}{c}(\mathrm{RR})_{\mathrm{m}} \\
{\left[\mathrm{nmol} / \mathrm{m}^{2}\right]}\end{array}$ & \\
\hline 0.59 & n. a. & 0.010 & 0.057 & 0.002 & -67.4 \\
\hline 1.18 & 0.052 & 0.100 & 0.057 & 0.017 & -67.4 \\
\hline 2.42 & 0.060 & 0.178 & 0.058 & 0.030 & -67.4 \\
\hline 4.87 & 0.067 & 0.316 & 0.058 & 0.054 & -67.3 \\
\hline 9.76 & 0.098 & 0.562 & 0.058 & 0.096 & -67.3 \\
\hline 19.6 & 0.147 & 1.00 & 0.059 & 0.170 & -67.1 \\
\hline 48.7 & 0.303 & 1.78 & 0.061 & 0.302 & -66.9 \\
\hline 94.3 & 0.487 & 3.16 & 0.065 & 0.535 & -66.5 \\
\hline 193. & 0.616 & 5.62 & 0.071 & 0.944 & -65.7 \\
\hline 486. & 0.853 & 10.0 & 0.085 & 1.65 & -64.4 \\
\hline 975. & 0.941 & 17.8 & 0.116 & 2.84 & -62.0 \\
\hline \multirow[t]{7}{*}{ additional } & data: & 31.6 & 0.189 & 4.64 & -57.9 \\
\hline & & 56.2 & 0.340 & 6.71 & -52.3 \\
\hline & & 100. & 0.535 & 8.41 & -46.6 \\
\hline & & 178. & 0.699 & 9.66 & -41.6 \\
\hline & & 316. & 0.814 & 10.6 & -37.1 \\
\hline & & 562. & 0.887 & 11.5 & -32.9 \\
\hline & & 1000. & 0.932 & 12.2 & -28.9 \\
\hline
\end{tabular}

$\mathrm{q}_{\mathrm{eff}}=3.6 ; \quad \beta_{\mathrm{mRR}}=0.236 \mathrm{~nm} ; \quad \chi^{2}=0.109 \cdot 10^{-1}$ 